\title{
Suplementação de vitamina A em lactantes: revisão sistemática
}

Julicristie Machado de Oliveira

Dissertação apresentada ao Programa de Pós-graduação em Saúde Pública da Faculdade de Saúde Pública da Universidade de São Paulo para obtenção do Título de Mestre em Saúde Pública

Área de Concentração: Epidemiologia Orientadora: Prof $^{a} \mathrm{Dr}^{\mathrm{a}}$ Denise Pimentel Bergamaschi

São Paulo

2006 
Autorizo, exclusivamente, para fins acadêmicos e científicos, a reprodução total ou parcial desta dissertação. Em caso de utilização, é obrigatória a citação da fonte no texto, com respectiva referência bibliográfica.

Citação sugerida: Oliveira JM. Suplementação de vitamina $A$ em lactantes: revisão sistemática. São Paulo; 2006. [Dissertação de Mestrado - Faculdade de Saúde Pública da Universidade de São Paulo/USP].

Assinatura:

Data: 


\section{Dedicatória}

Ao Carlos Henrique, meu amor e companheiro, sempre ao meu lado em todas as horas.

À Luísa, ao José Pedro, ao Giovani e ao Luís Henrique, meus amados sobrinhos e minhas fontes de inspiração. 


\section{Agradecimentos}

À Prof ${ }^{\mathrm{a}}$ Dr $^{\mathrm{a}}$ Denise Pimentel Bergamaschi, minha orientadora, pelo apoio e inúmeras oportunidades a mim concedidas.

À Prof ${ }^{\mathrm{a}}$ Dr $^{\mathrm{a}}$ Patrícia Helen de Carvalho Rondó, ao Prof. Dr. Joelcio Francisco Abbade, ao Prof. Dr. Lincoln Sakiara Miyasaka e ao Prof. Tit. José Maria Pacheco de Souza, pelas importantes sugestões prestadas a esse trabalho.

Aos meus pais, Vanda e Joaquim, e irmãos, Ludimila, Murilo e Adervani, pelo apoio e incentivo constantes.

Aos meus sogros, Jane e José Carlos, e meus cunhados, Guto e Du, pela convivência agradável.

Aos meus amigos e companheiros de pós-graduação, Maria Carolina, Claudia, Ana Carolina, Ana Paula, Ana Maria, Aline, Alexandre, Bruno, Delano, Giana, João, Juliana, Karen, Márcia, Mariana, Neuber, Patrícia, Pedro, Regina, Rosa, Rosani, Rosângela, Yara, pela convivência agradável e pelas inestimáveis trocas de experiências.

À Natália Sanchez Oliveira, aluna de Iniciação Científica, pela ajuda imprescindível, apoio e agradável convivência.

À Débora Tarasautchi e Thaís Arthur, alunas de Iniciação Científica, pelo apoio e agradável convivência.

À Bete e à Kátia, secretárias do Depto de Epidemiologia, pelo apoio constante e agradável convivência.

À Prof $^{\mathrm{a}}$ Tit. Néia Schor, pela primeira oportunidade de desenvolver atividades de pesquisa durante a minha graduação.

À FAPESP, pelo financiamento da pesquisa.

À CAPES, pela concessão de bolsa de estudos. 


\section{RESUMO}

OLIVEIRA JM. Suplementação de vitamina A em lactantes: revisão sistemática. São Paulo; 2006. [Dissertação de Mestrado - Faculdade de Saúde Pública - Universidade de São Paulo].

Objetivo: Avaliar os efeitos da suplementação de vitamina A em lactantes, por intermédio de uma revisão sistemática. Métodos: Realizou-se buscas por ensaios aleatorizados controlados em bases de dados bibliográficos. Localizou-se 2.547 resumos que foram lidos e selecionados por dois examinadores, segundo critérios de elegibilidade e qualidade. Foram considerados elegíveis e apresentando qualidade 16 estudos, cujos dados foram extraídos e armazenados no Excel. Para os desfechos clínicos efeitos adversos e morbi-mortalidade materna e infantil, não foi possível realizar metanálise. Para os desfechos concentração de retinol sérico e no leite, realizou-se metanálise. Resultados: Não foram descritas diferenças estatisticamente significativas na ocorrência de diarréia, infecção respiratória e pneumonia entre crianças dos grupos com e sem suplementação. Observou-se menores prevalências de evacuações aquosas e cegueira noturna em lactantes suplementadas, porém sem proteção em relação à mortalidade. Observou-se menor ocorrência de níveis de retinol no leite $\leq 0,28 \mu \mathrm{mol} / \mathrm{g}$ de lipídio no grupo suplementado aos seis meses $(\mathrm{OR}=0,73$; IC95\%: 0,54-0,99), mas não aos nove meses pós-parto (0,82; IC95\%:0,59 - 1,14). Para os níveis de retinol sérico infantis e maternos, obteve-se diferença de médias sumária de 0,25umol/L (IC95\%: 0,16 - 0,34) e

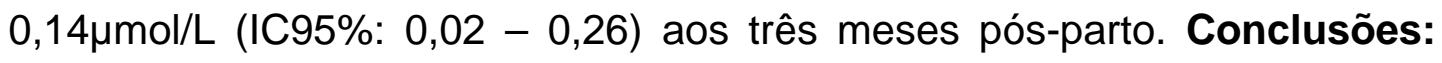
Não há evidências de benefícios da suplementação em relação à morbimortalidade infantil e mortalidade materna. Há indicação de que a suplementação seja protetora em relação à morbidade materna, esteja relacionada à manutenção de teor adequado de retinol no leite humano até o sexto mês e à maior concentração sérica de retinol materno e infantil no terceiro mês pós-parto.

Descritores: vitamina A, suplementos dietéticos, leite humano, período pósparto, literatura de revisão, metanálise, ensaios clínicos controlados aleatórios. 


\section{SUMMARY}

OLIVEIRA JM. Vitamin A supplementation for breastfeeding mothers: systematic review. São Paulo; 2006. [Master Dissertation - Faculdade de Saúde Pública - Universidade de São Paulo].

Objective: To assess the effects of vitamin A supplementation for breastfeeding mothers through a systematic review. Methods: Searches for randomized controlled trials were performed in bibliographic databases. The searches resulted in 2,547 summaries that were read and selected by two raters, by eligibility and quality criteria. Data from 16 quality studies were extracted and stored in Excel. It was not possible to carry out the metaanalysis for the clinical outcomes of adverse effects and maternal and infant morbidity and mortality. The meta-analysis was performed for retinol concentration in the serum and human milk. Results: No statistically significant differences were observed for diarrhea, respiratory infection or pneumonia between supplemented and non-supplemented infant groups. Reduced prevalences of loose stools and night blindness were observed in supplemented lactating women, but without protection for mortality. Lower occurrences of milk retinol concentration were observed $\leq 0.28 \mu \mathrm{mol} / \mathrm{g}$ of lipid in the supplemented group at six months (OR=0.73; IC95\%: $0.54-0.99$ ), but not at nine months postpartum (0.82; IC95\%:0.59 - 1.14). For infant and maternal serum retinol, the average difference in means was $0.25 \mu \mathrm{mol} / \mathrm{L}$

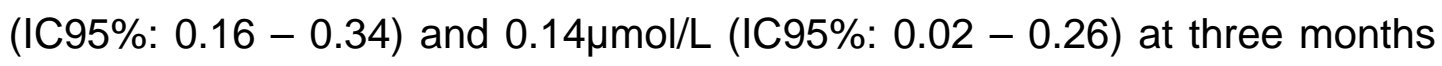
postpartum. Conclusions: There is no evidence of the benefit of supplementation for infant morbidity and mortality or for maternal mortality. There is an indication that the protection given by supplementation for maternal morbidity is related to suitable retinol levels in human milk until the sixth month postpartum and to the higher retinol concentration in maternal and infant serum in the third month postpartum.

Descriptors: vitamin A, dietary supplements, human milk, postpartum period, review literature, meta-analysis, randomized controlled clinical trials. 
ÍNDICE

1.1. VITAMINA A: DEFINIÇÃO E FONTES DIETÉTICAS 1

1.2. VITAMINA A: ASPECTOS FISIOLÓGICOS E METABÓLICOS___ 2

1.3. FUNÇÕES DA VITAMINA A

1.4. INDICADORES BIOLÓGICOS DO ESTADO NUTRICIONAL DE VITAMINA A

1.5. VITAMINA A: RECOMENDAÇÕES E DOSE SEGURA___ 9

1.6. VITAMINA A: TERATOGENIA E TOXICIDADE _ 10

1.7. A VITAMINA A NA LACTAÇÃO__ 11

1.8. DEFICIENNCIA DE VITAMINA A NO MUNDO _ 14

1.9. REVISÕES SISTEMÁTICAS E METANÁLISES QUE AVALIARAM O IMPACTO DA SUPLEMENTAÇÃO DE VITAMINA A ___ 15

1.10. JUSTIFICATIVA _ 17

2. OBJETIVOS 18

2.1. OBJETIVO GERAL

2.2. OBJETIVOS ESPECÍFICOS _ 18

3. MÉTODOS 19

3.1. TIPO DE ESTUDO

3.2. CRITÉRIOS DE INCLUSÃO DE ESTUDOS - ELEGIBILIDADE __ 20

3.3. TIPO DE PARTICIPANTES __ 20

3.4. TIPO DE INTERVENÇÃO__ 20

3.5. DESFECHOS _ 21

3.6. ESTRATÉGIA DE BUSCA PARA IDENTIFICAÇÃO DE ESTUDOS __ 23

3.6.1. BASES DE DADOS BIBLIOGRÁFICOS ___ 23

3.6.2. PALAVRAS-CHAVE

3.7. MÉTODO DE REVISÃO___ 25

3.8. EXTRAÇÃO DE DADOS PARA A METANÁLISE __ 28

3.9. ANÁLISE ESTATÍSTICA __ 29

4. RESULTADOS 31

4.1. AVALIAÇÃo DOS CRITÉRIOS DE ELEGIBILIDADE __ 31

4.2. ANÁLISE DA QUALIDADE DOS ESTUDOS 35

4.3. CARACTERÍSTICAS DOS ESTUDOS INCLUÍDOS NA REVISÃO _ 38

4.4. EFEITO DA SUPLEMENTAÇÃO DE VITAMINA A NA MORBIDADE INFANTIL _ 43

4.5. EFEITO DA SUPLEMENTAÇÃO DE VITAMINA A NA MORTALIDADE INFANTIL

4.6. EFEITO DA SUPLEMENTAÇÃO DE VITAMINA A NA MORBI-MORTALIDADE MATERNA _ 47

4.7. EFEITO DA SUPLEMENTAÇÃO DE VITAMINA A NA OCORRÊNCIA DE EFEITOS ADVERSOS _ 48

4.8. EFEITO DA SUPLEMENTAÇÃO DE VITAMINA A NA CONCENTRAÇÃO DE RETINOL DO LEITE HUMANO

4.9. EFEITO DA SUPLEMENTAÇÃO DE VITAMINA A NO ESTADO NUTRICIONAL DE VITAMINA A MATERNO 
4.10. EFEITO dA SUPLEMENTAÇÃO DE VITAMINA A NO ESTADO NUTRICIONAL DE VITAMINA A INFANTIL

7. CONFLITO DE INTERESSES

9. REFERÊNCIAS

ANEXOS:

Anexo 1: Questionário para avaliação dos critérios de inclusão Anexo 2: Características das buscas nas bases de dados bibliográficos Anexo 3: Questionário para avaliação da qualidade dos estudos Anexo 4: Formulário para coleta de dados dos estudos Anexo 5: Saídas da metanálise realizada no Stata 


\section{$\underline{\text { ÍNDICE DE FIGURAS, QUADROS, TABELAS E GRÁFICOS }}$}

Tipo $n^{\circ}$ Título

página

Figura 1 Estrutura de alguns retinóides que apresentam ação de vitamina A.

Quadro 1 Ingestões dietéticas de referência (DRI) de vitamina A para crianças (012 meses), gestantes e lactantes segundo faixa etária.

Quadro 2 Indicadores subclínicos do estado nutricional de vitamina A materno e infantil e pontos de corte indicativos de DVA subclínica.

Quadro 3 Avaliação dos Riscos de Vieses - interpretação.

Quadro 4 Avaliação da Adequação do Sigilo de Alocação - interpretação.

Autor ano, título e fonte dos estudos cujos resumos ou artigos na íntegra

Quadro 5 não foram localizados e foram excluídos por consenso entre os dois avaliadores.

Figura 2 Processo de seleção de estudos e motivos de exclusão (Adaptado de PAl et al., 2003).

Artigos excluídos após a leitura na íntegra, na etapa de análise de

Quadro 6 qualidade, segundo autor, ano, desenho de estudo, objetivo e justificativa de exclusão.

Tabela 1 Distribuição dos estudos segundo Adequação do Sigilo de Alocação Cochrane.

Tabela 2 Distribuição dos estudos segundo Avaliação dos Riscos de Vieses (ALDERSON \& GREEN, 2004).

Artigos excluídos, após a leitura na íntegra, por não cumprirem os

Quadro 7 critérios de qualidade, segundo autor, ano, desenho de estudo, objetivo e justificativa de exclusão.

Artigos excluídos após a leitura na íntegra, na etapa de extração de Quadro 8 dados, segundo autor, ano, desenho de estudo, objetivo e justificativa de exclusão.

Tabela 3

Distribuição dos estudos incluídos na revisão segundo características metodológicas.

Distribuição de estudos de acordo com o odds ratio (OR) da

Gráfico 1 concentração de retinol do leite humano menor ou igual a $0,28 \mu \mathrm{mol} / \mathrm{g}$ de lipídio aos seis meses pós-parto. 
Distribuição de estudos de acordo com o odds ratio (OR) da Gráfico 2 concentração de retinol do leite humano menor ou igual a $0,28 \mu \mathrm{mol} / \mathrm{g}$ de lipídio aos nove meses pós-parto.

Distribuição de estudos de acordo com o odds ratio (OR) da Gráfico 3 concentração de retinol do leite humano menor ou igual a 1,05 $\mu \mathrm{mol} / \mathrm{L}$ aos três meses pós-parto. concentração de retinol do leite humano menor ou igual a $1,05 \mu \mathrm{mol} / \mathrm{L}$ aos seis meses pós-parto.

Distribuição de estudos de acordo com o odds ratio (OR) da Gráfico 5 concentração de retinol do leite humano menor ou igual a $1,05 \mu \mathrm{mol} / \mathrm{L}$ aos três meses pós-parto, retirando-se o estudo conduzido por STOLTZFUS et al. (1993a).

Gráfico 6

Distribuição de estudos de acordo com a diferença de médias da concentração de retinol no leite humano aos três meses pós-parto

Gráfico 7 Distribuição de estudos de acordo com a diferença de médias da concentração de retinol no leite humano aos três meses pós-parto, retirando-se o estudo STOLTZFUS et al. (1993a).

Gráfico 8 Distribuição de estudos de acordo com a diferença de médias da concentração de retinol no leite humano aos seis meses pós-parto.

Gráfico 9 Distribuição de estudos de acordo com a diferença de médias da concentração de retinol sérico materno aos três meses pós-parto.

Distribuição de estudos de acordo com a diferença de médias da Gráfico 10 concentração de retinol sérico materno aos três meses pós-parto, retirando-se os artigos que utilizaram doses semanais (CONGDON et al., 2000; YAMINI et al., 2001).

Gráfico 11 Distribuição de estudos de acordo com a diferença de médias da concentração de retinol sérico materno aos seis meses pós-parto.

Gráfico 12 Distribuição de estudos de acordo com a diferença de médias da concentração de retinol sérico materno aos três meses pós-parto.

Gráfico 13

Distribuição de estudos de acordo com a diferença de médias da concentração de retinol sérico infantil aos três meses pós-parto.

Distribuição de estudos de acordo com a diferença de médias da

Gráfico 14 concentração de retinol sérico infantil aos três meses pós-parto, retirando-se o estudo que utilizou dose fracionada (KATZ et al., 2000).

Gráfico 15 Distribuição de estudos de acordo com a diferença de médias da concentração de retinol sérico infantil aos seis meses pós-parto.

Distribuição de estudos de acordo com a diferença de médias da Gráfico 16 concentração de retinol sérico infantil aos seis meses pós-parto, retirando-se o estudo de STOLTZFUS et al. (1993a). 


\section{Introdução}

\subsection{Vitamina A: definição e fontes dietéticas}

O termo Vitamina A é genérico e abrange substâncias lipossolúveis, tais como o retinol, o retinal, o ácido retinóico e o éster de retinila. Estas desempenham diversas funções no organismo humano relacionadas ao adequado funcionamento dos sistemas visual e reprodutor, à expressão gênica, ao crescimento e desenvolvimento físico, à função imunológica e à manutenção da integridade das células epiteliais (BUTTE et al., 2002; IOM, 2001; FAO/WHO, 2001; WHO, 1998, 1996; SAARI, 1994). Pode-se citar também, seu papel fundamental na gestação e lactação, considerando-se as demandas maternas, fetais e do recém-nascido (BUTTE et al., 2002; IOM, 2001; FAO/WHO, 2001; WHO, 1998, 1996).

A estrutura dos retinóides é relativamente simples e cada forma molecular apresenta uma modificação no carbono da $15^{\mathrm{a}}$ posição $\left(\mathrm{C}_{15}\right)$ do grupo funcional correspondente (SAARI, 1994). A Figura 1 apresenta as fórmulas químicas de alguns retinóides que possuem ação de vitamina A.

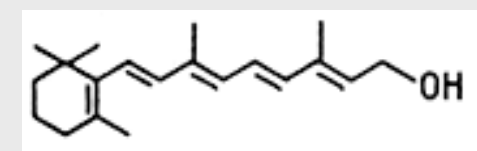

RETINOL

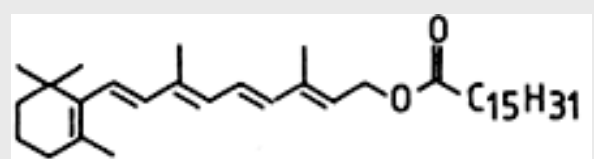

ÉSTER DE RETINILA

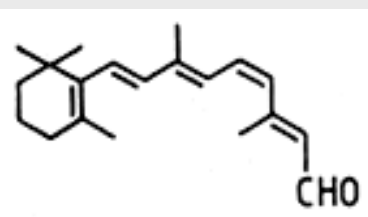

RETINAL

Figura 1: Estrutura de alguns retinóides que apresentam ação de vitamina A. 
Constituem-se fontes dietéticas de vitamina $\mathrm{A}$ alguns produtos de origem vegetal, ricos em pró-vitamina A (alfa e beta-caroteno e betacriptoxantina), e produtos de origem animal, ricos em vitamina $A$ préformada. A pró-vitamina é encontrada em hortaliças verdes escuras (espinafre, couve e brócoli), e em alguns vegetais alaranjados (cenoura, abóbora, mamão, manga e buriti) ou em alguns óleos vegetais (dendê africano). São exemplos de fontes de vitamina A pré-formada a gema de ovo, fígado, óleo de fígado de peixe, leite de vaca integral e seus derivados, e o leite humano (FAO/WHO, 2001; IOM, 2001; McLAREN e FRIGG, 2001).

Parte dos carotenóides provenientes da dieta, que possuem atividade de vitamina $A$, são absorvidos pelo intestino e bioconvertidos em retinol.

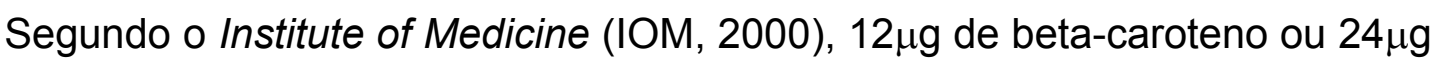
de alfa-caroteno/beta-criptoxantina são necessários para obter-se $1 \mu \mathrm{g}$ de equivalente ativo de retinol (RAE).

\subsection{Vitamina A: aspectos fisiológicos e metabólicos}

Em alimentos de origem animal, a vitamina A apresenta-se, predominantemente, na forma de éster de retinila, que pode estar presente nas membranas ou nos estoques lipídicos celulares. Os carotenóides também estão associados aos lipídios celulares, porém estão embebidos em estruturas complexas, como a matriz celulósica dos cloroplastos e a porção pigmentada dos cromoplastos (FAO/WHO, 2001). Por essa razão, suas fontes são processadas de maneira menos eficiente, o que leva a uma absorção limitada pelo intestino (SOMMER, 1995; FAO/WHO, 2001). 
No processo de digestão de alimentos fontes de vitamina A préformada, o éster de retinila é envolvido em micelas, formadas pela ação de sais biliares, ficando disponível para a conversão a retinol pela atividade de hidrolases de éster de retinila presentes no intestino delgado (HARRISON, 1993; BLANER e OLSON, 1994; FAO/WHO, 2001). O retinol é transportado, através do bordo em escova dos enterócitos, por uma proteína carreadora de retinol celular (CRBP-2 - celular retinol binding protein), tornando-se disponível para as células da mucosa, onde pode ser ligado a proteínas celulares ou re-convertido a éster de retinila (BLANER e OLSON, 1994; DEW e ONG, 1994; IOM, 2001).

Os carotenóides, solubilizados em micelas no lúmen duodenal, são absorvidos pelas células da mucosa por mecanismo de difusão passiva (IOM, 2001), e, em parte, são bioconvertidos a retinol por enzimas presentes no bordo em escova dos enterócitos (PARKER, 1996). Nessa etapa, os produtos da digestão da gordura e a secreção biliar são essenciais na solubilização dos carotenóides (FAO/WHO, 2001).

Uma dieta com baixo teor de lipídios ou condições patológicas especificas, que levem a esteatorréia, podem contribuir para uma inadequada absorção de vitamina A pré-formada ou pró-vitamina (JAYARAJAN et al., 1980; FAO/WHO, 2001).

O éster de retinila e os carotenóides são incorporados a quilomicrons, que são liberados aos canais linfáticos intestinais e atingem a circulação sanguínea por meio do ducto torácico (ONG, 1994). Os tecidos extraem a maior parte dos lipídios e parte dos carotenóides dos quilomicrons 
circulantes (FAO/WHO, 2001). Segundo BLANER e OLSON (1994), parte dos lipídios dos quilomicrons circulantes (1/3 a 1/2) são absorvidos pela medula óssea. Os autores apontam que esse tecido pode ser o maior responsável pela utilização da vitamina A dietética.

Após circularem pelo organismo, os quilomicrons tornam-se remanescentes e são metabolizados pelas células parenquimais do fígado. O éster de retinila é então hidrolisado a retinol antes de ser transferido para as células armazenadoras de gordura (stellate ou células Ito). O retinol é transportado diretamente das células parenquimais para as células armazenadoras de lipídios através de desmossomos (regiões de contato entre as membranas celulares) (BLANER e OLSON, 1994).

Em situações em que o organismo necessita imediatamente de vitamina $A$, o retinol, recém adquirido pela dieta, pode ligar-se à proteína carreadora de retinol (RBP - retinol binding protein), produzida pelas células parenquimais, e o complexo retinol-RBP é secretado na circulação sanguínea (BLOMHOFF et al., 1991; BLANER e OLSON, 1994). $\mathrm{Na}$ circulação o retinol-RBP liga-se à pré-albumina, também produzida pelo fígado, formando um complexo que previne as perdas da vitamina no processo de filtração dos rins (BLOMHOFF et al., 1991).

Em relação à absorção de vitamina $A$ presente em suplementos, há evidências de que a forma física das preparações orais poderá influenciar sua taxa de absorção. Há estudos que relatam que a utilização de solução aquosa (emulsão) de vitamina A resulta em maiores concentrações séricas, 
no fígado e menores perdas fecais da vitamina, quando comparadas às soluções à base de óleo (BAUERNFEIND, 1980).

De acordo com ALLEN e HASKELL (2002), quando uma dose de éster de retinila é administrada, há desesterificação no lúmem intestinal, incorporação nas micelas e transporte através das células do intestino. Nessas células, a maior parte do retinol é reesterificado e incorporado à fase lipídica dos quilomicrons, que atingem a circulação sistêmica por meio dos

vasos linfáticos. Pequena parte do retinol pode ser oxidada e absorvida como ácido retinóico através da veia porta. Quando há ingestão de alta dose de vitamina A, níveis aumentados de ácido retinóico e de éster de retinila podem estar presentes na circulação sanguínea. No fígado, o retinol pode se ligar à RBP e entrar na circulação, pode ser oxidado e excretado na bile, e pode ser reesterificado e armazenado no fígado.

\subsection{Funções da vitamina $A$}

As diversas formas da vitamina A podem apresentar funções específicas de acordo com o tecido, o órgão ou sistema orgânico. O retinal está envolvido no processo visual, o retinol é essencial no processo reprodutivo, e há evidências de que o ácido retinóico e seus derivados modulam a expressão gênica, a diferenciação e o padrão de formação celular durante a morfogênese. A especificidade de cada etapa desses processos pode aumentar quando se considera a utilização dos isômeros cis ou trans dessas substâncias (SAARI, 1994). 
Segundo SAARI (1994), o retinal desempenha função específica no sistema visual, sendo necessário no processo de transdução da luz em sinais neurais. A absorção da luz catalisa a fotoisomerização do 11-cisretinal, presente no pigmento rodopsina dos receptores rod, a all-transretinal. Tais receptores liberam sinais que ativam as células neurais associadas à porção do córtex cerebral responsável pela visão (IOM, 2001).

O ácido retinóico é essencial para a adequada diferenciação das células da córnea e da membrana conjuntival (SOMMER et al., 1996). Esse metabólito regula a expressão de vários genes codificadores de proteínas estruturais, enzimas, proteínas da matriz extracelular, proteínas carreadoras de retinol e receptores (IOM, 2001).

A vitamina A na forma de ácido retinóico desempenha papel fundamental no desenvolvimento embrionário, estando presente nas regiões envolvidas com o desenvolvimento da espina dorsal e das vértebras (MORRIS-KAY e SOKOLOVA, 1996). Esta substância também está envolvida no desenvolvimento dos membros, do coração e dos aparelhos visuais e auditivos (DICKIMAN e SMITH, 1996; HOFMANN e EICHELE, 1994; MACFEFERY e DRAGER, 1995 citado por IOM, 2001).

O ácido retinóico é importante na manutenção de níveis adequados de células natural killers circulantes, que possuem atividade antiviral e antitumor (ZHAO e ROSS, 1995). Segundo KATZ et al. (1987), o ácido retinóico contribui para o aumento da capacidade fagocitária dos macrófagos, sendo, também, importante no processo de diferenciação dos leucócitos. Há evidências, ainda, de que esteja envolvido no aumento da 
produção de interleucina 1 e outras citocinas, que medeiam o processo inflamatório (TRECHSEL et al., 1995).

\subsection{Indicadores biológicos do estado nutricional de vitamina $A$}

O estado nutricional de vitamina A pode ser classificado em cinco categorias: deficiência (deficiência clínica), estado marginal (deficiência subclínica), estado satisfatório, excesso e toxicidade. O estado de deficiência de vitamina A (DVA) é caracterizado pela presença de sinais clínicos de xeroftalmia, enquanto que o marginal relaciona-se, por exemplo, à dificuldade de adaptação ao escuro. No estado satisfatório todas as funções fisiológicas da vitamina A são cumpridas em decorrência das adequadas reservas corpóreas. O estado de excesso resulta de ingestão de quantidades relativamente grandes da vitamina $A$, porém sem presença de sinais clínicos, já a toxicidade caracteriza-se pela presença de uma série de sinais clínicos (UNDERWOOD e OLSON, 1993). O Quadro 1 apresenta os valores de limite superior tolerável de ingestão diária de vitamina A.

Tem-se assim, que a DVA pode se manifestar de maneira clínica ou subclínica, havendo indicadores específicos para cada uma delas.

A xeroftalmia é uma síndrome de DVA que inclui a mancha de Bitot, a xerose corneal e a queratomalácea, sinais que constituem indicadores clínicos da deficiência desse micronutriente. Os indicadores subclínicos podem ser funcionais, bioquímicos ou histológicos. Entre os funcionais, temse a cegueira noturna e a dificuldade de adaptação ao escuro (WHO, 1996). 
Em relação aos indicadores bioquímicos, considera-se como DVA subclínica teor de retinol sérico igual ou menor que $0,7 \mu \mathrm{mol} / \mathrm{L}$. No leite humano, constitui indicador de DVA subclínica, nível de retinol igual ou abaixo de $1,05 \mu \mathrm{mol} / \mathrm{L}$ ou $8 \mu \mathrm{g} / \mathrm{g}$ de lipídio ou $0,28 \mu \mathrm{mol} / \mathrm{g}$ de lipídio. Os testes de resposta relativa à dose (RDR), o modificado de resposta relativa à dose (MRDR) e o de resposta relativa à dose de 30 dias (+S30DR) são utilizados para avaliar indiretamente os estoques hepáticos de vitamina A (WHO, 1996).

Como indicador histológico, tem-se citologia da impressão conjuntival que, em situação de deficiência, é caracterizada por presença de células epiteliais planas aumentadas e redução significativa de células produtoras de mucina (WHO, 1996).

Outros sintomas inespecíficos também podem estar relacionados à DVA, tais como, aumento do risco de morbidade e mortalidade, e diminuição do ritmo de crescimento e desenvolvimento (FAO/WHO, 2001).

Segundo TANUMIHARDJO (2004), alguns métodos de avaliação do estado nutricional em relação à vitamina $A$ estão em desenvolvimento, incluindo a determinação da concentração de retinol utilizando-se gota de sangue seco, da concentração de RBP, da relação entre a concentração de RBP e de pré-albumina (RBP: pré-albumina), o teste de hidrólise do retinoyl $\beta$-glucuronide ou, ainda, a análise da diluição do isótopo ${ }^{13} \mathrm{C}$-retinol. 


\subsection{Vitamina A: recomendações e dose segura}

O IOM (2001) propõe as ingestões dietéticas de referência (DRI) para vitamina $A$ em micrograma de equivalente ativo de retinol (RAE), segundo idade, sexo e estado fisiológico. O Quadro 1 apresenta as DRI para crianças até um ano de idade, gestantes e lactantes.

Quadro 1 - Ingestões dietéticas de referência (DRI) de vitamina A para crianças (012 meses), gestantes e lactantes segundo faixa etária.

\begin{tabular}{|c|c|c|c|c|c|}
\hline Grupo & Faixa Etária & $\begin{array}{c}\text { RDA } \\
(\mu \mathrm{gRAE} / \mathrm{dia})\end{array}$ & $\begin{array}{c}\text { EAR } \\
(\mu \mathrm{gRAE} / \mathrm{dia})\end{array}$ & $\begin{array}{c}\text { Al } \\
(\mu g R A E / d i a)\end{array}$ & $\begin{array}{c}\text { UL } \\
\text { ( } \mu \text { g de vitamina A } \\
\text { pré-formada/dia) }\end{array}$ \\
\hline \multirow{2}{*}{ Crianças } & $0-6$ meses & - & - & 400 & 600 \\
\hline & $7-12$ meses & - & - & 500 & 600 \\
\hline \multirow{2}{*}{ Gestantes } & $14-18$ anos & 750 & 530 & - & 2800 \\
\hline & $19-50$ anos & 730 & 550 & - & 3000 \\
\hline \multirow{2}{*}{ Lactantes } & $14-18$ anos & 885 & 1200 & - & 2800 \\
\hline & $19-50$ anos & 900 & 1300 & - & 3000 \\
\hline
\end{tabular}

Até o ano de 2000, a Organização Mundial de Saúde (OMS) recomendava a suplementação com dose única $(200.000 U \mathrm{U})$ de vitamina $\mathrm{A}$ para lactantes, que poderia ser administrada até o final do segundo mês pós-parto. Para mulheres que não estivessem amamentando, uma dose única poderia ser administrada até o final do primeiro mês pós-parto. $\mathrm{O}$ IVACG (International Vitamin A Consultative Group), em uma reunião organizada pela OMS no ano de 2000 , apontou que a suplementação com duas mega doses de vitamina A (200.000Ul/cada) para lactantes, administradas separadamente com intervalo de 24 horas, poderia ser mais efetiva na manutenção das concentrações adequadas de retinol no leite materno quando comparada com a suplementação em dose única. Ressaltando-se a necessidade de respeitar-se o intervalo proposto entre 
uma e outra dose, uma vez que uma única dose com 400.000 U poderia resultar em aumento do teor de ácido retinóico no leite humano até o nível de toxicidade (ROSS, 2002).

Em relação às doses seguras de ingestão de vitamina $A$ para lactantes e gestantes, considera-se, como limite superior (UL), a ingestão

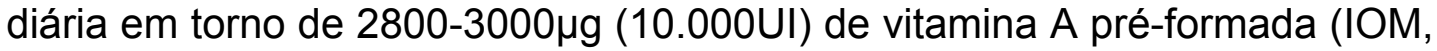
2001), como apresentado no Quadro 1.

\subsection{Vitamina A: teratogenia e toxicidade}

Há indícios que tanto as situações de excesso quanto as de DVA podem ser nocivas durante a gestação. Segundo RASMUSSEN (1998), estudos com animais indicam que baixas ou altas concentrações de vitamina A durante o período do desenvolvimento embrionário podem resultar em teratogenia. Dados que relacionam a ocorrência de teratogenia com a exposição a altas doses de vitamina $A$, na forma de éster de retinila ou retinal, no início da gravidez em humanos são escassos. Porém, estudos caso-controle indicam que efeitos teratogênicos em bebês estão relacionados com a exposição materna ao ácido retinóico, ou seus derivados, durante as primeiras seis semanas de gravidez (RASMUSSEN, 1998; LAMMER, 1998).

Em revisão conduzida por CLAGETT-DAME e DeLUCA (2002), os autores relatam que uma série de experimentos desenvolvidos na década de 40 descrevem a ocorrência de defeitos congênitos atribuídos à DVA. Nesses estudos, realizados com animais, foram observadas anormalidades oculares, 
no trato genito-urinário, nos rins, no diafragma, nos pulmões, no coração e nos membros.

Em relação à toxicidade, alguns efeitos colaterais podem ocorrer como conseqüência da ingestão de alta dose de vitamina A. Em crianças, foram descritas ocorrência de náusea, vômito, diarréia, febre e abaulamento da fontanela. Em adultos, os efeitos tóxicos incluíam náusea, vômito, pressão aumentada do fluido cérebro-espinal, visão borrada, dor de cabeça e falta de coordenação muscular. Em geral, esses efeitos tóxicos são transitórios e ocorrem em baixa freqüência. Em contrapartida, a ingestão prolongada de doses moderadas ou altas de vitamina A pode estar relacionada a inchaço dos olhos, queilose, eritema, eczema, alopecia, hemorragia, fratura óssea e lesões no fígado (BAUERNFEIND, 1980; RUSSEL, 2000; AZAIS-ABRAESCO e PASCAL, 2000; ALLEN e HASKELL, 2002).

\subsection{A vitamina A na lactação}

Durante a gravidez, o processo de transferência de vitamina A através da placenta ocorre de maneira limitada, mesmo considerando que, em geral, a quantidade de retinol transportada para o feto se mantém constante durante a gestação. Em decorrência da limitação imposta pela barreira placentária, os recém-nascidos possuem baixos estoques hepáticos de vitamina A. Nesse contexto, o colostro, que é rico em vitamina A, desempenha o importante papel de proteger o recém-nascido da deficiência desse micronutriente (DEBIER e LARONDELLE, 2005). 
A capacidade da glândula mamária de secretar leite materno é desenvolvida durante a gravidez, por meio de sua transformação em um órgão exócrino eficiente com estruturas alveolares desenvolvidas. Essa transformação é regulada por hormônio e envolve mudança tanto na composição celular da glândula mamária, quanto nas propriedades estruturais, celulares e bioquímicas das células alveolares que são imprescindíveis para o adequado transporte de solutos e para as funções secretoras (McMANAMAN e NEVILLE, 2003). Após o parto, a elevação do nível de prolactina e a queda dos níveis de estrógeno e progesterona resultam no início da secreção de leite pela glândula mamária (PICCIANO, 2003).

Segundo PICCIANO (2003), até o quinto dia pós-parto a mama secreta o colostro, que é rico em minerais e fatores imunológicos, como a lactoferrina e imunoglobulina A ( $\lg A)$, e contém baixos teores de lactose e proteína. No décimo dia pós-parto, a secreção passa a apresentar características do leite humano maduro.

Em relação à composição do leite humano, há evidências de que teores de proteínas e glicídios do leite materno podem sofrer mudanças de acordo com o período de lactação, apesar destes não variarem, de maneira importante, de mulher para mulher. Em contrapartida, a fração lipídica e alguns micronutrientes, entre eles a vitamina A, podem variar entre indivíduos e populações (BUTTE et al., 2002).

As reservas de vitamina $A$ do recém-nascido podem ser influenciadas pelo estado nutricional da mulher durante e anterior à gestação, assim bebês 
de gestante com deficiência desse micronutriente podem nascer com estoque restrito. Da mesma forma, o teor de vitamina $A$ no leite humano poderá depender do estado nutricional materno, principalmente no que diz respeito a esse micronutriente (BUTTE et al., 2002). Deve-se considerar também que deficiência de zinco, desnutrição materna e situações que ativem uma resposta de fase aguda podem limitar o transporte de vitamina $A$ para o leite materno (RASMUSSEN, 1998).

ROSS e HARVEY (2003) conduziram um estudo de simulação da contribuição do aleitamento materno para o estado nutricional de vitamina $A$ em crianças com idade entre zero e 24 meses, considerando-se quatro condições: consumo de leite ideal (consumo do colostro e aleitamento exclusivo) ou não ideal (descarte do colostro e aleitamento materno parcial) e a presença ou não de suplementação materna com alta dose de vitamina A. Segundo os autores, a combinação do aleitamento materno ideal com a suplementação materna, provê cerca de 95\% das recomendações de vitamina A para bebês até seis meses. A prática do aleitamento materno ideal na ausência da suplementação ou a suplementação na ausência do aleitamento ideal contribuem com aproximadamente $75 \%$ do recomendado para bebês da mesma faixa etária. Os autores apontam que a suplementação materna com altas doses de vitamina A e a prática do aleitamento materno ideal são estratégias altamente efetivas para melhorar o estado nutricional infantil em relação a esse micronutriente. 


\subsection{Deficiência de vitamina A no mundo}

A OMS divulgou em 1995 a base de dados Micronutrient Deficiency Information System (MDIS), que incluía informações sobre a prevalência de DVA no mundo. Nessa base, estavam compilados dados de pesquisas, realizadas em diferentes países, referentes a níveis de retinol sérico e a prevalência de sinais oculares e sintomas de DVA. Com bases nessas informações, os países foram categorizados como regiões de DVA clínica, subclínica grave e subclínica moderada (WHO, 1995). Em outubro de 2000, a base MDIS foi atualizada, e os países passaram a ser categorizados, considerando-se também a disponibilidade das informações, em região de DVA clínica, subclínica, insuficiência de dados com possibilidade de presença de DVA, insuficiência de dados, mas presença improvável de DVA (MacLAREN e FRIGG, 2001).

No continente Africano, encontram-se países com insuficiência de dados com possibilidade de presença de DVA e países classificados como regiões de DVA clínica e subclínica, como por exemplo Zimbábue, Angola e Moçambique. No continente Americano, nenhum país foi classificado como área de DVA clínica, e países tais como o Brasil, Peru e Guatemala, foram classificados como região de DVA subclínica.

Todos os países do sudeste da Ásia foram considerados áreas de DVA ou com possibilidade. Os países Bangladesh, Nepal, Índia, Butão e Sri Lanka, foram considerados regiões de DVA clínica, enquanto a Indonésia, Mianmar e Tailândia, regiões de DVA subclínica. No continente Europeu, França, Portugal, Itália e Reino Unido foram classificados como regiões com 
insuficiência de dados, mas com presença improvável de DVA. No oeste do pacífico, países como Camboja, Mongólia e Micronésia foram considerados áreas de DVA clínica.

\subsection{Revisões sistemáticas e metanálises que avaliaram o impacto da suplementação de vitamina $A$}

van den BROEK et al. (2004) conduziram uma revisão sistemática de ensaios clínicos controlados que avaliaram os efeitos da suplementação de vitamina A para mulheres durante a gestação. Os autores apontam, com base nos resultados de um estudo de base populacional realizado no Nepal, que a suplementação semanal pode estar relacionada à diminuição da mortalidade materna e de cegueira noturna. No referido estudo, foi observada redução na mortalidade materna por todas as causas, até 12 semanas pós-parto, no grupo suplementado com vitamina $A(R R=0,60$; IC95\%: 0,37 a 0,97) ou beta-caroteno (RR=0,51; IC95\%: 0,30 a 0,86; WEST et al., 1999). Em um estudo do tipo caso-controle aninhado ao estudo conduzido no Nepal, foi observada redução nas taxas de cegueira noturna entre mulheres suplementadas (CHRISTIAN et al.,1998a). Em relação à anemia, três estudos (SUHARMO et al., 1993; SEMBA et al., 2001; van den BROEK et al., 2001) investigaram o efeito da suplementação de vitamina $A$ combinada ao ferro, porém somente um estudo aponta efeito benéfico (SUHARMO et al., 1993).

FAWZI et al. (1993) conduziram uma metanálise com o objetivo de avaliar o efeito da suplementação de vitamina A na mortalidade infantil em 
crianças com idade entre seis e 72 meses. Os resultados apontam que a suplementação mostrou-se altamente protetora em relação à mortalidade por sarampo em crianças hospitalizadas $(\mathrm{OR}=0,39$; IC95\%: 0,22 a 0,66 ; $p=0,004)$. Os autores relatam também efeito protetor da suplementação quando se considera a mortalidade geral em estudos de base comunitária $(\mathrm{OR}=0,70 ; \mathrm{IC} 95 \%: 0,56$ a 0,$87 ; p=0,001)$.

Em outra metanálise, conduzida por GLASZIOU e MACKERRAS (1993), foram avaliados o impacto da suplementação de vitamina A na morbidade e na mortalidade por doenças infecciosas em crianças e adolescentes com idade inferior a 13 anos. A análise agregada dos resultados dos estudos de base comunitária aponta redução de $30 \%$ (IC95\%: 21 a $38 \%, p<0,001)$ na mortalidade por todas as causas. A análise por causa específica de mortalidade também mostrou benefício, com redução de 39\% (IC95\%: 24 a 50\%) da mortalidade por diarréia e de $70 \%$ (IC95\%: 15 a 90\%) por doença respiratória.

D'SOUZA e D'SOUZA (2005), conduziram uma revisão sistemática da literatura com metanálise para avaliar o benefício da suplementação de vitamina A no tratamento de sarampo em crianças e adolescentes com idade inferior a 15 anos. A análise agregada de todos os estudos selecionados não apontou redução na mortalidade ( $R R=0,60 ; \mathrm{IC} 95 \%$ : 0,32 a 1,12). Porém, foi observada uma redução de $64 \%$ na mortalidade quando se considerou somente os estudos que utilizaram suplementação com $200.000 U$ I de vitamina A (RR=0,36; IC95\%: 0,14 a 0,82). A utilização de solução aquosa de vitamina $\mathrm{A}$ estava associada a uma redução de $81 \%$ no risco de morte 
$(R R=0,19$; IC95\%: 0,02 a 0,85), enquanto a suplementação de vitamina $A$ em solução oleosa estava associada a uma redução de $48 \%$ ( $R R=0,52$; Cl95\% 0,16 a 1,40), porém não estatisticamente significante. A suplementação, tanto com solução aquosa quanto com oleosa, foi associada a uma redução de $67 \%$ na mortalidade por pneumonia ( $R R=0,33$; IC95\%: 0,08 a 0,92). Não houve evidência de que a suplementação com dose única de vitamina A (200.000Ul) estava associada à redução na mortalidade por sarampo $(R R=0,77 ; \mathrm{IC} 95 \%$ : 0,34 a 1,78).

\subsection{Justificativa}

Considerando-se a necessidade de agregar evidência sobre os efeitos da suplementação de vitamina A para lactantes, como estratégia para garantir um adequado estado nutricional em relação a essa vitamina para a mãe e a criança, via aleitamento materno, uma revisão sistemática sobre o assunto torna-se pertinente. Tal estudo pode ser útil no planejamento de novas pesquisas podendo, ainda, fornecer subsídios para a formulação de políticas públicas. 


\section{Objetivos}

\subsection{Objetivo Geral}

Avaliar os efeitos da suplementação de vitamina A em lactantes, por intermédio de uma revisão sistemática.

\subsection{Objetivos específicos}

- Comparar a ocorrência de episódios de morbidade infantil e materna entre os grupos intervenção e controle;

- Comparar a ocorrência de mortalidade infantil e materna entre os grupos intervenção e controle;

- Comparar a ocorrência de efeitos adversos maternos e infantis da suplementação com mega dose de vitamina A entre os grupos intervenção e controle;

- Comparar o estado nutricional em relação à vitamina $\mathrm{A}$ materno e infantil entre os grupos intervenção e controle;

- Comparar os teores de retinol do leite materno entre os grupos intervenção e controle. 


\section{Métodos}

\subsection{Tipo de estudo}

Estudo de revisão sistemática com metanálise, que pode ser definido como uma seleção criteriosa de trabalhos e combinação estatística dos resultados provenientes de vários estudos com o intuito de produzir uma única estimativa do efeito de uma intervenção de saúde (ATALLAH, 1996, 1997; EGGER et al., 2001a,b; ALDERSON e GREEN, 2004; PAI, 2004).

A importância da revisão sistemática com metanálise torna-se mais evidente quando se consideram as limitações que um único estudo pode apresentar: problemas na variabilidade amostral, no tamanho da amostra e conseqüente não detecção de associações (ATALLAH, 1996, 1997; EGGER et al., 2001a,b; ALDERSON e GREEN, 2004; PAI, 2004).

Sendo assim, estudos comparáveis podem ter seus resultados combinados, alcançando-se "tamanho" de amostra maior, tal que pequenos efeitos podem ser detectados ou excluídos com mais confiança (ATALLAH, 1996; 1997; EGGER et al., 2001a,b; ALDERSON e GREEN, 2004; PAI 2004).

As revisões bibliográficas tradicionais possuem desvantagens, pois os trabalhos são combinados de maneira subjetiva, podendo dificultar a identificação, controle e exclusão de vieses, apesar da revisão sistemática ser, também, susceptível a vícios, se forem considerados tantos os intrínsecos a cada ensaio clínico como os de seleção (ATALLAH, 1996; 1997; EGGER et al., 2001a,b; ALDERSON e GREEN, 2004; PAI, 2004). 
A revisão sistemática com metanálise é realizada com base em um protocolo que determina a priori os critérios de inclusão e exclusão dos estudos, as bases de dados para pesquisa, e estabelece os critérios para a avaliação da qualidade dos estudos e seleção daqueles que comporão a análise agregada (ATALLAH, 1996, 1997; EGGER et al., 2001a,b; ALDERSON e GREEN, 2004; PAI, 2004). Com base nos objetivos deste estudo, estes tópicos serão detalhados a seguir.

\subsection{Critérios de inclusão de estudos - elegibilidade}

Como critérios de inclusão, foram utilizados ensaios aleatorizados controlados, relacionados à suplementação medicamentosa de vitamina $A$ direcionadas a mulheres lactantes (pós-parto). Para a identificação inicial de estudos, utilizou-se o questionário apresentado no Anexo 1.

\subsection{Tipo de participantes}

Puérperas (adultas e/ou adolescentes), lactantes que não apresentaram doenças crônico-degenerativas ou infecciosas, com exceção de deficiência de micronutrientes, podendo ou não apresentar DVA anterior ao parto ou gestação.

\subsection{Tipo de intervenção}

Foram considerados os estudos com a suplementação somente por vitamina A (em forma de éster de retinila ou beta-caroteno), ou por vitamina A associada a outros micronutrientes (exemplo: ferro, ácido fólico), com 
presença de grupo controle. Como grupo controle, foram considerados os que receberam placebo, outro tipo de intervenção ou nenhuma intervenção.

A administração do suplemento poderia ser feita em doses fracionadas (diária ou semanal) ou em dose única (mega dose). Em relação ao momento da administração do suplemento, considerou-se elegíveis os estudos com intervenção somente no pós-parto ou antes, durante e após a gestação.

\subsection{Desfechos}

\section{Primários}

- Mortalidade infantil - mortalidade entre 28 dias e 24 semanas, mortalidade abaixo de 24 semanas, mortalidade no primeiro ano de vida, mortalidade por infecção respiratória aguda (IRA), diarréia aguda, sepsis e desnutrição.

- Mortalidade materna - óbitos entre 7 e 12 semanas após parto.

- Morbidade infantil (presença e duração dos episódios) - IRA, infecção do trato respiratório inferior, infecção do trato respiratório superior, pneumonia, diarréia, disenteria.

- Morbidade materna e sinais e sintomas (presença e duração dos episódios) - evacuações aquosas, cegueira noturna, febre, fraqueza, secreção vaginal.

- Efeitos adversos da suplementação - infantis: abaulamento da fontanela, vômito, irritabilidade e febre; maternos: dor de cabeça, 
náusea, vômito, visão borrada, sonolência, dor abdominal e falta de apetite.

\section{Secundários}

- Concentração de retinol do leite humano - variável contínua, resumida pela média e desvio-padrão ou classificação de DVA subclínica pela categorização segundo valores apresentados no Quadro 2.

- Concentração de retinol sérico materno ou infantil - variável contínua, resumida pela média e desvio-padrão ou classificação de DVA subclínica pela categorização segundo valores apresentados no Quadro 2.

- Classificação de DVA subclínica pela categorização dos grupos materno ou infantil de acordo com o teste de resposta relativa à dose (RDR) e teste modificado de resposta relativa à dose (MRDR), segundo valores apresentados no Quadro 2.

- Incidência de cegueira noturna no grupo materno - variável qualitativa (ausência ou presença do sintoma).

- Limiar de adaptação ao escuro no grupo materno - variável contínua, resumida pela média e desvio-padrão apresentados em $\log c d / \mathrm{m}^{2}$ (cd=candela - unidade internacional de luminância). Menores valores do limiar indicam melhor adaptação ao escuro. 
- Citologia da impressão conjuntival $(\mathrm{CIC})$ no grupo materno - variável qualitativa: presença de anormalidade nos dois olhos ou ausência de anormalidade.

Quadro 2: Indicadores subclínicos do estado nutricional de vitamina A materno e infantil e pontos de corte indicativos de DVA subclínica.

\begin{tabular}{|cc|}
\hline Indicador & DVA subclínica \\
\hline Retinol sérico & $\leq 0,7 \mu \mathrm{mol} / \mathrm{L}$ \\
\hline Retinol do Leite Materno & $\leq 1,05 \mu \mathrm{mol} / \mathrm{L}$ \\
& $\leq 0,28 \mu \mathrm{mol} / \mathrm{g}$ de lipídio \\
\hline RDR & $\geq 20 \%$ \\
\hline MRDR & $\geq 0,06$ \\
\hline
\end{tabular}

Fonte: WHO (1996).

\subsection{Estratégia de busca para identificação de estudos}

Optou-se por uma estratégia de busca ampla que contemplou bases de dados bibliográficos da grande área da saúde e específicas de nutrição, contribuindo para a minimização de vieses de seleção.

\subsubsection{Bases de dados bibliográficos}

A pesquisa foi realizada nas seguintes bases de dados bibliográficos:

CCTR - Cochrane Controlled Trials Register - Cochrane Library: Base de dados da Biblioteca Cochrane que contém registros de ensaios clínicos identificados por membros da Colaboração Cochrane e outros. Inclui artigos publicados em anais de congressos e outras fontes que não constam nas principais bases de dados eletrônicas (Acesso livre via BIREME).

LILACS: Base de dados bibliográficos produzida de forma cooperativa, onde está registrada a literatura produzida por autores latinoamericanos e do Caribe (Acesso livre via BIREME). 
PUBMED: Base de dados bibliográficas criada e mantida pela Biblioteca Nacional de Medicina dos Estados Unidos. Contém citações bibliográficas e resumo de aproximadamente 3.900 periódicos publicados no EUA e em outros 70 países (Acesso livre via National Library of Medicine).

WEB OF SCIENCE: Base de dados que contém trabalhos publicados nos mais importantes periódicos internacionais, apresenta as referências bibliográficas contidas nos mesmos e informa os trabalhos que os citaram (Acesso pelo SIBI/USP).

BIOLOGICAL ABSTRACTS: Base de dados que contém resumos de conferências, simpósios, dissertações e teses, sendo grande parte de origem européia (ERL-WebSPIRS - Eletronic Reference Library - Acesso pelo SIBI/USP).

HUMAN NUTRITION: Base de dados que possui resumos de artigos em nutrição humana, alimentos, agricultura e saúde pública (ERLWebSPIRS - Electronic Reference Library - Acesso pelo SIBI/USP).

FOOD SCIENCES \& TECH ABSTRACTS: Base de dados que abrange engenharia de alimentos, nutrição, microbiologia, marketing, corantes, bioquímica, regulamentos, contendo resumos de artigos publicados internacionalmente (ERL-WebSPIRS - Electronic Reference Library - Acesso pelo SIBI/USP).

FOOD AND HUMAN NUTRITION: Base de dados que possui resumos de artigos em nutrição humana, alimentos, agricultura e saúde pública (ERL-WebSPIRS - Electronic Reference Library - Acesso pelo SIBI/USP). 
AGRIS: Base de dados produzida pela FAO, abrange assuntos relacionados a agricultura, ciências aquáticas, veterinária, nutrição e solos (ERL-WebSPIRS - Electronic Reference Library - Acesso pelo SIBI/USP).

\subsubsection{Palavras-chave}

A identificação do tipo de participante (lactantes), do tipo de intervenção (suplementação de vitamina A no pós-parto) e do desenho metodológico do estudo (ensaio controlado aleatorizado) compuseram a estratégia de busca dos estudos (Anexo 2).

A documentação dos resultados de cada busca foi feita com detalhes, garantindo sua reprodutibilidade. Para cada pesquisa realizada, foram registradas as seguintes informações: o título da base de dados, nome do servidor, data da pesquisa, período coberto pela busca, a estratégia de busca utilizada (usando os comandos "copiar" e "colar") e a descrição de que não houve restrição de idiomas.

Ao final das buscas, o título, a referência, o resumo e o nome da base de dados bibliográficos foram armazenados em banco de dados no programa gerenciador de referências bibliográficas EndNote 7.0 (THOMSON, 2003), consistindo o primeiro banco de dados.

\subsection{Método de revisão}

\section{Análise de elegibilidade}

Após a busca inicial, os resumos foram lidos por dois avaliadores e selecionados, segundo critérios de elegibilidade, que se basearam em três 
aspectos: população, intervenção, tipo de estudo (Anexo 1), sobre os quais cada avaliador, de modo independente, decidia por "inclusão", "exclusão" ou "não claro". Os resultados discrepantes foram decididos por consenso entre avaliadores.

Para trabalhos sugestivos de preenchimento dos critérios de elegibilidade, decidiu-se pela manutenção dos mesmos e posterior exclusão caso fosse necessário.

\section{Análise de qualidade}

A análise de qualidade foi realizada com o intuito de diminuir vieses de seleção, para agregar conhecimentos em potenciais comparações e como guia na interpretação dos resultados.

Nessa etapa, os estudos foram avaliados em relação à presença de vieses de seleção (diferenças sistemáticas entre grupos), de desempenho (diferenças sistemáticas em atenção à saúde, além do interesse de investigação), de perdas de seguimento (diferenças sistemáticas de abandono nos grupos) e de detecção (diferenças sistemáticas na avaliação dos desfechos).

Dois avaliadores, de forma independente, avaliaram aspectos metodológicos dos artigos e realizaram uma classificação quanto à qualidade dos mesmos, sendo as discordâncias resolvidas por consenso. Para essa fase, utilizou-se dois instrumentos (Anexo 3): Avaliação de Riscos de Vieses (instrumento 1, Quadro 3) e Avaliação da Adequação do Sigilo de 


\begin{abstract}
Alocação (instrumento 2, Quadro 4), descritos no Cochrane Reviewer's Handbook (ALDERSON e GREEEN, 2004).
\end{abstract}

Quadro 3: Avaliação dos Riscos de Vieses - interpretação.

\begin{tabular}{|ll|}
\hline \multicolumn{1}{|c|}{ Risco de Vieses } & \multicolumn{1}{c|}{ Interpretação } \\
\hline A. Baixo risco de vieses & Vieses plausíveis que não alteram os resultados \\
B. Moderado risco de vieses & Vieses plausíveis que podem causar alguma dúvida nos resultados \\
C. Alto risco de vieses & Vieses plausíveis que enfraquecem a qualidade do estudo \\
\hline
\end{tabular}

Fonte: Adaptado de ALDERSON e GREEEN (2004).

Quadro 4: Avaliação da Adequação do Sigilo de Alocação - interpretação.

\begin{tabular}{|cl|}
\hline Sigilo de Alocação & \multicolumn{1}{c|}{ Interpretação } \\
\hline A - Adequado & $\begin{array}{l}\text { Aleatorização centralizada; administração seqüencial de pacotes/envelopes pré- } \\
\text { codificados ou numerados; dados gerados por um programa de computador; } \\
\text { pessoa responsável pelo sorteio não envolvida diretamente da alocação dos } \\
\text { pacientes. }\end{array}$ \\
B - “Não claro" & $\begin{array}{l}\text { Abordagem de alocação utilizada não mencionada ou se houver suspeita de } \\
\text { falha. }\end{array}$ \\
C - Inadequado & $\begin{array}{l}\text { Alternância, utilização de números de prontuários, datas de nascimento, dias da } \\
\text { semana, ou qualquer outro processo não sigiloso (lista aberta de números } \\
\text { aleatórios). }\end{array}$ \\
D - Não utilizado & Alocação dos participantes nos grupos não foi sigilosa. \\
\hline
\end{tabular}
Fonte: Adaptado de ALDERSON e GREEEN (2004).

Os artigos classificados como C - Alto risco de vieses, pelo instrumento 1, ou como C - Inadequado ou D - Não utilizado, pelo instrumento 2, não foram incluídos na revisão por não atenderem aos critérios de qualidade.

Os dados registrados pelos dois avaliadores nos formulários de análise de elegibilidade e de qualidade foram inseridos com dupla digitação em planilhas do Excel (MICROSOFT, 2003). Com o auxílio do Stat/Transfer 7 (CIRCLE SYSTEMS, 2003), os bancos foram transferidos para o Epilnfo 6 (DEAN et al., 1994), onde, utilizando-se o programa Validate, foi possível identificar e corrigir os erros de digitação. 


\subsection{Extração de dados para a metanálise}

Nesta fase, todos os artigos elegíveis e apresentando qualidade foram lidos na íntegra por dois avaliadores. Foram registradas informações sobre o desenho do estudo, a população, a composição e dose do suplemento, sua via de administração, as variáveis investigadas, bem como sua apresentação (em intervalos de classes, médias e desvios-padrão, intervalos de confiança ou outros), utilizando-se o Formulário de Extração de Dados (Anexo 4).

Os dados, foram extraídos e também comparados, sendo as discordâncias resolvidas mediante discussão. Os avaliadores tiveram acesso aos nomes dos autores, instituições às quais pertencem e nome da revista onde foi publicado.

Os dados foram inseridos com dupla digitação em planilhas do Excel (MICROSOFT, 2003) e após transferência para o Epi Info 6 (DEAN et al., 1994) e, utilizando-se o programa Validate, os erros de digitação foram identificados e corrigidos. Os dados foram transferidos para o Stata 9.0 (STATACORP, 2005) para realização da análise estatística agregada.

Os dados dos teores médios de retinol séricos foram apresentados em micromol por litro ( $\mu \mathrm{mol} / \mathrm{L})$ e de concentrações de retinol no leite em $\mu \mathrm{mol} / \mathrm{L}$ ou em micromol por grama de lipídio ( $\mu \mathrm{mol} / \mathrm{g}$ de lipídio). Para estudos que apresentaram os dados de retinol em micrograma por decilitro $(\mu \mathrm{g} / \mathrm{dl})$, foram realizadas conversões por meio do Conversor.xls (MS, 2004), utilizando-se as seguintes equivalências: $1 \mathrm{RE}=1 \mu \mathrm{g}$; $1 \mathrm{RE}=0,0034911 \mu \mathrm{mol}$; $1 \mathrm{RE}=3,33 \mathrm{UI}$. 


\subsection{Análise Estatística}

\section{Metanálise}

A análise estatística agregada foi realizada utilizando-se o software Stata 9.0 (2005). Os dados foram apresentados utilizando-se as formas tabular e gráfica. Em uma tabela foram apresentadas as características dos estudos incluídos: autor, ano de publicação, dosagem do suplemento, tempo de duração da intervenção e características metodológicas. Para a apresentação dos resultados da metanálise e comparação entre os estudos, foi utilizado o gráfico Forest Plot.

De acordo com a natureza do desfecho foram utilizadas medidas de efeito apropriadas. Para variáveis dicotômicas, utilizou-se o Odds Ratio (OR) e para variáveis contínuas, foi utilizada a diferença não padronizada de médias.

A análise agregada dos dados foi realizada utilizando-se o modelo de efeitos fixos. Para cada variável resposta, calculou-se uma "estimativaresumo" e o respectivo intervalo de confiança de 95\% (IC95\%), descrevendo o efeito do tratamento. As saídas da metanálise estão apresentadas no Anexo 5.

Para contornar as possíveis diferenças que podiam ocorrer entre os estudos incluídos, utilizou-se teste de heterogeneidade e exploração das possíveis causas. Quando alguma heterogeneidade era detectada, realizouse os seguintes procedimentos:

- checagem de dados originais (verificação de erro na extração dos dados); 
- exclusão de estudos (quando a heterogeneidade foi atribuída a metodologias distintas - diferentes doses do suplemento ou doses fracionadas).

\section{Análise de sensibilidade}

A análise de sensibilidade refere-se à quão sensíveis são os resultados da análise estatística realizada, assim torna-se base para testar a robustez da metanálise em relação às decisões sobre a inclusão de trabalhos. A análise de sensibilidade foi realizada retirando-se estudos que utilizaram doses de vitamina $\mathrm{A}$ superiores quando comparadas aos demais estudos ou doses fracionadas, e estudos que incluíam mulheres suplementadas antes, durante e após o parto. 


\section{Resultados}

\subsection{Avaliação dos critérios de elegibilidade}

As buscas realizadas nas bases de dados resultaram em 3.425 artigos. Na base de dados bibliográficos PubMed, foi identificado o maior número de estudos, $1.291(37,7 \%)$, seguida pela base Web of Science, 1.141 (33,3\%). As buscas nas bases ERL, Lilacs e CCTR resultaram em 649 $(18,9 \%), 201(5,9 \%)$ e $143(4,2 \%)$ estudos, respectivamente. Após a exclusão de 872 estudos duplicados, obteve-se a identificação de 2.553 artigos. Ao longo da etapa de organização dos trabalhos para leitura, identificou-se que mais alguns estudos $(n=6)$ apresentavam duplicidade. As cópias foram excluídas, atingindo-se o total de 2.547 estudos $(\mathrm{N})$.

Para 241 artigos (9,5\%), estavam disponíveis somente o título do trabalho, a revista onde foi publicado (com volume e ano) e os nomes dos autores. Para 193 artigos, foi possível tomar a decisão sobre a inclusão ou exclusão com base nessas informações, enquanto que para 48 isto não foi possível, assim procedeu-se a localização de resumos $(n=18)$, quando disponíveis, e de estudos completos $(n=24)$. Para seis estudos, não foi possível localizar os resumos ou os artigos completos, pois o volume do periódico não estava disponível, ou foram publicados em revistas científicas não disponíveis em bibliotecas brasileiras ou estrangeiras que possuem contrato de cooperação com a Bireme, ou o mesmo estava suspenso (Quadro 6).

Ao final da análise de elegibilidade, 24 artigos foram selecionados para a etapa de análise de qualidade, 2.416 foram excluídos e 10 foram 
classificados como "não claro" em relação à inclusão. Para 97 estudos, foi necessária discussão entre os avaliadores devido a discordâncias.

Os avaliadores procederam a segunda leitura de 107 ( $\mathrm{n}=97$ com decisões discordantes, $\mathrm{n}=10$ com classificação "não claro" por ambos avaliadores). Nesse conjunto, estavam incluídos os 48 artigos que apresentaram somente o título. Para os seis estudos cujos resumos ou artigos na íntegra que não foram localizados, os avaliadores decidiram por consenso pela não inclusão dos mesmos, pois os títulos indicavam de forma clara que os estudos não cumpriam os critérios de elegibilidade (Quadro 5).

Quadro 5: Autor ano, título e fonte dos estudos cujos resumos ou artigos na íntegra não foram localizados e foram excluídos por consenso entre os dois avaliadores.

\begin{tabular}{|c|c|c|}
\hline Autor/Ano & Título & Fonte \\
\hline $\begin{array}{l}\text { Buller et al., } \\
\qquad 1986\end{array}$ & $\begin{array}{l}\text { Vitamin } k \text { status beyond the neonatal period: a prospective } \\
\text { study in normal breast-fed formula fed infants. }\end{array}$ & $\begin{array}{l}\text { Eur J Pediatr } \\
1986 ; 145(6): 469-99\end{array}$ \\
\hline $\begin{array}{c}\text { Greer et al., } \\
1982\end{array}$ & $\begin{array}{l}\text { Bone mineral content and serum 25-hydroxyvitamin D } \\
\text { concentrations in breastfed infants with and without } \\
\text { supplemental vitamin D: one year follow up. }\end{array}$ & $\begin{array}{l}\text { J Pediatr 1982; } \\
\text { 100(6): 919-22 }\end{array}$ \\
\hline Dary, 1992 & $\begin{array}{l}\text { Intervenciones para la prevención y control de la deficiencia } \\
\text { de vitamina A en América Latina y el Caribe. }\end{array}$ & $\begin{array}{l}\text { Arch Latinoam Nutr } \\
\text { 1992; (3S): 123-6 }\end{array}$ \\
\hline $\begin{array}{l}\text { Ganguly e } \\
\text { Mukherjee, } \\
1988\end{array}$ & $\begin{array}{l}\text { Relationship between maternal serum vitamin A and vitamin } \\
\text { A status of the corresponding fetuses. }\end{array}$ & $\begin{array}{l}\text { J Trop Pediatr 1988; } \\
\text { 34(6): } 313-5\end{array}$ \\
\hline Berhe, 1997 & $\begin{array}{l}\text { Tulimbe Nutrition Project: a community-based dietary } \\
\text { intervention to combat micronutrient malnutrition in rural } \\
\text { southern Malawi. }\end{array}$ & $\begin{array}{l}\text { SCN News } \\
1997 ; 15: 25-6\end{array}$ \\
\hline $\begin{array}{l}\text { Saowakontha } \\
\text { et al., } 1975\end{array}$ & Distribution and content of vitamin $A$ in the liver of Thais & $\begin{array}{l}\text { J Med Assoc Thai } \\
\text { 1975; 58(5): } 249-52\end{array}$ \\
\hline
\end{tabular}

Como resultado da etapa de avaliação dos critérios de inclusão, foram considerados elegíveis para a análise de qualidade 44 estudos, descritos na 
caixa "n1 de resumos" (Figura 2). O esquema abaixo ilustra as etapas de exclusão e inclusão dos estudos.

2.547 (N) títulos e resumos localizados.

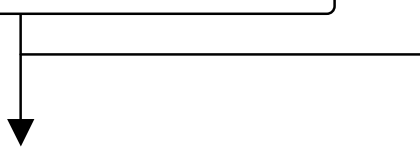

$2.503\left(n_{1}^{\prime}\right)$ resumos excluídos por não atenderem aos critérios de elegibilidade.

$44\left(n_{1}\right)$ estudos elegíveis identificados para avaliação de qualidade.

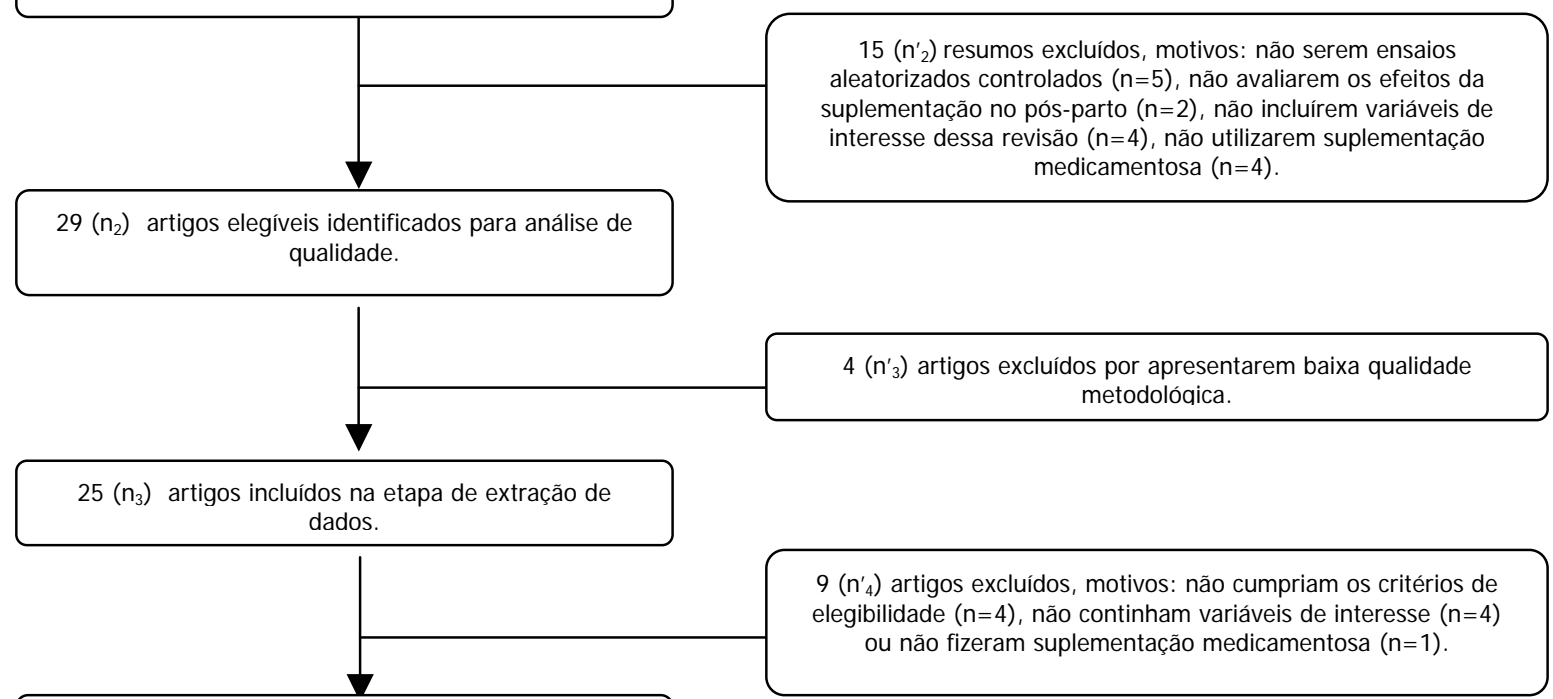

$16\left(\mathrm{n}_{4}\right)$ artigos incluídos na revisão sistemática.

Figura 2: Processo de seleção de estudos e motivos de exclusão (Adaptado de PAl et al., 2003).

Após a leitura na íntegra dos 44 artigos (n1), 15 deles foram excluídos por não serem ensaios aleatorizados controlados $(n=5)$, não avaliarem os efeitos da suplementação no pós-parto $(n=2)$, não incluírem variáveis de interesse dessa revisão $(n=4)$, não utilizarem suplementação medicamentosa ( $n=4)$ (Quadro 6). 
Quadro 6: Artigos excluídos após a leitura na íntegra, na etapa de análise de qualidade, segundo autor, ano, desenho de estudo, objetivo e justificativa de exclusão.

\begin{tabular}{|c|c|c|}
\hline Autor e Ano & Desenho de estudo e objetivo & Justificativa \\
\hline $\begin{array}{l}\text { Wedner et al., } \\
2004\end{array}$ & $\begin{array}{l}\text { Estudo caso-controle com crianças e mulheres (grávidas ou } \\
\text { lactantes) que apresentavam sinais de xeroftalmia. } \\
\text { Posteriormente, realizou-se suplementação de VA e } \\
\text { seguimento por três a quatro semanas. }\end{array}$ & $\begin{array}{l}\text { Não é ensaio } \\
\text { aleatorizado } \\
\text { controlado. }\end{array}$ \\
\hline $\begin{array}{c}\text { Ross e } \\
\text { Harvey, } 2003\end{array}$ & $\begin{array}{l}\text { Utiliza modelo de simulação para estimar a contribuição do } \\
\text { aleitamento materno no estado nutricional de vitamina } A \text {, } \\
\text { considerando os níveis de consumo de leite e a } \\
\text { suplementação materna de VA. }\end{array}$ & $\begin{array}{l}\text { Não é ensaio } \\
\text { aleatorizado } \\
\text { controlado. }\end{array}$ \\
\hline $\begin{array}{l}\text { Latham et al., } \\
2003\end{array}$ & $\begin{array}{l}\text { Ensaio aleatorizado controlado com placebo que avaliou o } \\
\text { impacto da suplementação com bebida fortificada com VA e } \\
\text { outros micronutrientes, direcionado a crianças e gestantes, na } \\
\text { concentração de hemoglobina, de retinol sérico e do leite } \\
\text { humano. }\end{array}$ & $\begin{array}{l}\text { Não avalia os } \\
\text { efeitos da } \\
\text { suplementação de } \\
\text { VA durante a } \\
\text { lactação. }\end{array}$ \\
\hline $\begin{array}{l}\text { Bahl et al., } \\
\quad 2002\end{array}$ & $\begin{array}{l}\text { Ensaio clínico aleatorizado controlado com grupo placebo que } \\
\text { avaliou o impacto da suplementação conjunta de VA, para a } \\
\text { lactante e para o bebê, na resposta dos anticorpos frente à } \\
\text { vacinação contra pólio. }\end{array}$ & $\begin{array}{l}\text { Não foram } \\
\text { incluídos desfechos } \\
\text { de interesse dessa } \\
\text { revisão. }\end{array}$ \\
\hline $\begin{array}{l}\text { Lietz et al., } \\
\quad 2001\end{array}$ & $\begin{array}{l}\text { Ensaio de campo controlado no qual se avaliou o efeito da } \\
\text { utilização do óleo de dendê africano ou folhas verde-escuras } \\
\text { nos níveis de retinol, beta e alfa caroteno séricos e do leite } \\
\text { humano de gestantes e lactantes. }\end{array}$ & $\begin{array}{l}\text { Não faz } \\
\text { suplementação } \\
\text { medicamentosa. }\end{array}$ \\
\hline $\begin{array}{c}\text { Christian et al., } \\
2001\end{array}$ & $\begin{array}{l}\text { Ensaio de campo aleatorizado controlado com grupo placebo } \\
\text { realizado no Nepal com mulheres casadas em idade } \\
\text { reprodutiva que avalia a relação entre a mortalidade infantil } \\
\text { até seis meses pós-parto e a ocorrência de cegueira noturna } \\
\text { materna durante a gravidez. }\end{array}$ & $\begin{array}{l}\text { Não avalia os } \\
\text { efeitos da } \\
\text { suplementação de } \\
\text { VA durante a } \\
\text { lactação. }\end{array}$ \\
\hline $\begin{array}{l}\text { Rice et al., } \\
2000 a\end{array}$ & $\begin{array}{l}\text { Estudo metodológico que utilizou dados de um ensaio } \\
\text { aleatorizado, no qual foi investigada a relação entre níveis de } \\
\text { retinol do fígado (estimado pelo MRDR) e as concentrações } \\
\text { de retinol no leite humano. }\end{array}$ & $\begin{array}{l}\text { Não foram } \\
\text { incluídos desfechos } \\
\text { de interesse dessa } \\
\text { revisão. }\end{array}$ \\
\hline $\begin{array}{l}\text { Lukoianova et } \\
\text { al., } 1999\end{array}$ & $\begin{array}{l}\text { Estudo transversal no qual foi determinado o teor de vitaminas } \\
\text { B1, B2, B6, A e E no leite humano de } 14 \text { lactantes que } \\
\text { receberam suplementos somente durante a gravidez ou } \\
\text { durante a gravidez e a lactação. }\end{array}$ & $\begin{array}{l}\text { Não é ensaio } \\
\text { aleatorizado } \\
\text { controlado. }\end{array}$ \\
\hline $\begin{array}{c}\text { Canfield et al., } \\
1998\end{array}$ & $\begin{array}{l}\text { Ensaio para investigar mudanças nos teores de carotenóides, } \\
\text { retinol e alfa-tocoferol do soro e do leite humano após } \\
\text { suplementação por beta-caroteno sem aleatorização e grupo } \\
\text { controle. }\end{array}$ & $\begin{array}{l}\text { Não é ensaio } \\
\text { aleatorizado } \\
\text { controlado. }\end{array}$ \\
\hline $\begin{array}{c}\text { Johnson et al., } \\
1997\end{array}$ & $\begin{array}{l}\text { Ensaio no qual } 12 \text { lactantes foram avaliadas previamente e } \\
\text { posteriormente à suplementação por beta-caroteno ou } \\
\text { placebo. Investigou-se a presença de dois isômeros do beta- } \\
\text { caroteno no soro e na mucosa bucal. }\end{array}$ & $\begin{array}{l}\text { Não foram } \\
\text { incluídos desfechos } \\
\text { de interesse dessa } \\
\text { revisão. }\end{array}$ \\
\hline
\end{tabular}




\begin{tabular}{|c|c|c|}
\hline Alvarez 1995 & $\begin{array}{l}\text { Estudo que investigou o efeito da suplementação combinada } \\
\text { de ferro e vitamina A no estado nutricional de ferro de } \\
\text { mulheres lactantes. }\end{array}$ & $\begin{array}{l}\text { Não foram } \\
\text { incluídos desfechos } \\
\text { de interesse dessa } \\
\text { revisão. }\end{array}$ \\
\hline $\begin{array}{c}\text { de Pee et al., } \\
1995\end{array}$ & $\begin{array}{l}\text { Ensaio clínico aleatorizado com grupo controle que avaliou o } \\
\text { impacto da suplementação com folhas verdes-escuras, } \\
\text { biscoitos tipo wafer enriquecidos com beta-caroteno para as } \\
\text { lactantes e os efeitos nos níveis de retinol e de beta-caroteno } \\
\text { séricos e do leite humano. }\end{array}$ & $\begin{array}{l}\text { Não faz } \\
\text { suplementação } \\
\text { medicamentosa. }\end{array}$ \\
\hline $\begin{array}{l}\text { Muhilal et } \\
\text { al.,1988 }\end{array}$ & $\begin{array}{l}\text { Ensaio comunitário controlado, no qual se comparou os níveis } \\
\text { de retinol e do leite humano de moradores de diferentes } \\
\text { comunidades que receberam glutamato monossódico } \\
\text { tradicional ou fortificado com VA. }\end{array}$ & $\begin{array}{l}\text { Não faz } \\
\text { suplementação } \\
\text { medicamentosa. }\end{array}$ \\
\hline $\begin{array}{c}\text { Muhilal et al., } \\
1988\end{array}$ & $\begin{array}{l}\text { Ensaio comunitário controlado, no qual se comparou as } \\
\text { variáveis antropométricas, prevalência de sinais de } \\
\text { xeroftalmia e níveis de hemoglobina em crianças de diferentes } \\
\text { comunidades que receberam glutamato monossódico } \\
\text { tradicional ou fortificado com VA. }\end{array}$ & $\begin{array}{l}\text { Não faz } \\
\text { suplementação } \\
\text { medicamentosa. }\end{array}$ \\
\hline $\begin{array}{c}\text { Villard e Bates, } \\
\qquad 1986\end{array}$ & $\begin{array}{l}\text { Estudo que compara o teor de retinol do leite humano e sérico } \\
\text { de mulheres durante a gravidez e lactação, provenientes de } \\
\text { duas vilas de área rural. Sendo que, em uma delas as } \\
\text { mulheres receberam alimentos fortificados com VA. }\end{array}$ & $\begin{array}{l}\text { Não é ensaio } \\
\text { clínico controlado; } \\
\text { não faz } \\
\text { suplementação } \\
\text { medicamentosa. }\end{array}$ \\
\hline
\end{tabular}

VA - Vitamina A.

\subsection{Análise da qualidade dos estudos}

Após análise de qualidade, observou-se que 14 (48,3\%) estudos foram classificados como adequados em relação ao sigilo de alocação. Em parte importante deles, $(n=12,41,4 \%)$, o processo de alocação dos participantes não estava descrito detalhadamente, havendo, porém, indícios de processo de aleatorização adequado. Em dois estudos, classificados como sigilo de alocação inadequado, foram descritas a utilização de alternância e alocação das mulheres por ordem de chegada. Em somente um estudo, não foi utilizado sigilo de alocação (Tabela 1). 
Tabela 1: Distribuição dos estudos segundo Adequação do Sigilo de Alocação Cochrane.

\begin{tabular}{lcr}
\hline Sigilo de Alocação & Número & \multicolumn{1}{c}{$\%$} \\
\hline A - Adequado & 14 & 48,3 \\
B - Não-claro & 12 & 41,4 \\
C - Inadequado & 2 & 6,9 \\
D - Não utilizado & 1 & 3,4 \\
\hline Total & 29 & 100 \\
\hline
\end{tabular}

Considerando-se o método descrito no Cochrane Handbook (ALDERSON e GREEN, 2004), 19 (65,5\%) estudos foram classificados como apresentado "baixo risco de vieses". Nas categorias "moderado" e "alto risco de vieses", foram classificados $24,1 \%$ e $10,4 \%$ dos estudos, respectivamente (Tabela 2 ).

Tabela 2: Distribuição dos estudos segundo Avaliação dos Riscos de Vieses (ALDERSON e GREEN, 2004).

\begin{tabular}{lcl}
\hline Risco de Vieses & Número & $\%$ \\
\hline Baixo & 19 & 65,5 \\
Moderado & 7 & 24,1 \\
Alto & 3 & 10,4 \\
\hline Total & 29 & 100 \\
\hline
\end{tabular}

Ao final dessa etapa, quatro estudos foram excluídos por não cumprirem critérios de qualidade estabelecidos na Avaliação de Riscos de Vieses e na Adequação do Sigilo de Alocação (Quadro 8).

Quadro 7: Artigos excluídos, após a leitura na íntegra, por não cumprirem os critérios de qualidade, segundo autor, ano, desenho de estudo, objetivo e justificativa de exclusão.

\begin{tabular}{|c|c|c|}
\hline Autor e Ano & Desenho do estudo e objetivo & Justificativa \\
\hline $\begin{array}{c}\text { Basu et al., } \\
2003\end{array}$ & $\begin{array}{l}\text { Ensaio controlado com grupo placebo que avaliou o impacto } \\
\text { da suplementação de VA na concentração de retinol sérico } \\
\text { materno, infantil e do leite humano, bem como na ocorrência } \\
\text { de morbidade infantil. }\end{array}$ & $\begin{array}{l}\text { Alocação dos } \\
\text { participantes feita } \\
\text { por alternância. }\end{array}$ \\
\hline
\end{tabular}




\begin{tabular}{|c|c|c|}
\hline $\begin{array}{l}\text { Canfield et al., } \\
2001\end{array}$ & $\begin{array}{l}\text { Estudo que avalia os efeitos da suplementação com alimentos } \\
\text { fontes de VA (óleo de dendê africano), durante } 10 \text { dias, nos } \\
\text { níveis séricos de beta-caroteno materno, do bebê e do leite } \\
\text { humano. Participaram do estudo } 76 \text { bebês com idade entre } 1 \\
\text { e } 24 \text { meses. }\end{array}$ & $\begin{array}{l}\text { Não utilização de } \\
\text { alocação sigilosa } \\
\text { dos participantes. }\end{array}$ \\
\hline $\begin{array}{c}\text { Ncube et al., } \\
2001\end{array}$ & $\begin{array}{l}\text { Estudo que avalia os efeitos da suplementação com alimentos } \\
\text { fonte de VA, durante } 10 \text { dias (mamão e cenoura), nos níveis } \\
\text { séricos de retinol, de hemoglobina e de proteína C reativa } \\
\text { maternos. }\end{array}$ & $\begin{array}{l}\text { Alocação dos } \\
\text { participantes feita } \\
\text { por ordem de } \\
\text { chegada. }\end{array}$ \\
\hline $\begin{array}{c}\text { Roy et al., } \\
1997\end{array}$ & $\begin{array}{l}\text { Ensaio controlado com placebo que avaliou o impacto da } \\
\text { suplementação de VA na concentração de retinol sérico } \\
\text { materno, infantil e do leite humano, bem como na ocorrência } \\
\text { de morbidade infantil. }\end{array}$ & $\begin{array}{l}\text { Os participantes e } \\
\text { os responsáveis } \\
\text { pelos cuidados } \\
\text { conheciam a quais } \\
\text { grupos pertenciam. }\end{array}$ \\
\hline
\end{tabular}

VA - Vitamina A.

Para nove artigos, considerados inicialmente elegíveis e apresentado

qualidade, na etapa de extração de dados constatou-se inadequação e

optou-se pela exclusão, por não cumprirem os critérios de elegibilidade

$(n=4)$, não conter os desfechos de interesse $(n=4)$ ou não utilizaram

suplementação medicamentosa $(n=1)$. São apresentados no Quadro 8, os

resumos de cada estudo e a justificativa de sua exclusão.

Quadro 8: Artigos excluídos após a leitura na íntegra, na etapa de extração de dados, segundo autor, ano, desenho de estudo, objetivo e justificativa de exclusão.

\begin{tabular}{|cll|}
\hline Autor e Ano & \multicolumn{1}{c|}{ Desenho de estudo e objetivo } & Justificativa \\
\hline $\begin{array}{c}\text { Christian et al., } \\
2003\end{array}$ & $\begin{array}{l}\text { Ensaio aleatorizado controlado com grupo placebo que } \\
\text { comparou suplementação de VA e suplementação de VA } \\
\text { adicionada de outros micronutrientes na perda fetal. }\end{array}$ & $\begin{array}{l}\text { Não cumpre os } \\
\text { critérios de } \\
\text { elegibilidade. }\end{array}$ \\
\hline $\begin{array}{c}\text { Christian et al., } \\
2003\end{array}$ & $\begin{array}{l}\text { Ensaio aleatorizado controlado com grupo placebo que } \\
\text { suplementação de VA adicionada de outros micronutrientes } \\
\text { no estado hematológico durante a gravidez. }\end{array}$ & $\begin{array}{l}\text { Não cumpre os } \\
\text { critérios de } \\
\text { elegibilidade. }\end{array}$ \\
\hline $\begin{array}{c}\text { Gossage et al., } \\
2002\end{array}$ & $\begin{array}{l}\text { Estudo que investigou os efeitos da suplementação com beta- } \\
\text { caroteno na concentração de carotenóides do leite humano } \\
\text { durante o primeiro mês pós-parto. }\end{array}$ & $\begin{array}{l}\text { Não foram } \\
\text { incluídos desfechos } \\
\text { de interesse dessa } \\
\text { revisão. }\end{array}$ \\
\hline $\begin{array}{c}\text { Gossage et al., } \\
2000\end{array}$ & $\begin{array}{l}\text { Estudo que comparou os efeitos da suplementação com beta- } \\
\text { proliferação de linfócito T em mulheres lactantes e não } \\
\text { lactantes. }\end{array}$ & $\begin{array}{l}\text { Não cumpre os } \\
\text { critérios de } \\
\text { elegibilidade. }\end{array}$ \\
\hline
\end{tabular}




\begin{tabular}{|c|c|c|}
\hline $\begin{array}{l}\text { Rice et al., } \\
2000 \mathrm{~b}\end{array}$ & $\begin{array}{l}\text { Estudo que utiliza dados de um ensaio aleatorizado e } \\
\text { controlado que avalia os efeitos da suplementação de } \\
\text { vitamina A ou beta-caroteno em lactantes. }\end{array}$ & $\begin{array}{l}\text { Não foram } \\
\text { incluídos desfechos } \\
\text { de interesse dessa } \\
\text { revisão. }\end{array}$ \\
\hline $\begin{array}{c}\text { Filteau et al., } \\
1999\end{array}$ & $\begin{array}{l}\text { Estudo que investigou o efeito da suplementação de vitamina } \\
\text { A ou beta-caroteno para lactantes na concentração de fatores } \\
\text { imunológicos (imunoglobulina A, lactoferrina, lisozina e } \\
\text { interleucina 8) no leite humano. }\end{array}$ & $\begin{array}{l}\text { Não cumpre os } \\
\text { critérios de } \\
\text { elegibilidade. }\end{array}$ \\
\hline $\begin{array}{c}\text { Canfield et al., } \\
1997\end{array}$ & $\begin{array}{l}\text { Estudo que avaliou os efeitos da suplementação com alimento } \\
\text { fonte de beta-caroteno em mulheres lactantes nos níveis de } \\
\text { retinol e carotenóides séricos e do leite materno, durante } 8 \\
\text { dias após a intervenção. }\end{array}$ & $\begin{array}{l}\text { Não faz } \\
\text { suplementação } \\
\text { medicamentosa. }\end{array}$ \\
\hline $\begin{array}{c}\text { Stoltzfus et al., } \\
1993 \mathrm{~b}\end{array}$ & $\begin{array}{l}\text { Estudo metodológico que investigou a habilidade de três } \\
\text { indicadores em detectar mudanças no estado nutricional de } \\
\text { vitamina A em lactantes. }\end{array}$ & $\begin{array}{l}\text { Não foram } \\
\text { incluídos desfechos } \\
\text { de interesse dessa } \\
\text { revisão. }\end{array}$ \\
\hline $\begin{array}{c}\text { Stoltzfus et al., } \\
1993 c\end{array}$ & $\begin{array}{l}\text { Estudo metodológico que investigou a habilidade da citologia } \\
\text { de impressão conjuntival como indicador do estado nutricional } \\
\text { de vitamina A em lactantes. }\end{array}$ & $\begin{array}{l}\text { Não foram } \\
\text { incluídos desfechos } \\
\text { de interesse dessa } \\
\text { revisão. }\end{array}$ \\
\hline
\end{tabular}

\subsection{Características dos estudos incluídos na revisão}

Foram considerados elegíveis e apresentando qualidade 16 artigos, cujas características estão descritas na Tabela 3. Treze artigos relacionamse a estudos conduzidos no continente Asiático, dois foram conduzidos na África e um é multicêntrico, desenvolvido na África, Ásia e América do Sul. Seis artigos (37,5\%), estão relacionados ao estudo realizado no Nepal, denominado Nepal Nutrition Intervention Project - Sarlahi (NNIPS-2). Dois artigos $(12,5 \%)$ referem-se à investigação realizada no Zimbábue denominada ZVITAMBO, outros dois trabalhos $(12,5 \%)$ referem-se ao estudo multicêntrico WHO/CHD Immunisation Linked Vitamin $A$ Supplementation Study Group (WHO/CHD ILVASSG) realizado em Gana, Índia e Peru. 
Dez artigos $(62,5 \%)$ referem-se a estudos que investigaram os efeitos da suplementação em dose única de vitamina $A$, sendo que um dos estudos foi conduzido utilizando-se dois grupos: suplementação de vitamina $A$ em dose única e suplementação diária de beta-caroteno. Seis trabalhos, que se referem ao estudo NNIPS-2, avaliaram os efeitos da suplementação de vitamina A e de beta-caroteno em doses semanais.

Entre os artigos que investigaram os efeitos da suplementação em dose única $(n=10)$, seis $(60 \%)$ utilizaram dose de $200.000 U$, dois $(20 \%)$ utilizaram dose de 300.000 U e dois (20\%) deles utilizaram dose de 400.000UI de vitamina A.

O método de determinação de retinol sérico ou no leite humano empregado na maior parte dos artigos, $n=8(72,7 \%)$, foi o High Performance Liquid Chromatography (HPLC). Em três estudos $(27,3 \%)$ foram utilizadas outras metodologias: fluorometria, espectrofluorimetria e espectrofotometria, para determinação do retinol sérico e colorometria ou espectrofotometria para determinação do retinol do leite.

A suplementação conjunta de vitamina A para a mãe e para o bebê esteve presente em três estudos. No estudo WHO/CHD ILVASSG (1998) a suplementação infantil foi fracionada em três doses de $25.000 U$ l recebidas nos meses de vacinação $\left(2^{\circ}, 3^{\circ}, 4^{\circ}\right.$ mês $)$ durante o primeiro ano de vida. No estudo de VENKATARAO et al. (1996) os bebês foram suplementados aos seis meses com dose única de $200.000 U$ I de vitamina $\mathrm{A}$. Na investigação do ZVITAMBO (MALABA et al., 2005) os bebês foram suplementados com dose única de $50.000 U$ I de vitamina A no pós-parto imediato. 
Quanto ao momento da suplementação, somente o estudo NNIPS-2, realizado no Nepal, utilizou a suplementação contínua (antes, durante a gravidez e após o parto) de vitamina A ou beta-caroteno. Dos dez estudos que investigaram os efeitos da suplementação somente no pós-parto, cinco deles $(50 \%)$ a realizaram nas primeiras 96 horas após o parto. Para os demais estudos, $n=5(50 \%)$, o momento da suplementação variou entre 7 e 42 dias. 
Tabela 3: Distribuição dos estudos incluídos na revisão segundo características metodológicas.

\begin{tabular}{|c|c|c|c|c|c|c|c|c|c|c|c|}
\hline $\mathrm{n}^{\circ}$ & Referência & Local & $\begin{array}{l}\text { Desenho do } \\
\text { estudo }\end{array}$ & $\begin{array}{l}\text { Administração } \\
\text { (dose) }\end{array}$ & $\begin{array}{l}\text { Momento da } \\
\text { suplementação }\end{array}$ & $\begin{array}{c}\text { Tempo de } \\
\text { tratamento } \\
\text { (meses) }\end{array}$ & $\begin{array}{l}\text { Composição do } \\
\text { suplemento e do placebo }\end{array}$ & $\begin{array}{c}\text { Dose de } \\
\text { vitamina } A \text { ou } \\
\text { beta-caroteno }\end{array}$ & $\begin{array}{c}\text { Suplementação } \\
\text { do bebê }\end{array}$ & Amostra & $\begin{array}{c}\text { Método de } \\
\text { determinação } \\
\text { do retinol }\end{array}$ \\
\hline 1 & $\begin{array}{l}\text { Malaba et al., } \\
2005\end{array}$ & Zimbábue & $\mathrm{EA}, \mathrm{DC}, \mathrm{CP}$ & Única & $\begin{array}{l}\text { Pós-parto } \\
\text { (1 dia) }\end{array}$ & - & $\begin{array}{c}P R+V E \\
P \text { (óleo de soja) }\end{array}$ & $\begin{array}{c}400.000 \mathrm{UI} \\
400.000 \mathrm{UI} \\
\mathrm{P} \\
\mathrm{P}\end{array}$ & $\begin{array}{c}50.000 \mathrm{UI} \\
\mathrm{P} \\
50.000 \mathrm{UI} \\
\mathrm{P}\end{array}$ & $\begin{array}{l}2.319 \\
2.300 \\
2.280 \\
2.309\end{array}$ & HPLC \\
\hline 2 & Bahl et al., 2002 & Índia/Gana/Peru & $\begin{array}{l}\text { EA multicêntrico, } \\
\text { DC, CP }\end{array}$ & Única & $\begin{array}{l}\text { Pós-parto } \\
\text { (18-42 dias) }\end{array}$ & - & $\begin{array}{c}\mathrm{PR}+\mathrm{VE} \\
\mathrm{P} \text { (óleo de soja) }\end{array}$ & $\begin{array}{c}200.000 \mathrm{UI} \\
\mathrm{P}\end{array}$ & $\begin{array}{c}75.000 \mathrm{UI} \\
(3 \times 25.000 \mathrm{UI}) \\
\mathrm{P}\end{array}$ & $\begin{array}{l}1.491 \\
1.499\end{array}$ & HPLC \\
\hline 3 & Yamini et al., 2001 & Nepal & ECAC, DC, CP & Semanal & $\begin{array}{l}\text { Antes, durante e } \\
\text { após a gravidez }\end{array}$ & 42 & $\begin{array}{c}\mathrm{PR}+\mathrm{VE} \\
\mathrm{BC}+\mathrm{VE} \\
\mathrm{P} \text { (óleo de amendoim) }\end{array}$ & $\begin{array}{l}23.300 \mathrm{UI} \\
42 \mathrm{mg} \\
\mathrm{P}\end{array}$ & Não & $\begin{array}{l}336 \\
360 \\
377\end{array}$ & HPLC \\
\hline 4 & $\begin{array}{l}\text { Congdon et al., } \\
2000\end{array}$ & Nepal & ECAC, DC, CP & Semanal & $\begin{array}{l}\text { Antes, durante e } \\
\text { após a gravidez }\end{array}$ & 42 & $\begin{array}{c}\mathrm{PR}+\mathrm{VE} \\
\mathrm{BC}+\mathrm{VE} \\
\mathrm{P} \text { (óleo de amendoim) }\end{array}$ & $\begin{array}{c}23.300 \mathrm{UI} \\
42 \mathrm{mg} \\
\mathrm{P}\end{array}$ & Não & $\begin{array}{c}93 \\
113 \\
87\end{array}$ & HPLC \\
\hline 5 & Katz et al., 2000 & Nepal & ECAC, DC, CP & Semanal & $\begin{array}{l}\text { Antes, durante e } \\
\text { após a gravidez }\end{array}$ & 38 & $\begin{array}{c}\mathrm{PR}+\mathrm{VE} \\
\mathrm{BC}+\mathrm{VE} \\
\mathrm{P} \text { (óleo de amendoim) }\end{array}$ & $\begin{array}{l}23.300 \mathrm{UI} \\
42 \mathrm{mg} \\
\mathrm{P}\end{array}$ & Não & $\begin{array}{l}5.381 \\
4.952 \\
4.978\end{array}$ & HPLC \\
\hline 6 & $\begin{array}{l}\text { Vinutha et al., } \\
2000\end{array}$ & Índia & EA, C & Única & $\begin{array}{l}\text { Pós-parto } \\
\text { (2 dias) }\end{array}$ & - & Solução aquosa (emulsão) & $200.000 \mathrm{UI}$ & Não & $\begin{array}{l}53 \\
56\end{array}$ & Espectrofotometria \\
\hline 7 & $\begin{array}{l}\text { Christian et al., } \\
2000\end{array}$ & Nepal & ECAC, DC, CP & Semanal & $\begin{array}{l}\text { Antes, durante e } \\
\text { após a gravidez }\end{array}$ & 42 & $\begin{array}{c}\mathrm{PR}+\mathrm{VE} \\
\mathrm{BC}+\mathrm{VE} \\
\mathrm{P} \text { (óleo de amendoim) }\end{array}$ & $\begin{array}{l}23 . \overline{3000 \mathrm{Ul}} \\
42 \mathrm{mg} \\
\mathrm{P}\end{array}$ & Não & $\begin{array}{l}4.493 \\
4.137 \\
4.142\end{array}$ & - \\
\hline 8 & $\begin{array}{l}\text { Bhaskaram et al., } \\
2000\end{array}$ & Índia & $E A, D C, C P$ & Única & $\begin{array}{l}\text { Pós-parto } \\
\text { (1 dia) }\end{array}$ & - & $\begin{array}{c}\text { PR } \\
\text { P (óleo de amendoim) }\end{array}$ & $\begin{array}{c}200.000 \mathrm{UI} \\
P\end{array}$ & Não & $\begin{array}{l}50 \\
52\end{array}$ & $\begin{array}{l}\text { Espectrofluorimetria } \\
\text { e Colorometria }\end{array}$ \\
\hline 9 & $\begin{array}{c}\text { Bhaskaram e } \\
\text { Balakrhisna, } 1998\end{array}$ & Índia & EA, DC, CP & Única & $\begin{array}{l}\text { Pós-parto } \\
\text { (1 dia) }\end{array}$ & - & $\ldots$ & $\begin{array}{c}200.000 \mathrm{UI} \\
\mathrm{P}\end{array}$ & Não & $\begin{array}{l}50 \\
50\end{array}$ & $\begin{array}{l}\text { Fluorometria e } \\
\text { Colorometria }\end{array}$ \\
\hline 10 & Rice et al., 1999 & Bangladesh & $\mathrm{ECpA}, \mathrm{DC}, \mathrm{CP}$ & $\begin{array}{l}\text { Única } \\
\text { Diária }\end{array}$ & $\begin{array}{l}\text { Pós-parto } \\
\text { (7-21 dia) }\end{array}$ & 9 & $\begin{array}{l}P R+V E \\
B C+V E \\
P \text { (óleo) }\end{array}$ & $\begin{array}{c}200.000 \mathrm{UI} \\
7,8 \mathrm{mg} \\
\mathrm{P}\end{array}$ & Não & $\begin{array}{l}74 \\
73 \\
73\end{array}$ & HPLC \\
\hline 11 & lliff et al., 1999 & Zimbábue & ECA, DC, CP & Única & $\begin{array}{l}\text { Pós-parto } \\
\text { (1 dia) }\end{array}$ & - & $\begin{array}{c}P R+V E \\
P \text { (óleo de soja) }\end{array}$ & $\begin{array}{l}400.000 \mathrm{UI} \\
\mathrm{P}\end{array}$ & $\begin{array}{c}50.000 \mathrm{UI} \\
\mathrm{P}\end{array}$ & $\begin{array}{l}398 \\
390\end{array}$ & - \\
\hline 12 & West et al., 1999 & Nepal & ECAC, DC, CP & Semanal & $\begin{array}{l}\text { Antes, durante e } \\
\text { após a gravidez }\end{array}$ & 42 & $\begin{array}{c}P R+V E \\
B C+V E \\
P \text { (óleo de amendoim) }\end{array}$ & $\begin{array}{l}23.300 \mathrm{UI} \\
42 \mathrm{mg} \\
\mathrm{P}\end{array}$ & Não & $\begin{array}{l}7.747 \\
7.201 \\
7.241\end{array}$ & - \\
\hline 13 & $\begin{array}{l}\text { WHO/CHD } \\
\text { ILVASSG, } 1998\end{array}$ & Índia/Gana/Peru & $\begin{array}{l}\text { EA multicêntrico, } \\
\text { DC, CP }\end{array}$ & Única & $\begin{array}{l}\text { Pós-parto } \\
\text { (18-42 dias) }\end{array}$ & - & $\begin{array}{c}P R+V E \\
P(\text { óleo de soja) }\end{array}$ & $\begin{array}{c}200.000 \mathrm{UI} \\
\mathrm{P}\end{array}$ & $\begin{array}{c}75.000 \mathrm{U} \\
(3 \times 25.000 \mathrm{UI}) \\
\mathrm{P}\end{array}$ & $\begin{array}{l}4716 \\
4708\end{array}$ & HPLC \\
\hline 14 & $\begin{array}{l}\text { Christian et al., } \\
1998\end{array}$ & Nepal & ECAC, DC, CP & Semanal & $\begin{array}{l}\text { Antes, durante e } \\
\text { após a gravidez }\end{array}$ & 42 & $\begin{array}{c}\mathrm{PR}+\mathrm{VE} \\
\mathrm{BC}+\mathrm{VE} \\
\mathrm{P} \text { (óleo de amendoim) }\end{array}$ & $\begin{array}{l}23.300 \mathrm{UI} \\
42 \mathrm{mg} \\
\mathrm{P}\end{array}$ & Não & $\begin{array}{l}3530 \\
3133 \\
3269\end{array}$ & - \\
\hline 15 & $\begin{array}{l}\text { Venkatarao et al., } \\
1996\end{array}$ & Índia & $\mathrm{ECpA}, \mathrm{DC}, \mathrm{CP}$ & Única & $\begin{array}{l}\text { Pós-parto } \\
\text { (7-14 dia) }\end{array}$ & - & $\mathrm{P}$ & $\begin{array}{l}300.000 \mathrm{UI} \\
300.000 \mathrm{Ul} \\
\mathrm{P}\end{array}$ & $\begin{array}{c}200.000 \mathrm{UI} \\
\mathrm{P} \\
\mathrm{P}\end{array}$ & $\begin{array}{l}311 \\
301 \\
297\end{array}$ & - \\
\hline 16 & $\begin{array}{l}\text { Stoltzfus et al., } \\
1993 a\end{array}$ & Indonésia & EA, DC, CP & Única & $\begin{array}{l}\text { Pós-parto } \\
\text { (7-21 dia) }\end{array}$ & - & $\begin{array}{l}\mathrm{PR}+\mathrm{VE} \\
\mathrm{P} \text { (óleo) }\end{array}$ & $\begin{array}{c}300.000 \mathrm{UI} \\
\mathrm{P}\end{array}$ & Não & $\begin{array}{l}77 \\
76 \\
\end{array}$ & HPLC \\
\hline
\end{tabular}

$\mathrm{EA}=$ ensaio aleatorizado, $\mathrm{ECAC}=$ ensaio comunitário aleatorizado por conglomerado, $\mathrm{ECpA}=$ ensaio de campo aleatorizado, $\mathrm{ECA}=$ ensaio clinico aleatorizado, $\mathrm{DC}=$ duplo-cego, $\mathrm{CP}=\mathrm{controlado}$ com placebo, $\mathrm{C}=$ controlado, $\mathrm{PR}=$ palmitato de retinila, $\mathrm{VE}=$ vitamina $\mathrm{E}$ (alfa-tocoferol), $\mathrm{BC}=$ beta-caroteno, $\mathrm{P}=$ placebo, $=$ não se aplica, ...=sem informação. 



\subsection{Efeito da suplementação de vitamina $A$ na morbidade infantil}

Duas investigações avaliaram o efeito da suplementação de vitamina A na ocorrência e duração de episódios de doenças na infância. Não foi possível realizar a análise agregada desses dados, pois os estudos utilizaram definições diferentes para cada doença.

No estudo de VENKATARAO et al. (1996), foram utilizadas as seguintes definições:

- Diarréia: três ou mais evacuações inconsistentes num espaço de tempo de 24h;

- Infecção respiratória aguda (IRA): episódios de infecções agudas do trato respiratório superior ou inferior. Identificadas pela presença de tosse, ou secreção nasal, ou secreção de ouvido por no máximo 14 dias. Como episódio de infecção do trato respiratório inferior, foi considerada a presença de dificuldade para respirar por no máximo 30 dias, para crianças com até 2 meses de idade, e dificuldade para respirar juntamente com tosse por no máximo 30 dias, para crianças 2 meses ou mais.

- Episódio grave de doenças: Todos episódios de infecção do trato respiratório inferior, episódios de infecção do trato respiratório superior ou diarréia que necessitaram de hospitalização, ou episódios de diarréia associados a vômito ou inapetência foram considerados graves.

Para ambos, diarréia e IRA, episódios de doenças, separados por um período de pelo menos dois dias sem presença de queixas, foram considerados episódios distintos. 
Não foi observada diferença no número médio de episódios de diarréia durante o primeiro ano de vida entre os grupos com suplementação materna $(4,6)$, com suplementação materna e infantil $(4,4)$ e para o grupo placebo (4,2 episódios; $\left.p>0,2^{1}\right)$. Para os episódios graves de diarréia, encontrou-se médias de 1,3; 1,1 e 1,2 episódios, durante o primeiro ano de vida, respectivamente, também sem diferença estatística significante $\left(p>0,2^{1}\right)$. Não foram identificadas diferenças segundo o número mediano de dias com diarréia durante $o$ ano $\left(p>0,2^{1}\right): 26,26$ e 22 dias, para os grupos suplementação materna, suplementação materna e infantil e placebo, respectivamente. Para os episódios graves de diarréia, encontrou-se medianas de 7,5 e 5 dias, respectivamente, também sem diferença estatisticamente significante $\left(p>0,2^{1}\right)$.

Em relação ao número médio de episódios de IRA até o primeiro ano de vida, as médias também foram semelhantes entre os grupos: 5,1 para o grupo suplementação materna, 4,8 para grupo suplementação materna e infantil e 4,8 episódios para o grupo placebo $\left(p>0,2^{1}\right)$. O número de dias no ano com episódios de IRA também foi similar entre os grupos, variando de 32 a 34 dias $\left(p>0,2^{1}\right)$. Para episódios graves de $A R I$, os autores também não relatam diferenças entre os grupos, com média de 0,1 episódios durante o primeiro ano nos três grupos.

\footnotetext{
${ }^{1}$ Valor de $p$ está apresentado como consta no artigo (VENKATARAO et al., 1996).
} 
No estudo WHO/CHD ILVASSG (1998), foram utilizadas as seguintes definições:

- Diarréia: três ou mais evacuações inconsistentes ou aquosas, dentro de $24 \mathrm{~h}$, reportadas pela mãe;

- Disenteria: diarréia com presença visível de sangue;

- Diarréia persistente: episódio de diarréia com duração de 14 dias ou mais;

- Infecção aguda do trato respiratório inferior: presença de tosse e respiração acelerada, duas medidas de taxa respiratória iguais a 60 respirações/minuto ou mais, para crianças com até dois meses de idade, duas medidas de taxa respiratória iguais a 50 respirações/minuto ou mais, para crianças com idade superior a dois meses.

- Pneumonia clínica: presença de tosse ou crepitações ao auscultar.

Nesse estudo, não foram observadas diferenças estatisticamente significantes entre os grupos intervenção e controle em relação aos episódios de infecção aguda do trato respiratório inferior, pneumonia ou entre qualquer categoria de diarréia. Foram observados riscos relativos de 1,05 (IC95\%: 0,95 a 1,16) para infecção aguda do trato respiratório inferior e pneumonia, de 0,98 (IC95\%: 0,91 a 1,05) para diarréia, de 0,77 (IC95\%: 0,56 a 1,06) para diarréia persistente e de 1,18 (IC95\%: 0,95 a 1,47) para disenteria.

\subsection{Efeito da suplementação de vitamina A na mortalidade infantil}

Três estudos avaliaram o efeito da suplementação de vitamina A na ocorrência de mortalidade infantil. Não foi possível realizar a análise 
agregada referente à mortalidade, pois em um deles foi analisada somente a mortalidade nas primeiras 24 semanas, e em outro não estavam explicitas as causas de morte consideradas.

No estudo WHO/CHD ILVASSG (1998), de um total de 9.424 crianças, 233 haviam falecido até o primeiro ano de idade. Para 178 crianças as informações sobre a causa do óbito estavam disponíveis: $54 \%$ (96) foram atribuídas às doenças respiratórias e diarréicas (causa básica) e para $44 \%$ (78) as mortes tiveram a desnutrição como causa básica ou associada. Não foi descrita diferença estatística significante na ocorrência de mortalidade no $6^{\circ}, 9^{\circ}$ e $12^{\circ}$ mês pós-parto entre os grupos intervenção e controle. A razão de taxas de mortalidade entre os grupos intervenção e controle foi de 0,96 (IC95\%: 0,73 a 1,27) para todas as causas de morte até os nove meses.

$\mathrm{Na}$ investigação conduzida por KATZ et al. (2000), não foi encontrado efeito da suplementação nas taxas de mortalidade entre 28 dias e 24 semanas de vida e na acumulada de 24 semanas. As taxas de mortalidade entre 28 dias e 24 semanas foram de 24,5; 23,5; 22,1 e 22,8 /1000 nascidos vivos, respectivamente, para os grupos placebo, vitamina A, beta-caroteno e vitamina A ou beta-caroteno. Os riscos relativos foram de 0,96 (IC95\%: 0,73 a 1,27); 0,90 (IC95\%: 0,67 a 1,23) e 0,93 (IC95\%: 0,72 a 1,20) para a suplementação de vitamina $A$, de beta-caroteno e de vitamina $A$ ou betacaroteno, respectivamente.

No estudo desenvolvido por MALABA et al. (2005), observou-se que, de um total de 9.208 crianças, 170 morreram no primeiro ano de vida, sendo que 168 mortes ocorreram até o $6^{\circ}$ mês. A taxa de mortalidade infantil aos 
12 meses foi de 20,1/1000 nascidos vivos. Foram excluídas das análises nove mortes decorrentes de problemas congênitos. Não houve associação entre a suplementação materna ou infantil e a mortalidade infantil aos seis ou 12 meses ( $p=0,89$ ou $p=0,60$, respectivamente). Aos seis meses, não se observou efeito da suplementação materna, com hazard ratio de 1,10 (IC95\%: 0,79 a 1,53), ou da suplementação infantil, com harzad ratio de 1,11 (IC95\%: 0,80 a 1,55). As doenças associadas à mortalidade foram infecção respiratória aguda, diarréia aguda, sepsis e desnutrição, porém não houve diferença entre os grupos.

\subsection{Efeito da suplementação de vitamina A na morbi-mortalidade materna}

Somente um estudo, que foi conduzido no Nepal e denominado NNIPS-2, investigou os efeitos da suplementação de vitamina $A$ ou beta-caroteno na morbi-mortalidade materna.

No artigo de CHRISTIAN et al. (2000), foi descrita menor cifra de episódios de febre entre mulheres suplementadas com beta-caroteno, em comparação com os demais grupos, aos três meses pós-parto $(\mathrm{OR}=0,88$; $p<0,025^{2}$ ). No grupo vitamina $A$, foi descrita prevalência reduzida de episódios de fraqueza (debilidade) em relação aos demais grupos $(\mathrm{OR}=0,88$; $p<0,025^{2}$ ).

Os autores também relatam menores prevalências de evacuações aquosas $(\mathrm{OR}=0,80$ e $\mathrm{OR}=0,87)$, no período de três a seis meses pós-parto, 
entre mulheres que receberam vitamina $A$ ou beta-caroteno $\left(p<0,025^{2}\right.$; $\left.p<0,05^{3}\right)$, respectivamente. A suplementação de vitamina A estava associada a aumento da secreção vaginal em mulheres $\left(O R=1,33 ; p<0,05^{3}\right)$.

Em relação à mortalidade, WEST et al. (1999) relatam taxas de 110, 52, 26 e 40 mortes/100.000 gestações, entre sete e doze semanas pósparto, para os grupos placebo, vitamina A, beta-caroteno e vitamina A ou beta-caroteno, respectivamente. Não foi verificado efeito estatisticamente significante da suplementação em relação ao risco de morte, pois os riscos relativos observados foram de 0,47 (IC95\%: 0,13 a 1,76), 0,25 (IC95\%: 0,04 a 1,42) e 0,36 (IC95\%: 0,11 a 1,14) para os grupos vitamina $A$, beta caroteno e vitamina A ou beta-caroteno.

\subsection{Efeito da suplementação de vitamina $A$ na ocorrência de efeitos adversos}

Dois estudos avaliaram os efeitos adversos da suplementação de vitamina A entre mães e bebês. Em estudo, conduzido por VENKATARAO et al. (1996), não foram observados casos de hipervitaminose e nenhum outro efeito adverso foi reportado até o terceiro dia após a administração do suplemento.

No estudo conduzido por ILIFF et al. (1999), observou-se que 1,8\% dos bebês do grupo suplementado com vitamina A e 1,3\% do grupo placebo apresentaram abaulamento da fontanela (OR=1,38; IC95\%: 0,37 a 5,56). As mães reportaram a ocorrência de vômito, irritabilidade e febre em 6,0\%;

\footnotetext{
${ }^{2}$ Valor de p está apresentado como consta no artigo (CHRISTIAN et al., 2000).

${ }^{3}$ Valor de p está apresentado como consta no artigo (CHRISTIAN et al., 2000).
} 
$7,5 \%$ e $0,8 \%$ dos crianças, respectivamente, para o grupo suplementado com vitamina A. Para o grupo controle, foram observadas cifras semelhantes: 4,6\% para vômito, 5,4\% para irritabilidade e 1,3\% para febre $\left(p>0,2^{4}\right)$.

Em relação a efeitos adversos maternos, uma mulher do grupo vitamina A referiu dor de cabeça forte. Entre as mulheres que receberam vitamina A, 3\% apresentaram dor de cabeça moderada, sendo que essa cifra foi de $2,3 \%$ no grupo placebo (OR=1,33; IC95\%: 0,52 a 3,47). As taxas de náusea, vômito, visão borrada, sonolência, dor abdominal, falta de apetite não foram diferentes entre os grupos $\left(p>0,1^{5}\right)$.

\subsection{Efeito da suplementação de vitamina $A$ na concentração de retinol do leite humano}

Dois estudos, conduzidos por RICE et al. (1999) e por BAHL et al. (2002), avaliaram a concentração de retinol no leite humano, apresentando os dados em $\mu \mathrm{mol} / \mathrm{g}$ de lipídio.

A combinação dos dados apresentados pelos dois estudos para níveis abaixo de 0,28 $\mu \mathrm{mol} / \mathrm{g}$ de lipídio resultou em OR sumário de 0,73 (IC95\%: 0,54 a 0,99 ) aos seis meses, e de 0,82 (IC95\%: 0,59 a 1,14) aos nove meses pós-parto. Os Gráficos 1 e 2 ilustram esses resultados. Não foi constatada heterogeneidade entre os estudos, com qui-quadrado igual a $0,27(p=0,606)$, para a análise referente ao sexto mês, e qui-quadrado igual a 2,26 $(p=0,133)$, para análise referente ao nono mês após o parto.

\footnotetext{
${ }^{4}$ Valor de p está apresentado como consta no artigo (ILIFF et al., 1999).

${ }^{5}$ Valor de p está apresentado como consta no artigo (ILIFF et al., 1999).
} 


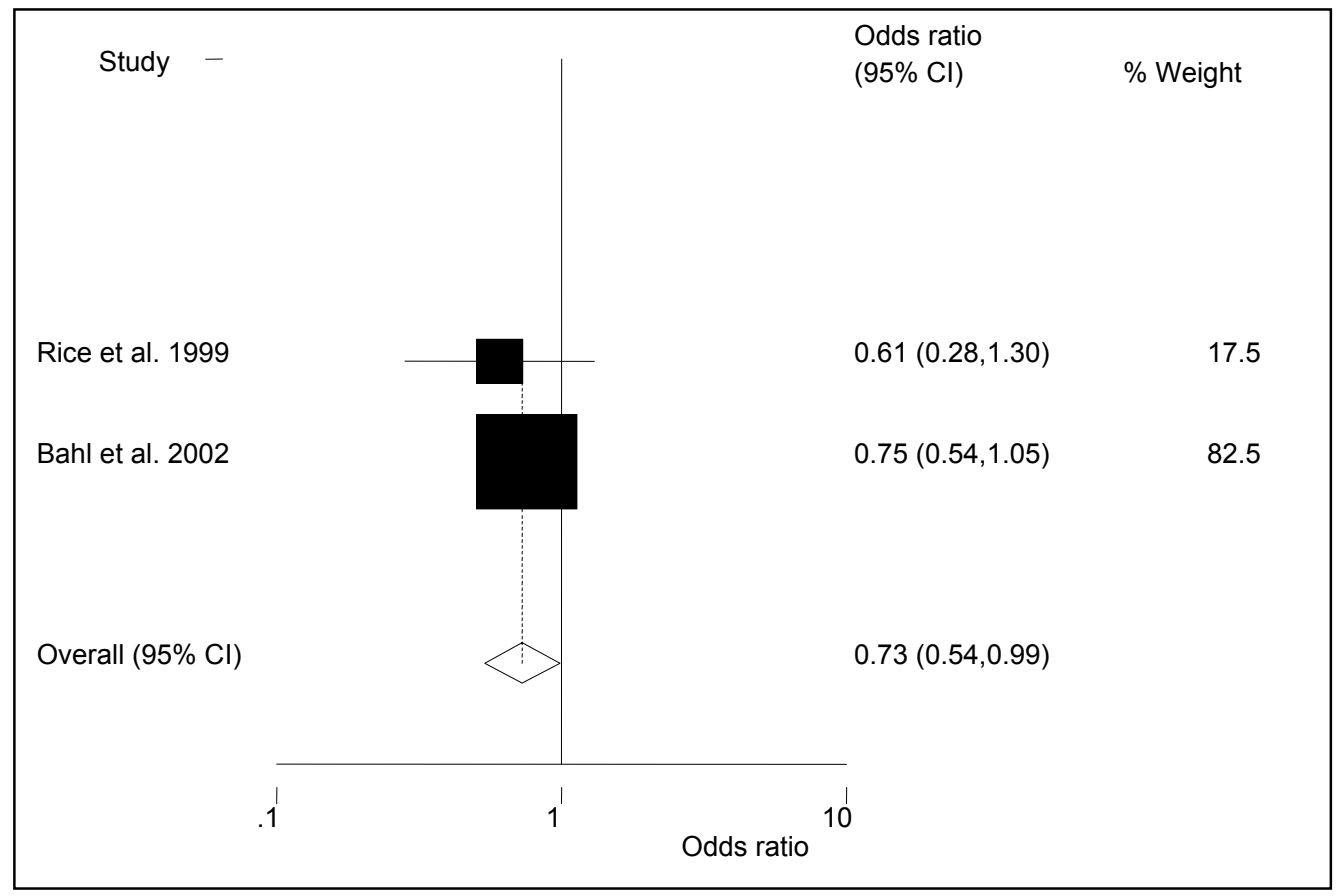

Gráfico 1: Distribuição de estudos de acordo com o odds ratio (OR) da concentração de retinol no leite humano menor ou igual a $0,28 \mu \mathrm{mol} / \mathrm{g}$ de lipídio aos seis meses pós-parto.

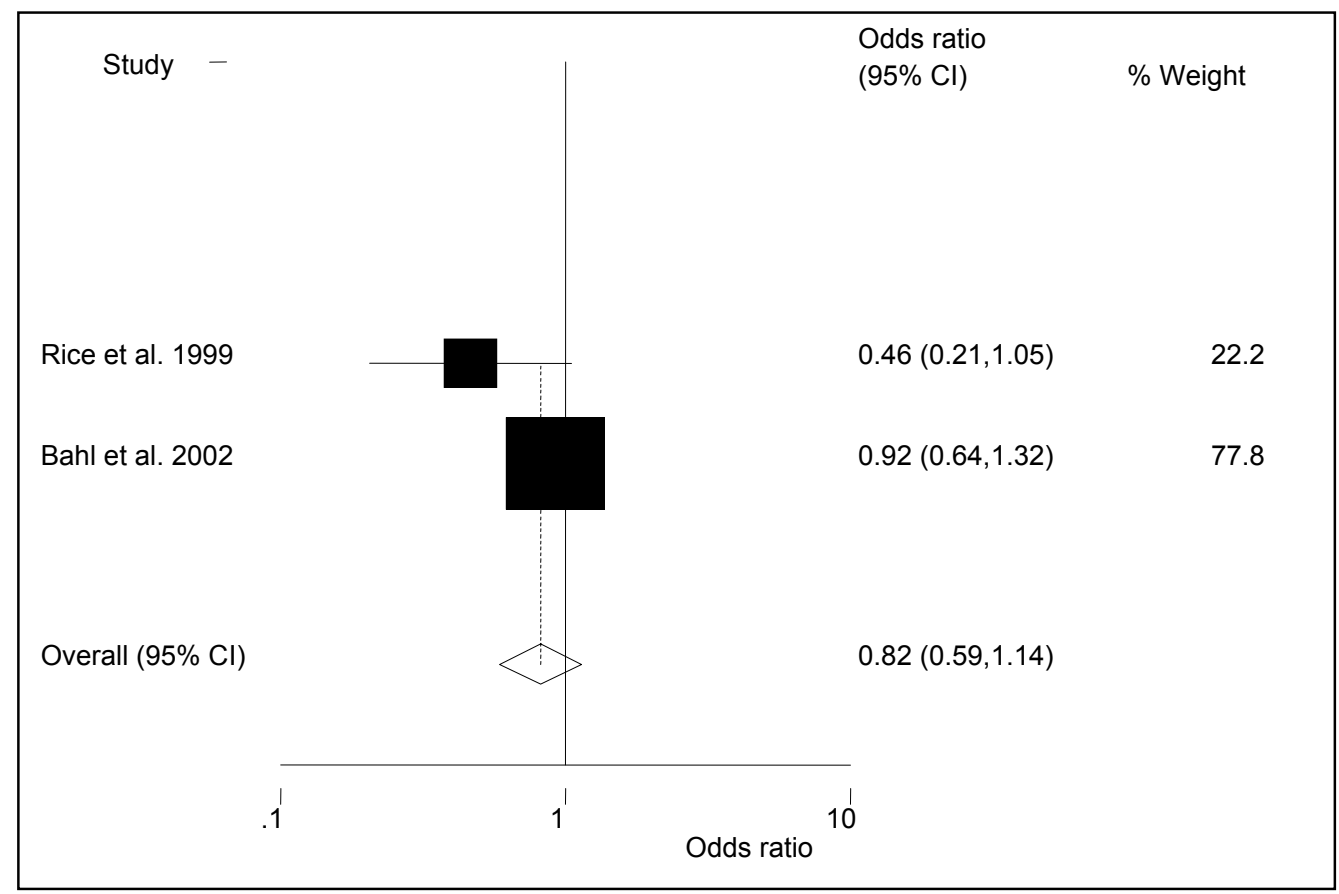

Gráfico 2: Distribuição de estudos de acordo com o odds ratio (OR) da concentração de retinol no leite humano menor ou igual a $0,28 \mu \mathrm{mol} / \mathrm{g}$ de lipídio aos nove meses pós-parto. 
Três estudos, conduzidos por VINUTHA et al. (2000), RICE et al. (1999) e por STOLTZFUS et al. (1993a), avaliaram o efeito da suplementação na concentração de retinol no leite humano, apresentando os dados em $\mu \mathrm{mol} / \mathrm{L}$ ou $\mu \mathrm{g} / \mathrm{dL}$.

A combinação dos três estudos para níveis iguais ou abaixo de

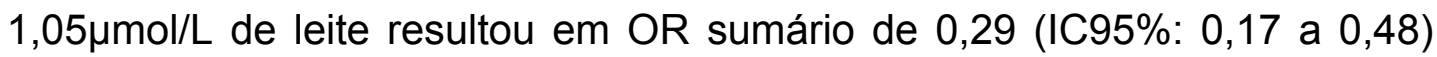
aos três meses pós-parto. Dois estudos apresentaram informações referentes ao sexto mês pós-parto, com OR sumário de 0,62 (IC95\%: 0,34 a 1,11). Os gráficos 3 e 4 ilustram esses resultados.

Não houve evidência de heterogeneidade entre os estudos, com quiquadrado igual a $0,37(p=0,830)$, para a análise referente ao terceiro mês, e qui-quadrado igual a $3,03(p=0,082)$, para análise referente ao sexto mês após o parto.

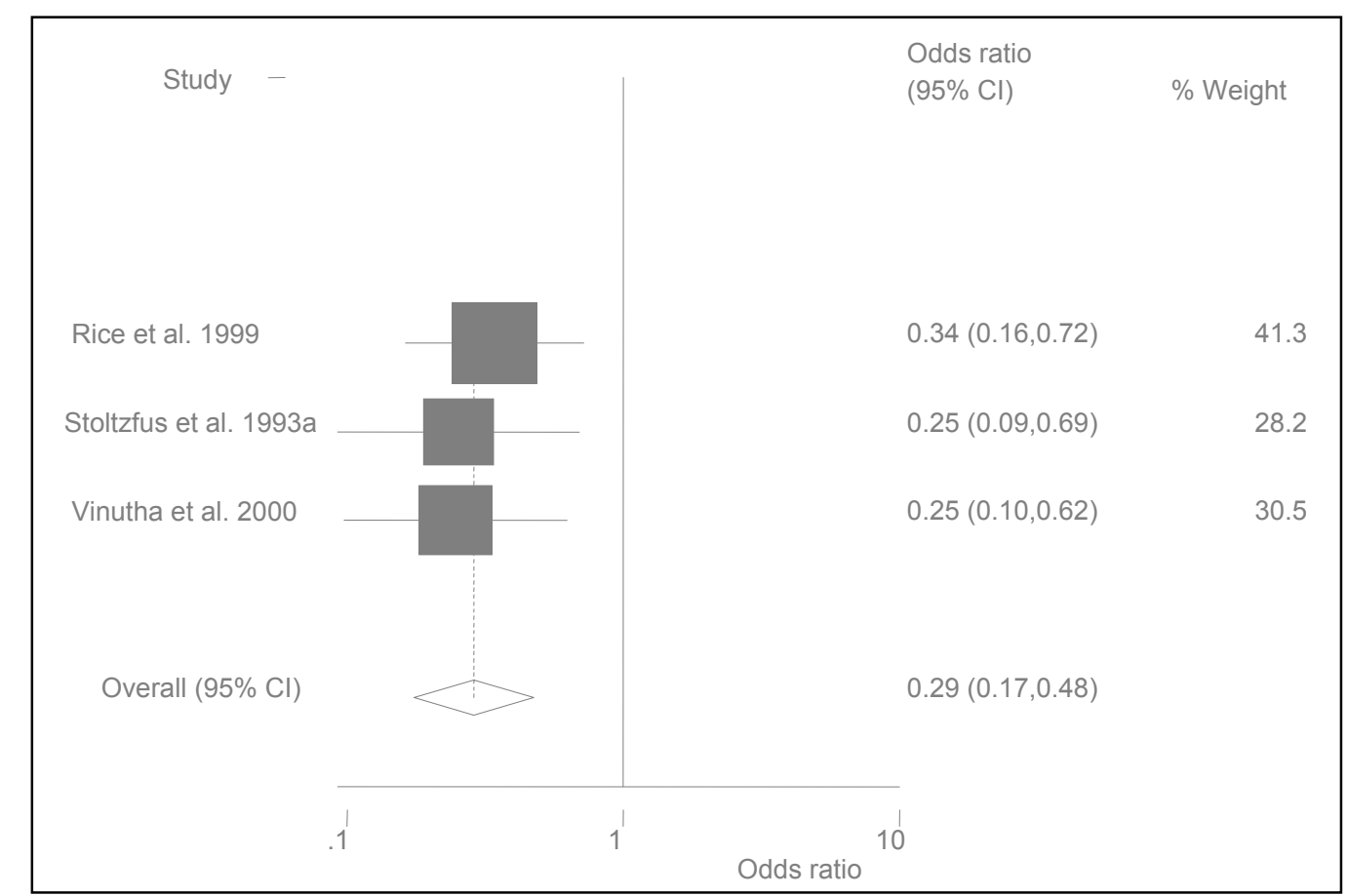

Gráfico 3: Distribuição de estudos de acordo com o odds ratio (OR) da concentração de retinol no leite humano menor ou igual a $1,05 \mu \mathrm{mol} / \mathrm{L}$ aos três meses pós-parto. 


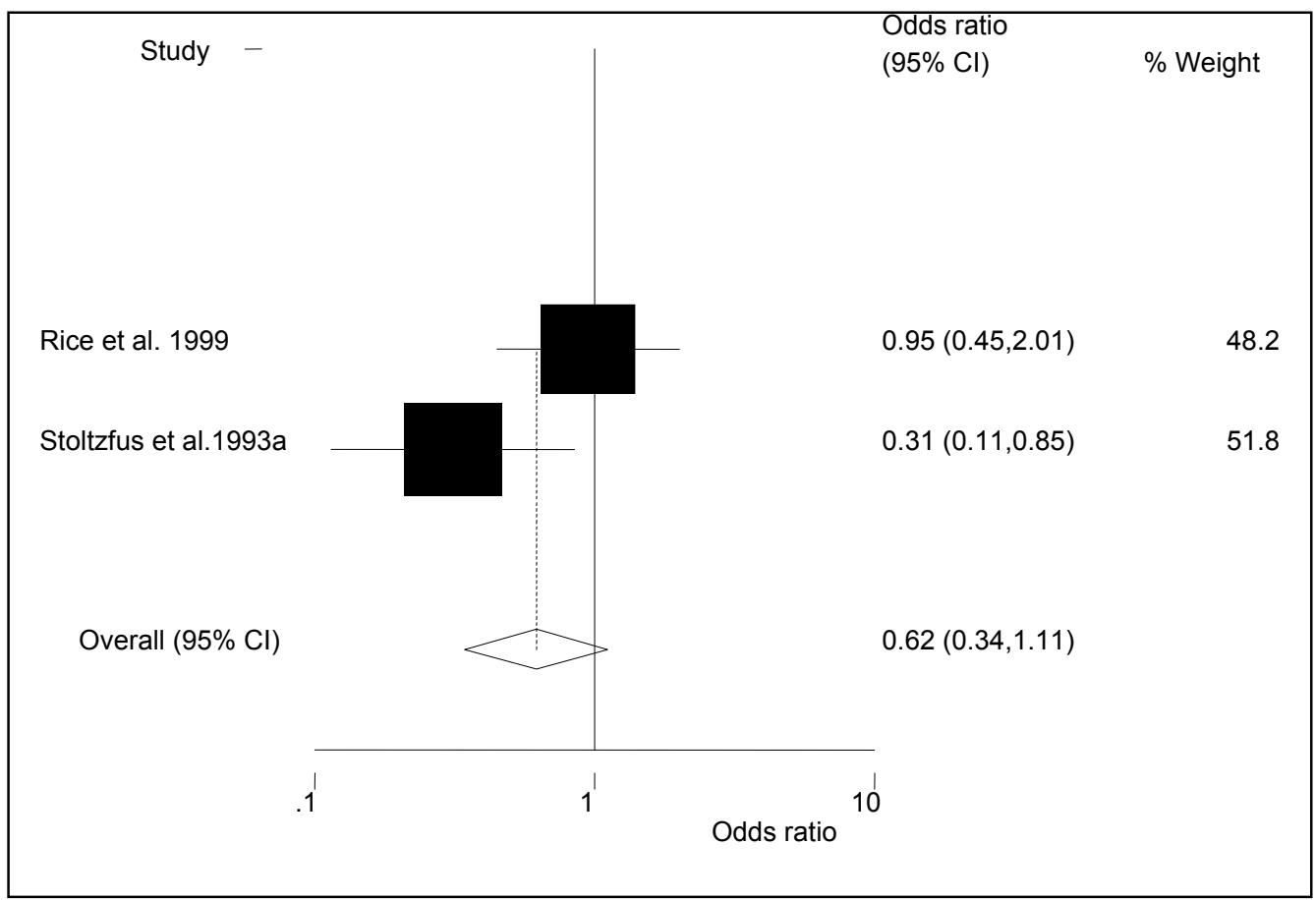

Gráfico 4: Distribuição de estudos de acordo com o odds ratio (OR) da concentração de retinol no leite humano menor ou igual a $1,05 \mu \mathrm{mol} / \mathrm{L}$ ao seis meses pós-parto.

Não incluindo na análise agregada o estudo de STOLTZFUS et al. (1993a), que utilizou dose de 300.000Ul de vitamina A e não 200.000Ul como os demais trabalhos, obtém-se OR sumário de 0,30 (IC95\%: 0,17 a 0,54), como pode ser observado no Gráfico 5. Não houve evidência de heterogeneidade entre os estudos (qui-quadrado=0,29; $p=0,592$ ). 


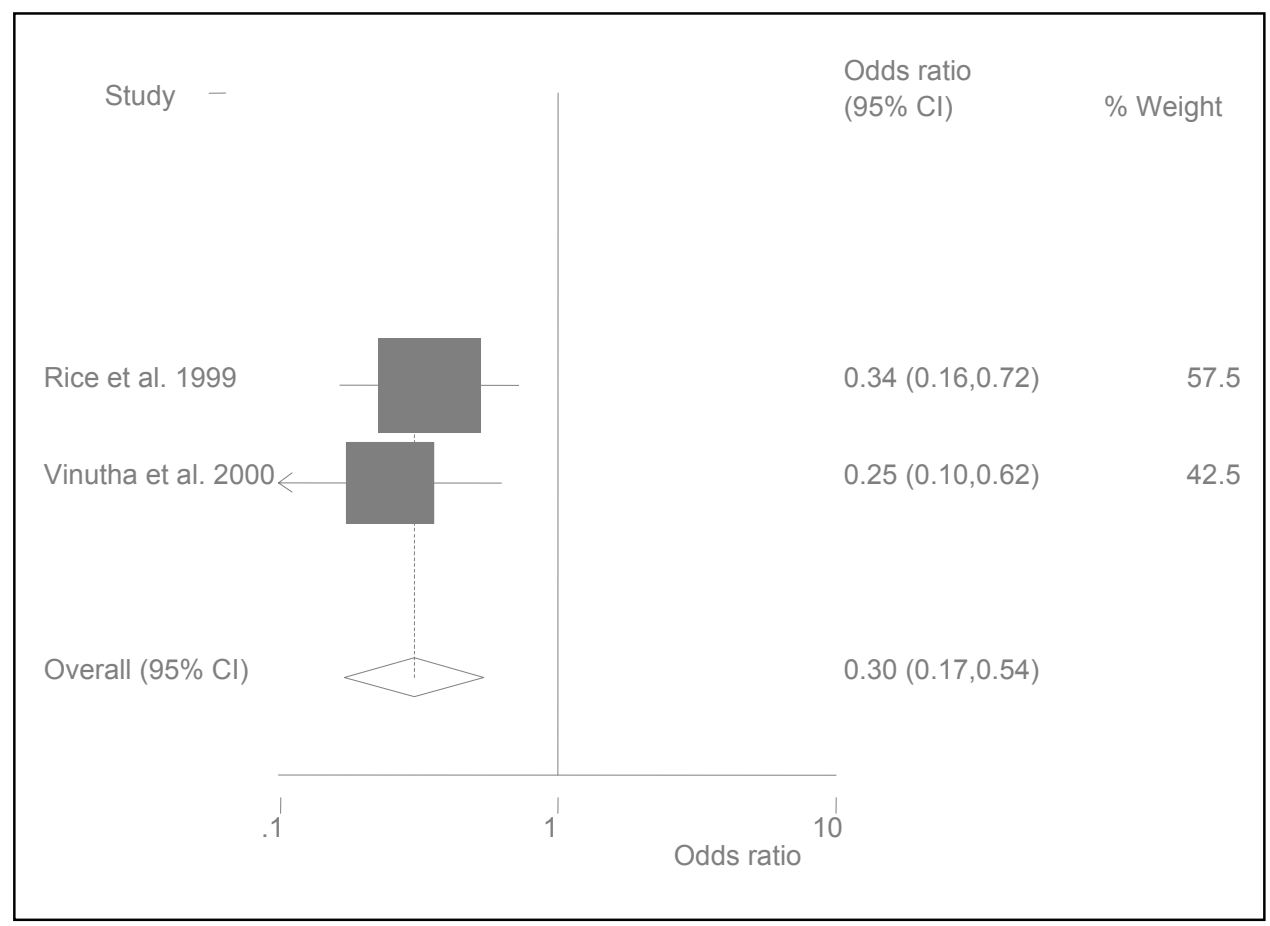

Gráfico 5: Distribuição de estudos de acordo com o odds ratio (OR) da concentração de retinol no leite humano menor ou igual a $1,05 \mu \mathrm{mol} / \mathrm{L}$ aos três meses pós-parto, retirando-se o estudo conduzido por STOLTZFUS et al. (1993a).

A combinação dos dados apresentados pelos três artigos (STOLTZFUS et al., 1993a; RICE et al., 1999; VINUTHA et al., 2000)

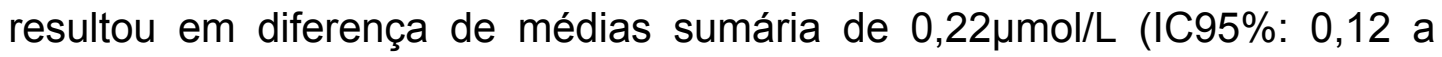
0,32) aos três meses pós-parto, como ilustra o Gráfico 6. Não houve evidência de heterogeneidade entre os estudos, com qui-quadrado igual a $5,24(p=0,073)$.

Retirando-se da metanálise o estudo de STOLTZFUS et al. (1993a), que utilizou dose de 300.000 Ul de vitamina A e não 200.000Ul como os demais trabalhos, obtém-se diferença de médias sumária de $0,20 \mu \mathrm{mol} / \mathrm{L}$ (IC95\%: 0,10 a 0,30), como pode ser observado no Gráfico 7. Nesta configuração, a ausência de heterogeneidade entre os estudos se mantém (qui-quadrado=1,98; $p=0,159$ ). 


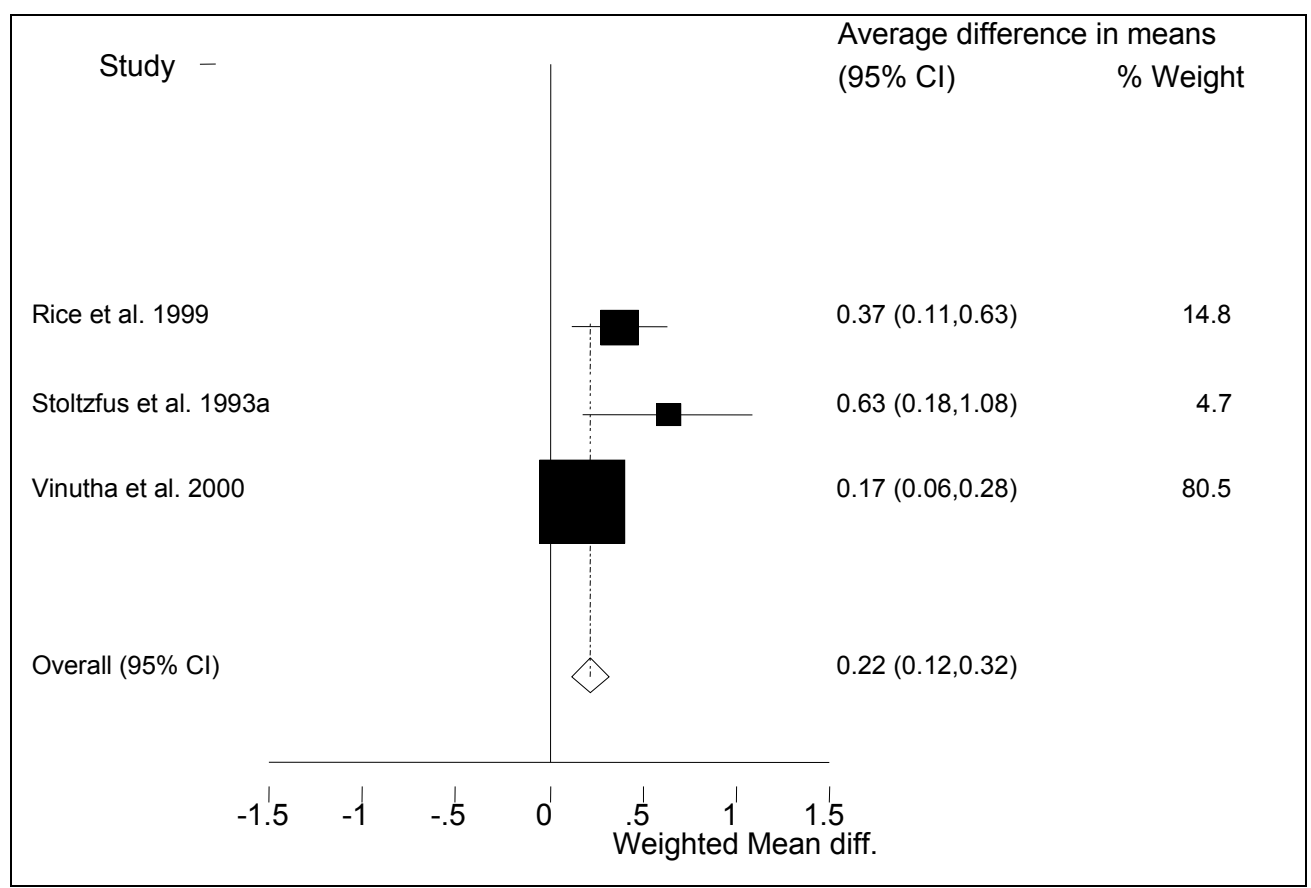

Gráfico 6: Distribuição de estudos de acordo com a diferença de médias da concentração de retinol no leite humano aos três meses pós-parto.

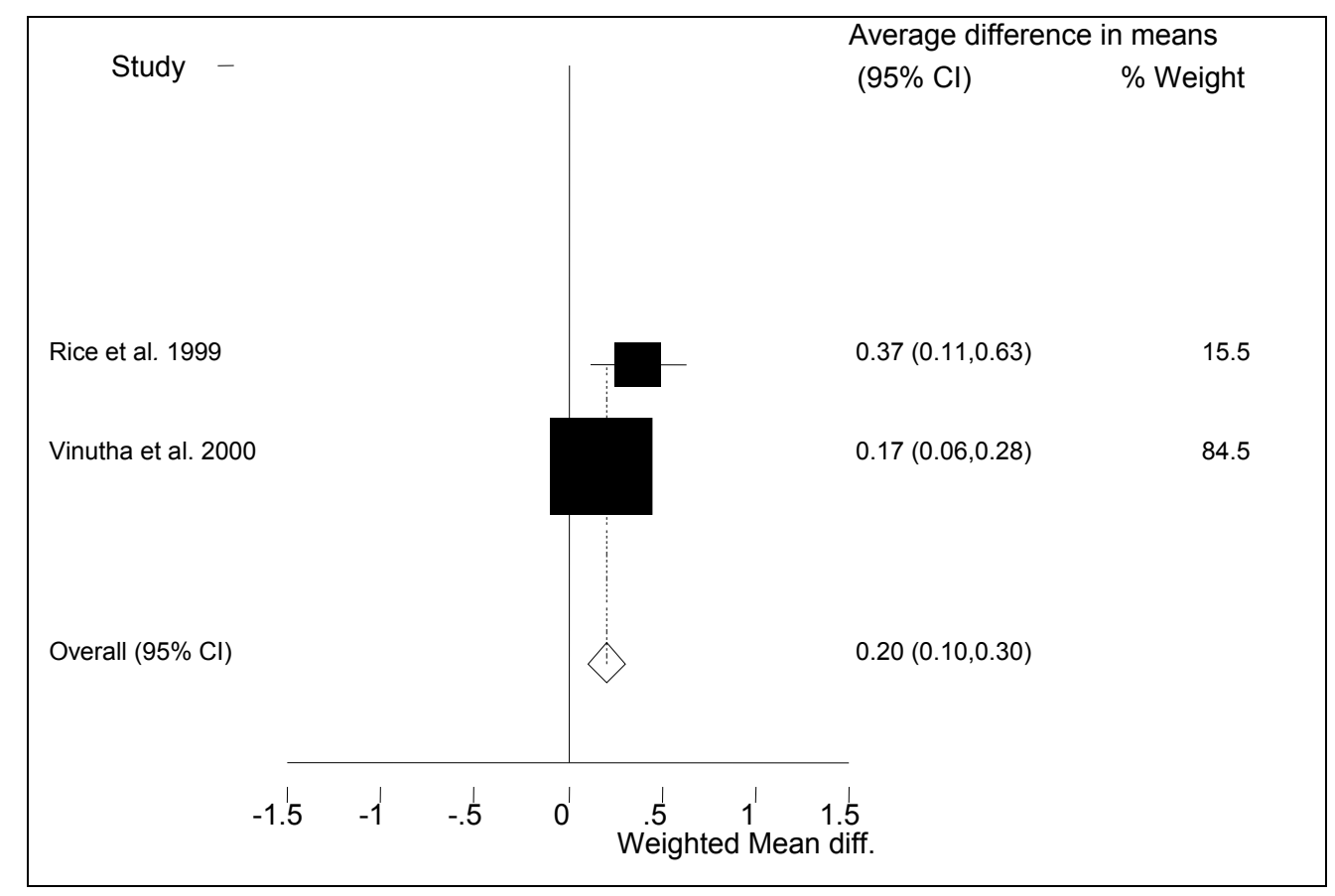

Gráfico 7: Distribuição de estudos de acordo com a diferença de médias da concentração de retinol no leite humano aos três meses pós-parto, retirando-se o estudo STOLTZFUS et al. (1993a). 
Dois estudos apresentaram informações referentes ao sexto mês pósparto e a análise agregada desses dados resultou em diferença de médias

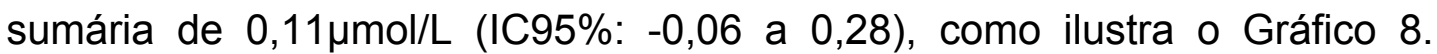
Porém, constatou-se heterogeneidade entre os estudos (qui-quadrado $=8,54$; $p=0,003)$.

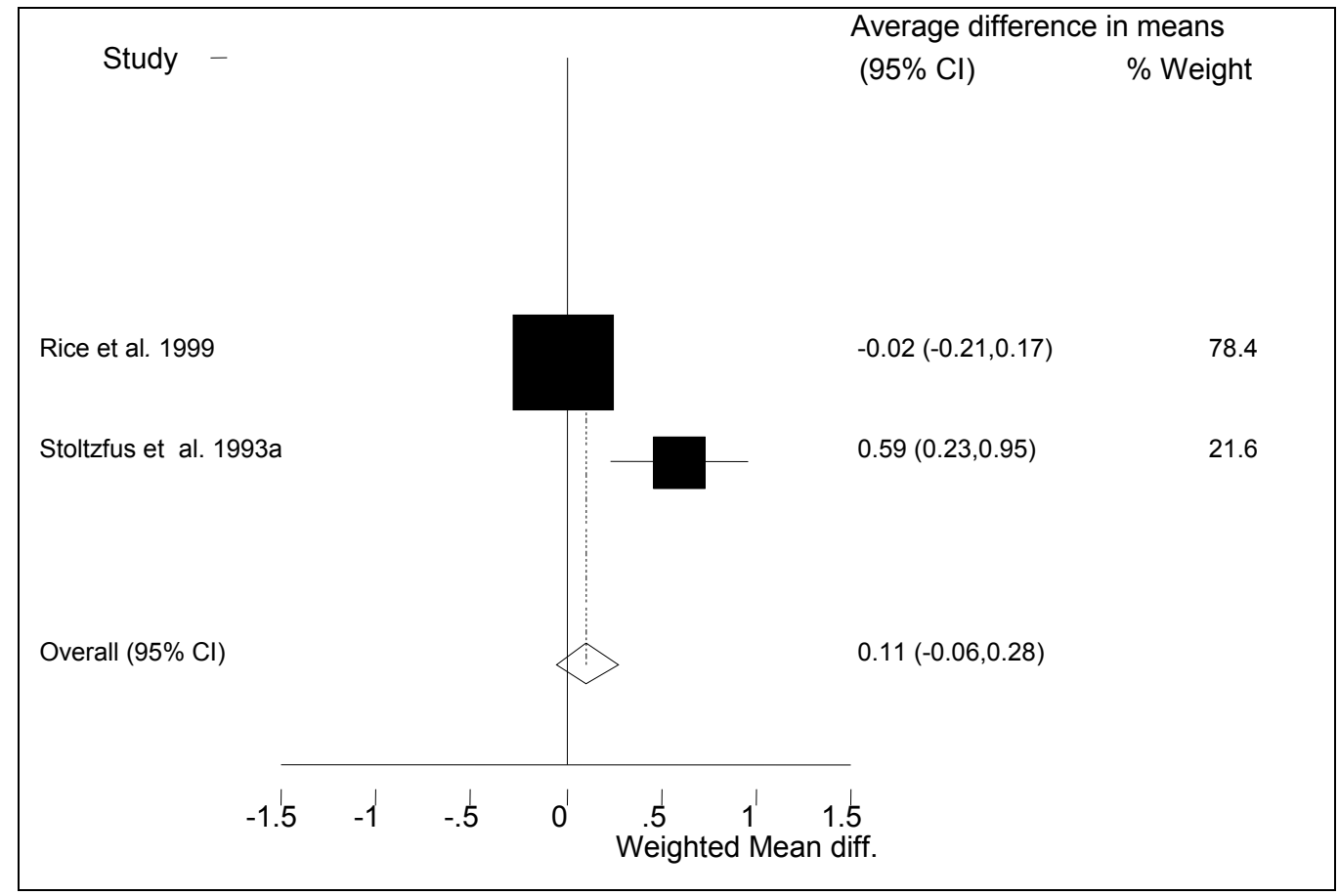

Gráfico 8: Distribuição de estudos de acordo com a diferença de médias da concentração de retinol no leite humano aos seis meses pós-parto.

\subsection{Efeito da suplementação de vitamina A no estado nutricional de vitamina A materno \\ Concentração sérica de retinol}

Em quatro artigos, publicados por RICE et al. (1999), STOLTZFUS et al. (1993a), CONGDON et al. (2000) e YAMINI et al. (2001), foram descritos os efeitos da suplementação de vitamina A pré-formada (palmitato de retinila) nas concentrações médias de retinol sérico maternas. 
A combinação dos dados apresentados pelos quatro artigos resultou

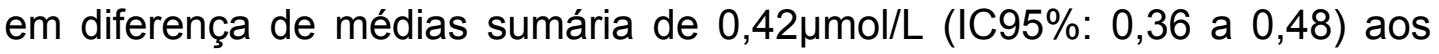
três meses pós-parto, como ilustra o Gráfico 9. Porém, foi observada heterogeneidade entre os estudos, com qui-quadrado igual a 27,21 $(p<0,001)$.

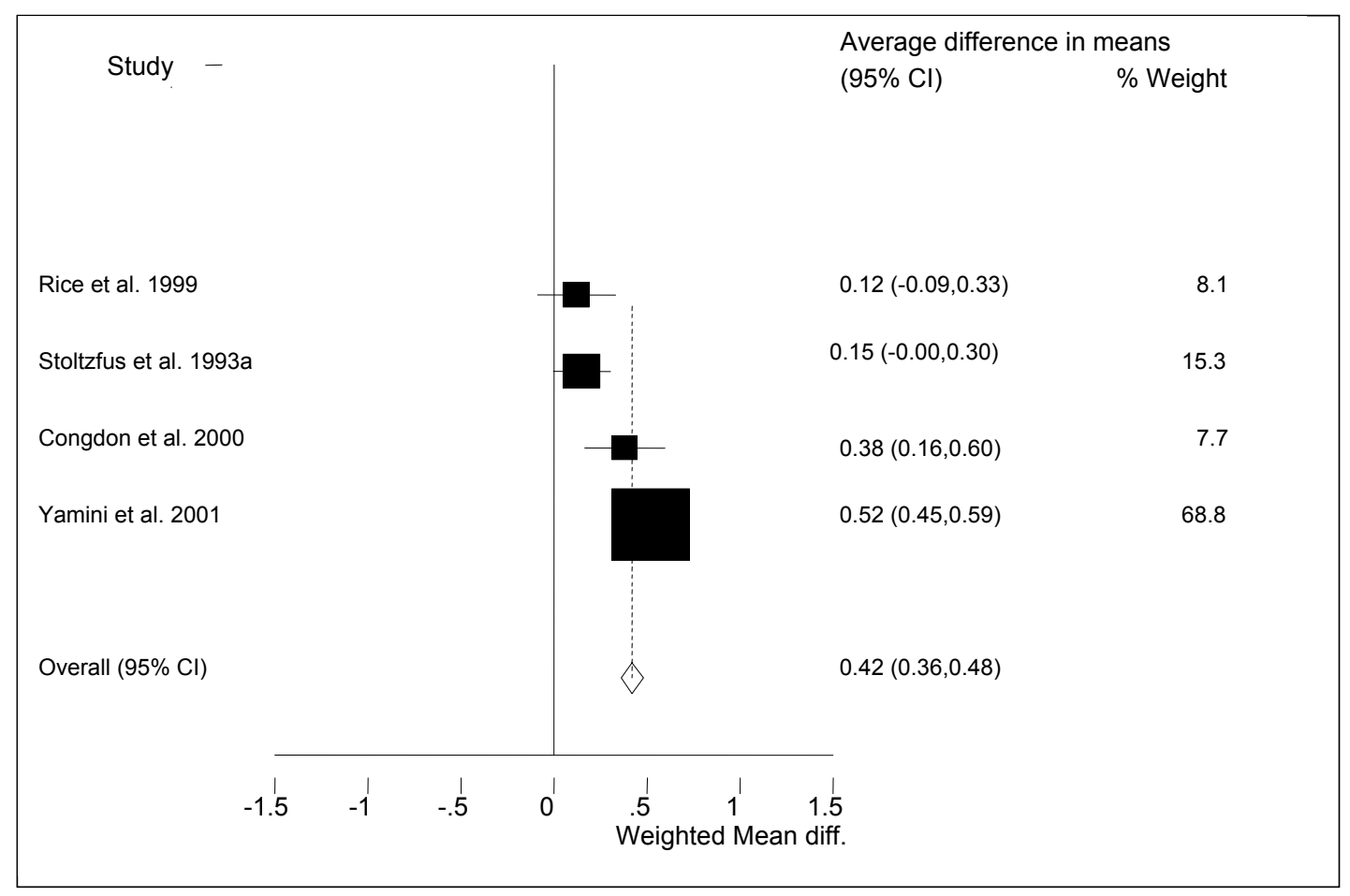

Gráfico 9: Distribuição de estudos de acordo com a diferença de médias da concentração de retinol sérico materno aos três meses pós-parto.

Não incluindo na metanálise os artigos que utilizaram dose semanal, a diferença de média sumária se reduz para 0,14 $\mathrm{mol} / \mathrm{L}$ (IC95\%: 0,02 a 0,26), como pode ser observado no Gráfico 10. Nesta configuração, não existe evidência de estatística de heterogeneidade entre os estudos (quiquadrado=0,05; $p=0,821)$. 


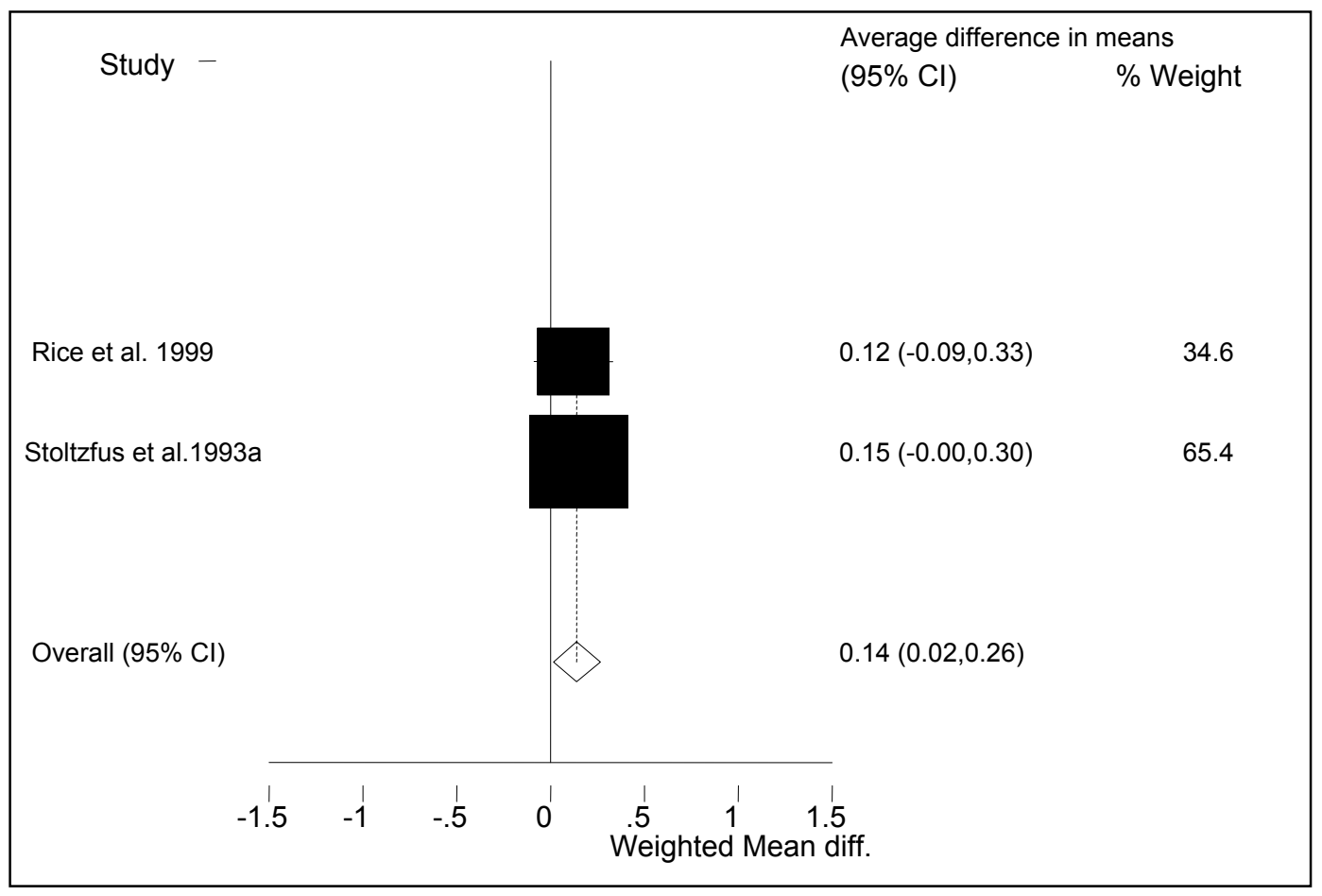

Gráfico 10: Distribuição de estudos de acordo com a diferença de médias da concentração de retinol sérico materno aos três meses pós-parto, retirando-se os artigos que utilizaram doses semanais (CONGDON et al., 2000; YAMINI et al., 2001).

A análise agregada dos dados referentes ao sexto mês pós-parto, apresentada no Gráfico 11, resultou em diferença de médias sumária de 0,11 $\mu \mathrm{mol} / \mathrm{L}$ (IC95\%: 0,00 a 0,21). Não houve evidência de heterogeneidade entre os estudos (qui-quadrado=2,43; $p=0,119$ ). 


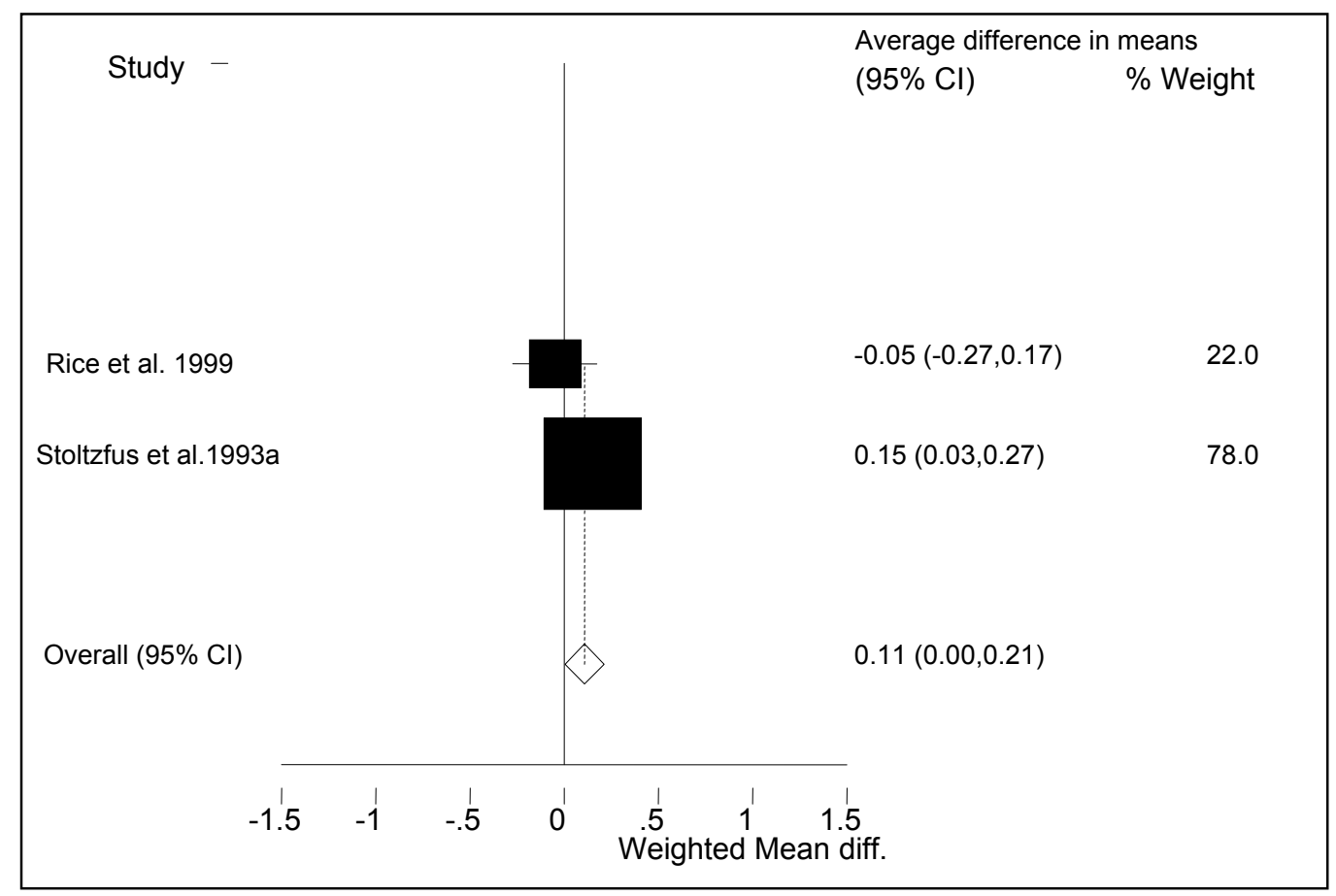

Gráfico 11: Distribuição de estudos de acordo com a diferença de médias da concentração de retinol sérico materno aos seis meses pós-parto.

Em três artigos, publicados por RICE et al. (1999), CONGDON et al. (2000) e YAMINI et al. (2001), foi descrito o efeito da suplementação de próvitamina A (beta-caroteno) nas concentrações médias de retinol sérico maternas.

A combinação dos dados apresentados pelos três artigos resultou em

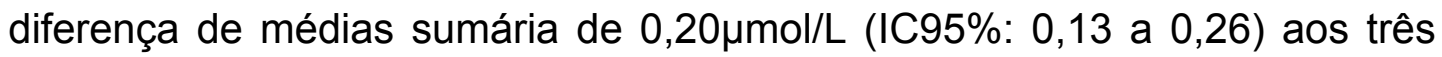
meses pós-parto, como ilustra o Gráfico 12. Não houve evidência de heterogeneidade entre os estudos (qui-quadrado=1,71; $p=0,425$ ). 


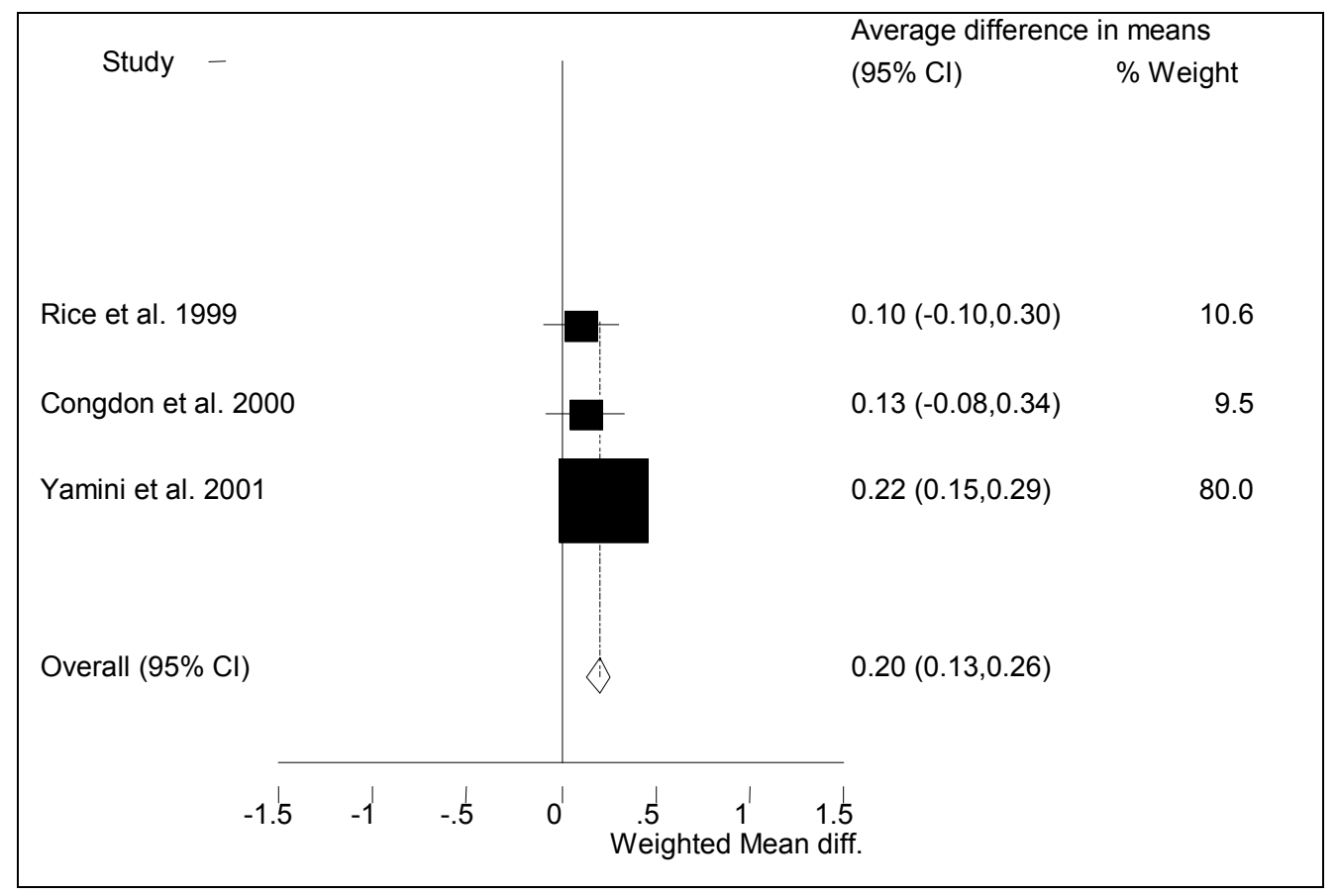

Gráfico 12: Distribuição de estudos de acordo com a diferença de médias da concentração de retinol sérico materno aos três meses pós-parto.

\section{Demais parâmetros de avaliação do estado nutricional de vitamina $A$ materno}

No estudo conduzido por CHRISTIAN et al. (1998) observou-se taxas de incidência de cegueira noturna, durante os três primeiros meses pósparto, de 4,3; 8,7 e 11,3/100 pessoas-ano para os grupos vitamina A, betacaroteno e placebo, respectivamente, com RR de 0,38 (IC95\%: 0,26 a 0,55) e 0,77 (IC95\%: 0,57 a 1,04), considerando-se como referência o grupo placebo. Os autores descrevem maior risco de cegueira noturna nos primeiros 30 dias pós-parto. Para o período entre o $3^{\circ}$ e $6^{\circ}$ mês pós-parto, foram observadas taxas de 3,6 para o grupo vitamina $A, 3,2$ para o grupo beta-caroteno e 7,1/100 pessoas-ano para o grupo placebo, com $\mathrm{RR}$ de 0,51 (IC95\%: 0,29 a 0,81) e 0,45 (IC95\%: 0,24 a 0,83), considerando-se como referência o grupo placebo. Tanto a suplementação de vitamina A, quanto de 
beta-caroteno, reduziram em $50 \%$ a ocorrência de cegueira noturna nesse período.

CONGDON et al. (2000), ao investigarem o efeito da suplementação de vitamina A ou beta-caroteno no limiar de adaptação ao escuro, relatam ausência de diferença estatisticamente significativa entre os grupos no terceiro mês pós-parto. As médias e desvios padrão de limiar foram iguais a $-1,15 \pm 0,37 ;-1,15 \pm 0,43$ e $-1,14 \pm 0,39 \log c d / m^{2}$, para os grupos vitamina $A$, beta-caroteno e placebo, respectivamente.

STOLTZFUS et al. (1993a), utilizando os testes de RDR e CIC, descrevem ausência de influência da suplementação de vitamina A. Observou-se porcentagem de mulheres com RDR $\geq 20 \%$ no baseline, aos três e aos seis meses iguais a: 9,2; 10,3 e 3,0\%, para o grupo vitamina A, e 4,$4 ; 9,0$ e $1,5 \%$, para o grupo placebo, respectivamente. As diferenças entre os grupos e a tendência interna em cada grupo não foram estatisticamente significativas.

No mesmo estudo, utilizou-se também a CIC como indicador de DVA. Com base na definição padrão de deficiência (CIC anormal em ambos os olhos), os autores não observaram tendência estatisticamente significativa de diminuição ou aumento da prevalência de CIC anormal nos grupo placebo ou vitamina A no decorrer do tempo. Utilizando-se o critério de anormalidade em um ou em ambos os olhos, a tendência decrescente no grupo vitamina A torna-se estatisticamente significativa $\left(p<0,006^{7}\right.$; STOLTZFUS et al., 1993a).

\footnotetext{
${ }^{7}$ Valor de p está apresentado como consta no artigo (STOLTZFUS et al. 1993a).
} 
RICE et al. (1999) investigaram o efeito da suplementação em dose única de vitamina A (200.000Ul) e estimaram as reservas hepáticas maternas de vitamina A no $3^{\circ}, 6^{\circ}$ e $9^{\circ}$ mês pós-parto utilizando-se o teste MRDR. Para o $3^{\circ}$ mês, os autores observaram proporções de 18 , 42 e $54 \%$ de $M R D R \geq 0,06$ para os grupos vitamina $A$, beta-caroteno e placebo, respectivamente. A proporção de $M R D R \geq 0,06$ no grupo vitamina $A$ foi estatisticamente diferente do grupo placebo $(p<0,01)$. Nos $6^{\circ}$ e $9^{\circ}$ meses, são descritas as cifras de 31 e $28 \%$, para o grupo vitamina A, 19 e $26 \%$, para o grupo beta-caroteno, e 33 e $42 \%$, para o grupo placebo, sem diferenças significativas entre os grupos.

\subsection{Efeito da suplementação de vitamina A no estado nutricional de vitamina A infantil \\ Concentração sérica de retinol}

BHASKARAM et al. (2000), BAHL et al. (2002); RICE et al. (1999); VINUTHA et al. (2000) e STOLTZFUS et al. (1993a), descrevem as concentrações médias de retinol sérico entre crianças. No estudo conduzido por BAHL et al. (2002), foi utilizada suplementação combinada para a mãe e para o bebê, por isso seus dados não foram incluídos na metanálise.

A combinação dos resultados apresentados pelos quatro artigos

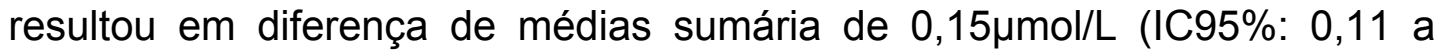
$0,20)$ aos três meses após o parto, como ilustra o Gráfico 13. Porém, foi observada heterogeneidade entre os estudos (qui-quadrado=9,20; $p=0,010$ ). 
Retirando-se da análise o estudo que utilizou dose fracionada, observou-se um aumento na diferença de médias sumária para $0,25 \mu \mathrm{mol} / \mathrm{L}$ (IC95\%: 0,16 a 0,34) aos três meses após o parto, como pode ser observado no Gráfico 14. Nesta configuração, a heterogeneidade observada na análise anterior não se mantém (qui-quadrado=3,79; $p=0,052$ ).

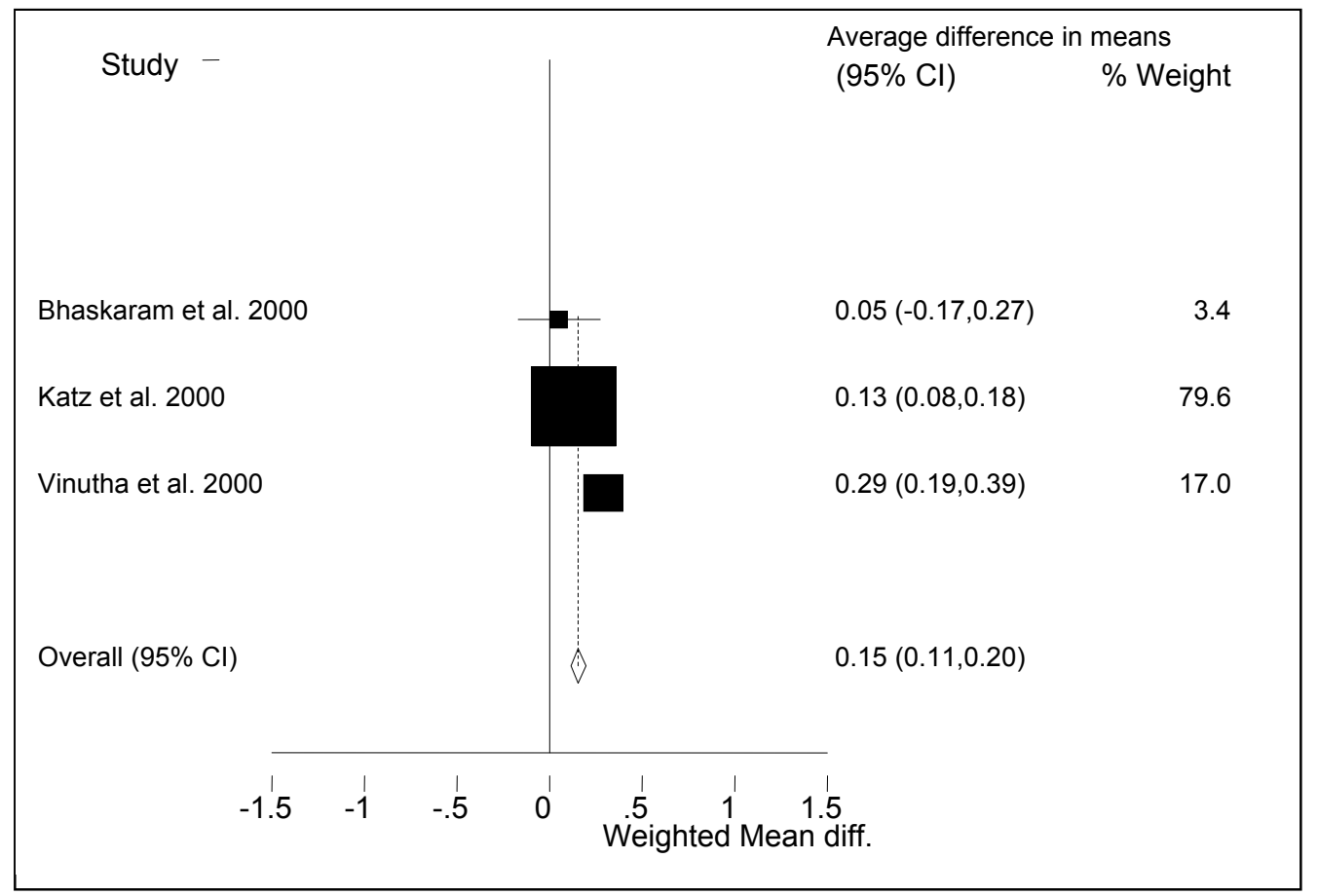

Gráfico 13: Distribuição de estudos de acordo com a diferença de médias da concentração de retinol sérico infantil aos três meses pós-parto. 


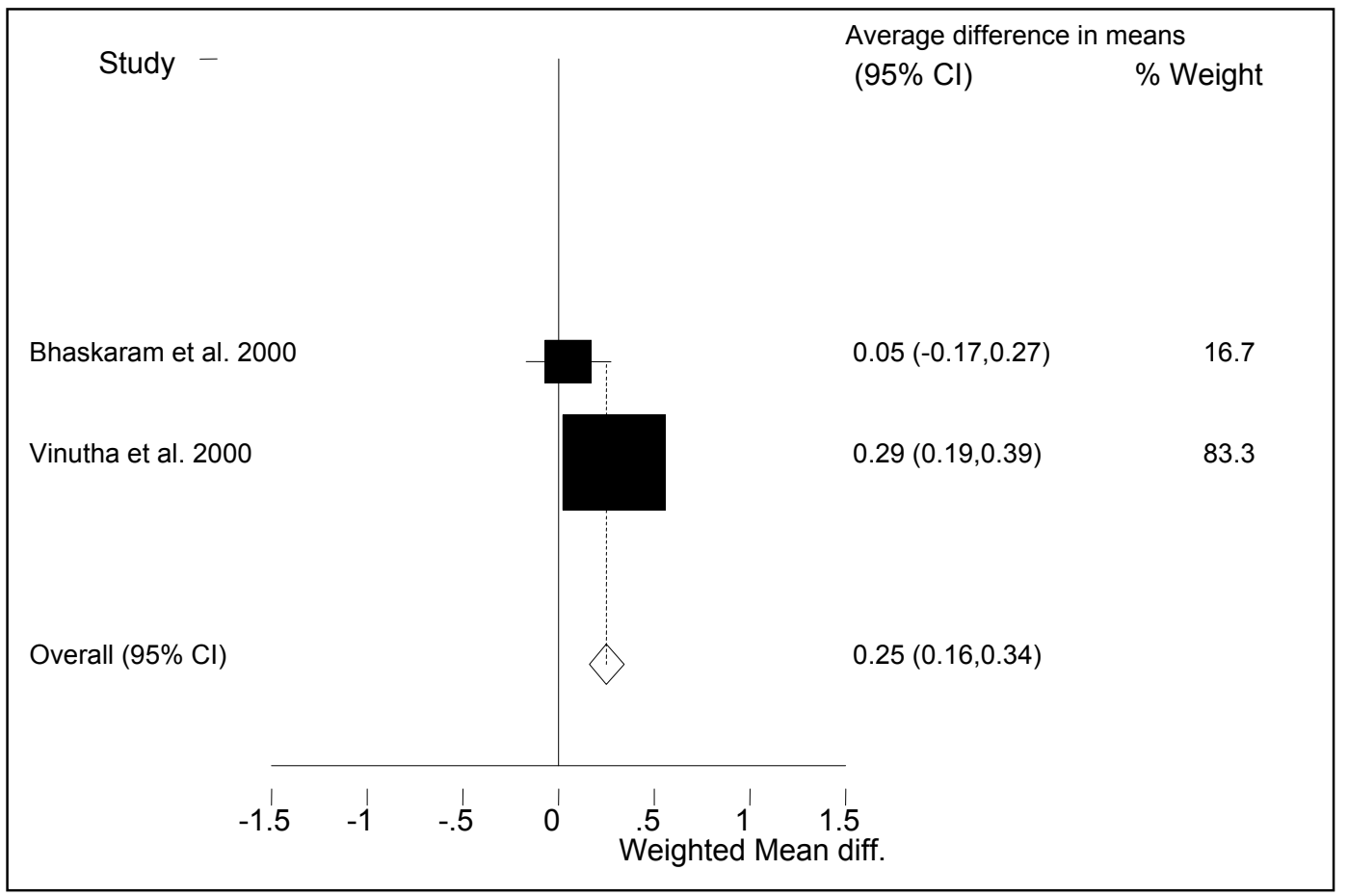

Gráfico 14: Distribuição de estudos de acordo com a diferença de médias da concentração de retinol sérico infantil aos três meses pós-parto, retirando-se o estudo que utilizou dose fracionada (KATZ et al., 2000).

A análise agregada dos resultados disponíveis para o sexto mês pósparto resultou em diferença de médias sumária de 0,04 $\mu$ mol/L (IC95\%: -0,01 a 0,09$)$, como ilustra o Gráfico 15 . Não há evidência de heterogeneidade entre os estudos (qui-quadrado=2,19; $p=0,335$ ). 


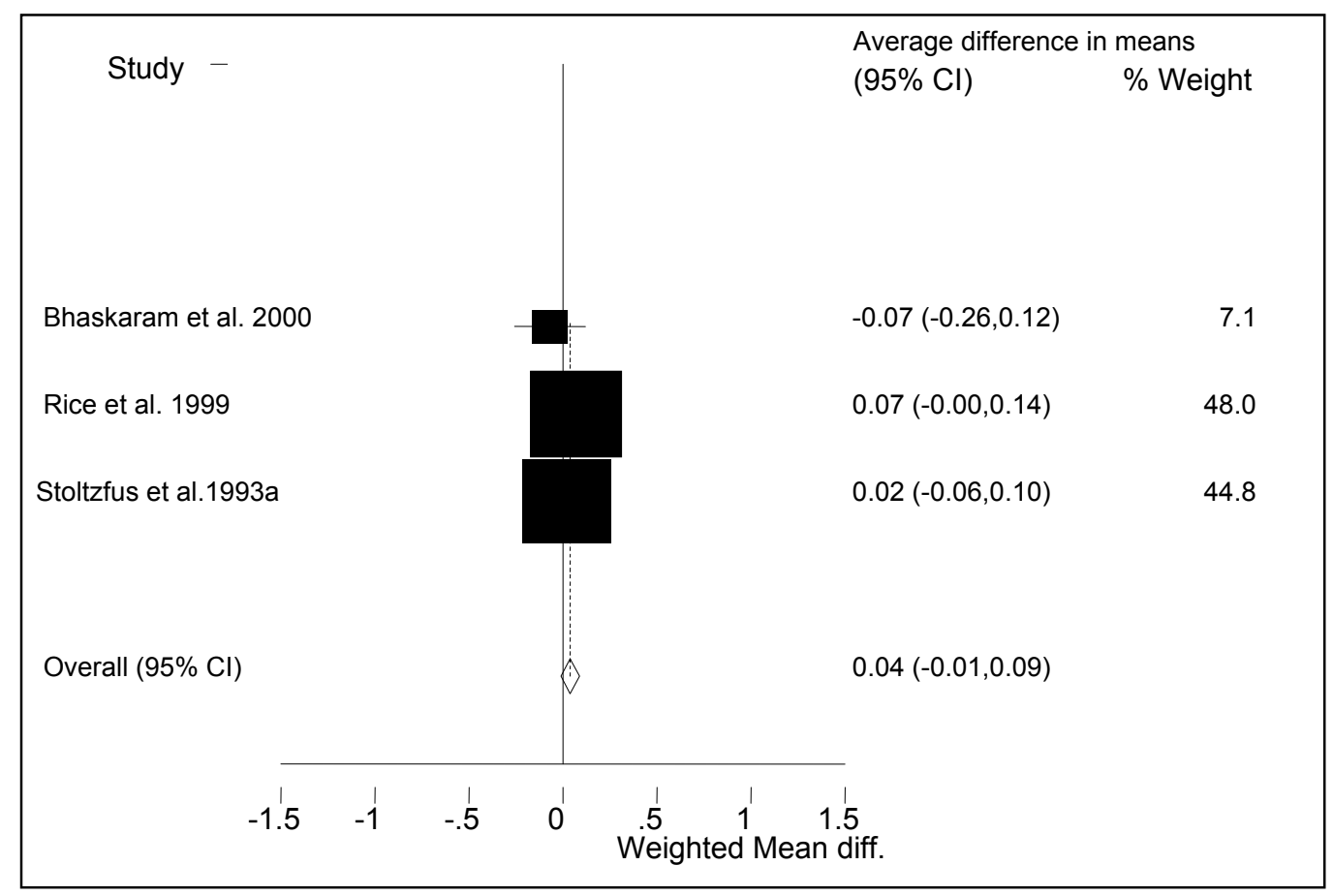

Gráfico 15: Distribuição de estudos de acordo com a diferença de médias da concentração de retinol sérico infantil aos seis meses pós-parto.

Retirando-se da metanálise o estudo que utilizou dose de 300.000UI, a diferença de médias sumária é de 0,05 $\mathrm{mol} / \mathrm{L}$ (IC95\%: -0,02 a 0,12), como pode ser observado no Gráfico 16. Não foi constatada heterogeneidade entre os estudos (qui-quadrado=1,81; $p=0,178$ ). 


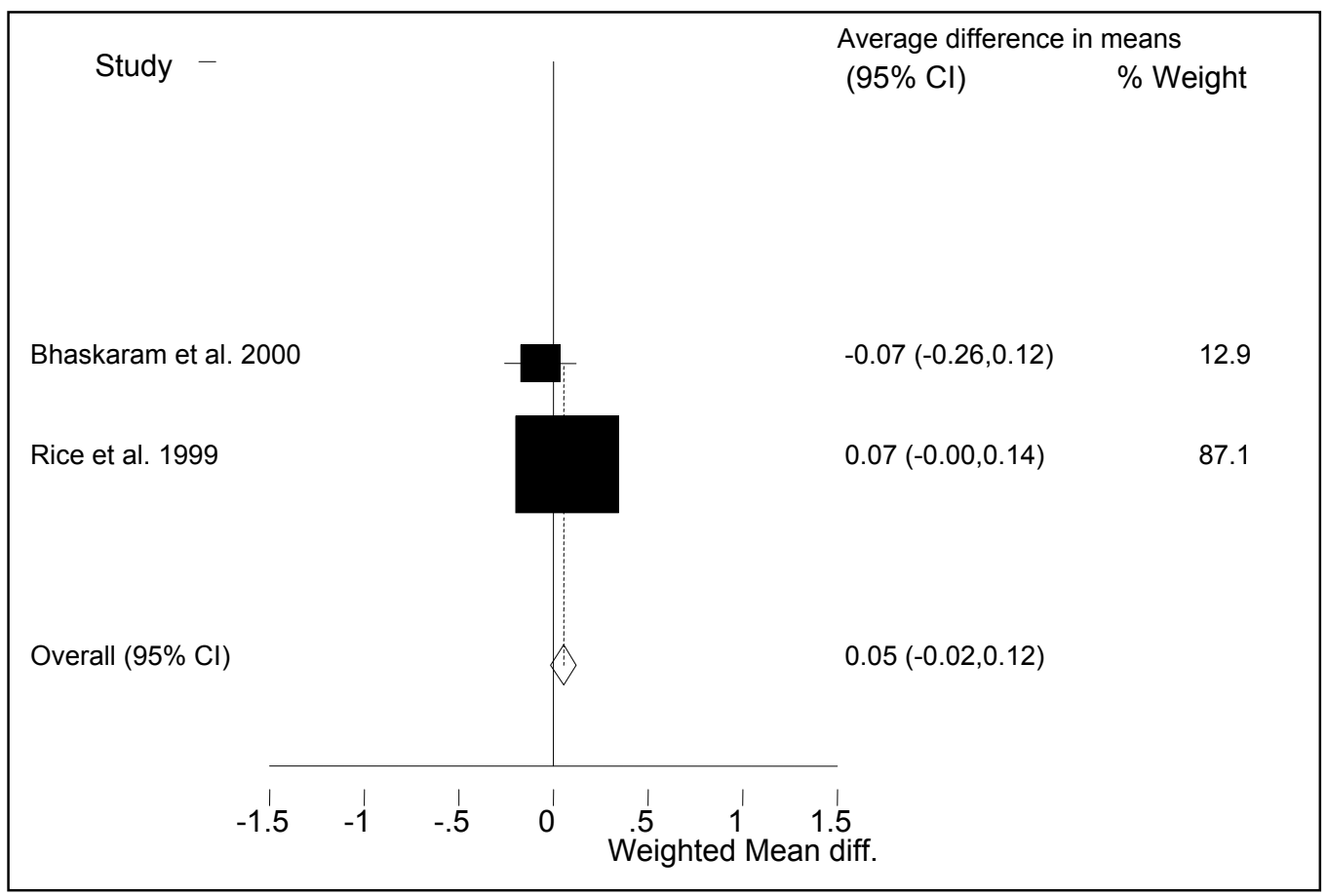

Gráfico 16: Distribuição de estudos de acordo com a diferença de médias da concentração de retinol sérico infantil aos seis meses pós-parto, retirando-se o estudo de STOLTZFUS et al. (1993a).

\section{Estimativa das reservas de vitamina A entre crianças}

STOLTZFUS et al. (1993a) utilizaram dose única de 300.000Ul e estimaram as reservas hepáticas de vitamina $A$ ao seis meses pós-parto utilizando-se o teste RDR. Os autores apontam associação significativa entre o grupo, vitamina A ou placebo, e o resultado do $\operatorname{RDR}(p<0,03)$, com prevalências de $10 \%$ de DVA (RDR $\geq 20 \%$ ), para o grupo vitamina $A$, e de $23 \%$, para o grupo controle.

RICE et al. (1999) investigaram o efeito da suplementação em dose única de vitamina A (200.000UI) e estimaram as reservas hepáticas infantis no $6^{\circ}$ mês de vida, utilizando-se o teste MRDR. Os autores observaram altas prevalências de $M R D R \geq 0,06$ em todos os grupos: $87 \%$ para o grupo 
vitamina A, $84 \%$ para grupo beta-caroteno e $93 \%$ para o grupo placebo, sem diferenças estatísticas entre os grupos.

Em outro estudo, BAHL et al. (2002) investigaram o efeito da suplementação conjunta de vitamina A para a mãe e para o bebê. Os autores descrevem freqüências de 81,8 e $78,5 \%$ de DVA (MRDR $\geq 0,06)$ em bebês na sexta semana pós-parto, para os grupos vitamina A e placebo, respectivamente. Nos $6^{\circ}$ e $9^{\circ}$ meses de vida, são descritas as cifras de 44,2 e $37,1 \%$, para o grupo vitamina A, e 52,9 e $36,5 \%$, para o grupo placebo. Para o $6^{\circ}$ mês, observou-se diferença significativa entre os grupos $\left(p<0,05^{6}\right)$.

${ }^{6}$ Valor de p está apresentado como consta no artigo (BAHL et al. 2002). 


\section{Discussão}

\section{Avaliação dos critérios de elegibilidade}

Na presente revisão sistemática, optou-se por uma estratégia ampla de busca de trabalhos, que contemplou várias bases de dados com relevância nos campos da Saúde Pública e da Nutrição, o que minimizou a possibilidade de ocorrência de vieses de seleção. EGGER et al. (2003) considera, porém, que as revisões sistemáticas estão sujeitas principalmente a vieses de publicação, pois estudos que relatam efeitos benéficos de determinada intervenção são mais facilmente publicáveis, em detrimento dos estudos que não descrevem efeito. Por outro lado, há também duplicidade de publicações dos resultados de um único estudo, especialmente daqueles que encontraram efeito positivo, que, por conseqüência, podem aumentar a possibilidade de serem localizados e incluídos em revisões sistemáticas.

A presente revisão pode estar sujeita a vieses de publicação, uma vez que só foram localizados trabalhos publicados, sendo possível a existência de estudos não publicados que não relataram benefícios da suplementação de vitamina A.

A utilização de uma estratégia de busca ampla resultou em um grande número inicial de estudos (3.425), que após a eliminação das duplicidades se reduziu para 2.547. Apesar do trabalho vultoso empreendido na leitura dos resumos desses trabalhos, acredita-se que a possibilidade de não identificação de um estudo elegível esteja reduzida.

As estratégias de buscas de ensaios aleatorizados e controlados utilizadas foram desenvolvidas por especialistas da área de informação, e 
estão disponíveis no Cochrane Handbook (Pubmed e ERL) e na Bireme (Lilacs). Porém, para a base Web of Science, não foi possível localizar uma estratégia de busca de ensaios aleatorizados controlados, o que pode ter contribuído para o grande número de trabalhos identificados inicialmente.

Entre os trabalhos identificados inicialmente, observou-se que muitos foram desenvolvidos em modelo animal, que não eram objeto de estudo da presente revisão. Há possibilidade de que a utilização da base Agris possa ter contribuído com essa ocorrência, o que indica a necessidade de desenvolvimento de estratégias de buscas mais sensíveis ou utilização de bases de dados mais adequadas com o objetivo do estudo.

Para quase $10 \%$ dos artigos identificados, não foi possível localizar os resumos, assim foi necessária a busca dos artigos na íntegra. Dessa parcela, não foram localizados seis estudos que foram excluídos por consenso entre os dois avaliadores. Considerando-se que existe uma relação entre o título e o conteúdo do artigo, acredita-se que as decisões tomadas com base somente no título não tenham contribuído com vícios de seleção.

\section{Análise de qualidade dos estudos}

Para a presente revisão, constatou-se que cerca de $10 \%$ dos estudos foram considerados de baixa qualidade segundo os instrumentos de Avaliação da Adequação do Sigilo de Alocação e Avaliação dos Riscos de Vieses. 
Segundo JÜNI et al. (2003) há uma variedade de escalas que podem ser utilizadas para avaliar a qualidade de estudos, entretanto estas diferem em relação às dimensões cobertas e sua complexidade, assim a utilização de diferentes escalas pode estar relacionada a resultados conflitantes. Apesar disso, optou-se pela exclusão dos estudos considerados de baixa qualidade pelos instrumentos Avaliação da Adequação do Sigilo de Alocação e/ou Avaliação dos Riscos de Vieses. Segundo JÜNI et al. (2003), a exclusão de estudos de baixa qualidade pode ser uma boa estratégia, porém deve ser feita com prudência para evitar a não inclusão de estudos que poderiam contribuir com informações de qualidade.

\section{Efeito da suplementação de vitamina A na morbi-mortalidade infantil}

Somente dois estudos avaliaram o impacto da suplementação na morbidade infantil. Nestes trabalhos, não são relatadas diferenças significativas na ocorrência e duração dos episódios de diarréia, infecção respiratória, pneumonia entre os grupos suplementação e controle (VENKATARAO et al., 1996; WHO/CHD et al., 1998). É importante pontuar que em ambos os estudos foi realizada, em um dos grupos de intervenção, a suplementação conjunta para a mãe e o bebê. Sendo assim, poderia ser esperada evidência de efeito protetor associado a este esquema de suplementação. Porém, deve-se considerar que o estado de resistência a infecções está relacionado também à integridade da pele e mucosas, imunidade específica, capacidade de adaptação, ausência de outras patologias e de outras deficiências nutricionais específicas. Assim, torna-se 
difícil a avaliação da suplementação somente de vitamina $A$ em relação à morbidade infantil.

Segundo DINIZ e SANTOS (2000), diversos estudos foram desenvolvidos com o intuito de avaliar o efeito da suplementação de vitamina $A$ sobre a morbidade na infância, porém a maior parte deles não encontra efeito preventivo. Porém, considerando-se somente a diarréia, há indicação de atenuação da gravidade do quadro, com diminuição dos número de episódios diários.

Há evidências, também, de que a suplementação de vitamina $A$ em crianças com idade superior a seis meses seja efetiva em atenuar a gravidade do quadro de determinadas doenças, tendo como conseqüência a diminuição do risco de morte por sarampo (FAWZI et al., 1993; D'SOUZA e D`SOUZA, 2005), bem como redução da mortalidade por diarréia (GLASZIOU e MACKERRAS, 1993).

A coexistência das deficiências de zinco e vitamina A pode ser um dos fatores explicativos da ausência de efeito preventivo da suplementação da vitamina em relação à morbidade infantil. RAHMAN et al. (2006) conduziram um ensaio aleatorizado duplo-cego, com 665 crianças (1 a 3 anos de idade) que receberam zinco, vitamina $A$, zinco e vitamina $A$, ou placebo; e relatam que a suplementação combinada (zinco com vitamina A) é mais efetiva na redução de diarréia persistente e disenteria, quando comparada à suplementação somente por vitamina A ou zinco.

Entre os estudos incluídos na presente revisão, três analisaram as taxas de mortalidade infantil (KATZ et al., 2000; MALABA et al., 2005) e, 
apesar de um deles utilizar a suplementação simultânea para a mãe e o bebê (WHO/CHD, 1998), não foram relatadas diferenças significativas nas taxas de mortalidade infantil entre os grupos intervenção e controle. Entretanto, em metanálise realizada por FAWZI et al. (1993), há relato de efeito protetor da suplementação na mortalidade geral em estudos de base comunitária ( $O R=0,70 ; \mathrm{IC} 95 \%$ : 0,56 a 0,87; $p=0,001)$ em crianças com idade entre 6 e 72 meses.

\section{Efeito da suplementação de vitamina A na morbi-mortalidade materna}

As investigações conduzidas por CHRISTIAN et al. (2000) apontam efeito benéfico da suplementação semanal de vitamina $A$ e/ou de betacaroteno na prevalência de evacuações aquosas, episódios de febre e de fraqueza (debilidade) em mulheres lactantes. A suplementação de vitamina A também se apresentou relacionada com o aumento de secreção vaginal.

A diminuição da prevalência de evacuações aquosas (sintoma de infecção gastrintestinal), associado à suplementação de vitamina $A$, pode ser explicada à sua função de recuperar e manter a integridade da mucosa epitelial (VILLAMOR e FAWZI, 2005). Segundo CHRISTIAN et al. (2000), a redução de episódios de febre, que é indicador de infecção, também foi relatada em outros dois estudos (HAKIMI et al., 1999; GREEN et al., 1931). Assim, a redução desse indicador pode estar associada ao impacto da suplementação de vitamina A na produção de anticorpos específicos e na produção/diferenciação dos linfócitos (VILLAMOR e FAWZI, 2005). 
CHRISTIAN et al. (2000) apontam que o efeito benéfico da suplementação de vitamina $\mathrm{A}$ em relação à fraqueza é possivelmente reflexo da redução na prevalência de anemia. Estudos que investigaram a interação entre o ferro e a vitamina A relatam que DVA esteja relacionada à diminuição da síntese de hemoglobina e aumento dos estoques hepáticos de ferro. Investigações conduzidas em crianças sugerem que suplementação de vitamina A pode estar relacionada a aumento da concentração de hemoglobina (LYNCH, 1997). Porém, van den BROEK et al. (2004), em revisão sistemática, localizaram três estudos que avaliaram o impacto da suplementação de vitamina A na anemia em gestantes (SUHARMO et al., 1993; SEMBA et al., 2001; van den BROEK et al., 2001), com relato de efeito benéfico em somente uma das investigações (SUHARMO et al., 1993).

O aumento significativo da secreção vaginal, associado à suplementação de vitamina A, pode ser explicado pela melhoria da nutrição dessa vitamina nos tecidos dos tratos reprodutivo e urinário, o que teria como conseqüência a elevação da produção de muco (CHRISTIAN et al., 2000).

Para a mortalidade, WEST et al. (1999) não descrevem diferenças de risco de morte entre os grupos intervenção e controle, quando se considera a mortalidade entre sete e doze semanas pós-parto. Porém, relatam diminuição da mortalidade materna durante a gravidez até 12 semanas pósparto no grupo suplementado com vitamina A ( $R R=0,60$, IC95\%: 0,37 a 0,97) e com beta-caroteno ( $R R=0,56$; IC95\%: 037 a 0,84). 
É importante pontuar que para o cálculo da mortalidade materna foram consideradas, além das causas obstétricas, os óbitos relacionados a infecção (febre tifóide, tétano, hepatite e leishmaniose), injúria (queimadura, afogamento, enforcamento e envenenamento por picada de cobra) e doenças crônicas (anemia, asma e leucemia). Quando se considera somente as causas obstétricas, não há evidência de efeito protetor tanto da suplementação de vitamina A ( $R R=0,88$; IC98\%: 0,42 a 1,81), quanto de beta-caroteno (RR=0,56; IC98\%: 0,24 a 1,31; WEST et al., 1999).

Neste estudo, conduzido por WEST et al. (1999), a ocorrência de óbito materno foi obtida através de entrevista com um familiar (autópsia verbal). A causa relatada era revisada por dois médicos que desconheciam os grupos de intervenção aos quais as mulheres pertenciam. Essa metodologia é útil em investigações em populações com pouco acesso a diagnóstico médico, porém está sujeita a imprecisão e erros de classificação, especialmente quando se considera a complexidade da natureza do óbito relacionado à gravidez e ausência de sinais e sintomas específicos que podem ser percebidos pelos familiares.

Efeito da suplementação de vitamina $A$ na ocorrência de efeitos adversos

Não foram descritas diferenças na proporção de efeitos adversos agudos, maternos ou infantis, decorrentes da administração de mega dose (200.000 ou 400.000UI) de vitamina A para lactantes (VENKATARAO et al., 1996; ILIFF et al., 1999). 
É importante ressaltar que, em situação de utilização de suplementação com 400.000UI de vitamina A, UNDERWOOD (2001) citado por ROSS (2002), recomenda a utilização de duas doses de 200.000UI cada, administradas com 24 horas de diferença, para evitar o aumento transitório de ácido retinóico a níveis tóxicos no leite humano. Porém no estudo de ILIFF et al. (1999) não foi descrita a utilização esse procedimento e não há relato da mensuração dos níveis de ácido retinóico no leite humano.

\section{Efeito da suplementação de vitamina $A$ na concentração de retinol do} leite humano

Observou-se pela análise agregada que a suplementação com mega dose de 200.000Ul de vitamina A está relacionada a menores proporções de DVA em mulheres considerando-se, como desfecho, as concentrações de retinol no leite humano $\leq 0,28 \mu \mathrm{mol} / \mathrm{g}$ de lipídeo aos seis meses pós-parto quando comparada ao grupo placebo ( $\mathrm{OR}=0,73$; IC95\%: 0,54 a 0,99$)$. Porém, esse efeito protetor não se sustenta até $\circ 9^{\circ}$ mês pós-parto $(\mathrm{OR}=0,82 ; \mathrm{IC} 95 \%$ : 0,59 a 1,14$)$.

A análise agregada dos estudos, que utilizaram como ponto de corte $o$ valor $1,05 \mu \mathrm{mol} / \mathrm{L}$, aponta para presença de efeito protetor aos três meses (OR=0,29; IC95\%: 0,17 a 0,48 ou OR=0,30; IC95\%: 0,17 a 0,54), porém este efeito não perdura aos seis meses pós-parto (OR=0,62; IC95\%: 0,34 a 1,11). Resultados semelhantes foram encontrados para a diferença de médias sumária (dms) da concentração de retinol no leite, que é significantemente 
maior no grupo suplementado com vitamina $A$ aos três $(\mathrm{dms}=0,20 \mu \mathrm{mol} / \mathrm{L}$;

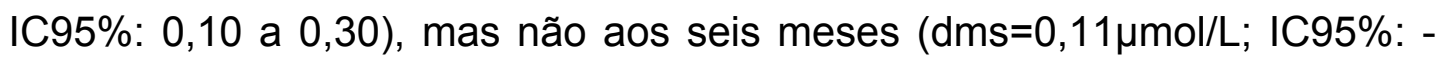
$0,06$ a 0,28$)$.

Resultados de estudos metodológicos, que avaliaram a habilidade de diferentes parâmetros, têm apontado que a concentração de retinol no leite humano, expressa por grama de lipídio, seja um dos melhores indicadores do estado nutricional de vitamina A (STOLTZFUS et al., 1993b; RICE et al., 2000a). Segundo Rice et al. (2000a), as amostras casuais de leite, retiradas em diferentes momentos do dia e sem controlar quando ocorreu a última amamentação, constituíram-se o melhor preditor do estado nutricional materno.

Outra questão importante é a possibilidade da limitação da utilização da concentração de retinol no leite, como indicador de estado nutricional de vitamina $A$, em situações que ativem uma resposta de fase aguda (RASMUSSEN, 1998). DANCHECK et al. (2005) investigaram a influência da inflamação e da reação de fase aguda na concentração de retinol no leite de mulheres de Malawi, e não observaram diferença na média dos teores da vitamina no leite das lactantes que apresentavam ou não sinais de

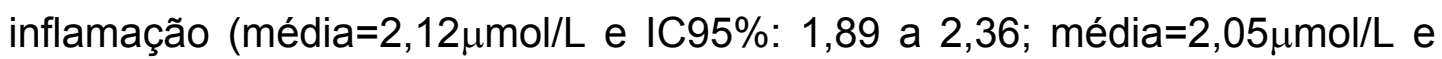
IC95\%: 1,75 a 2,39; respectivamente). Os autores concluem que este pode ser melhor indicador de DVA subclínica quando comparado ao retinol sérico, pois, aparentemente, não sofre influência da reação de fase aguda.

Segundo STOLTZFUS e UNDERWOOD (1995) a concentração de vitamina A no leite maduro de mães bem nutridas é suficiente para atender 
às necessidades dos recém-nascidos e para promover 0 adequado armazenamento hepático. Porém, alguns estudos realizados em países em desenvolvimento, relatam teores médios de retinol do leite variando entre 0,4 e 1,8 $\mu \mathrm{mol} / \mathrm{L}$ (MELLO NETO, 2005; PRESTA, 2001; PANPANICH et al., 2002; GROSS 1998; MUHILAL et al., 1988; BUTTE et al., 1981), o que é, segundo UNDERWOOD (1994), suficiente apenas para atender as necessidades metabólicas dos recém-nascidos, sem permitir a constituição de reservas hepáticas.

Alguns estudos relatam associação (ou correlação) entre a concentração sérica de retinol materna e no leite humano (PANPANICH et al., 2002; BUTTE et al., 1981; THEIN, 1979), porém em outros não se observam esses resultados (PRESTA, 2001). Segundo STOLTZFUS e UNDERWOOD (1995) a melhor evidência de que a concentração de vitamina A no leite está relacionada ao estado nutricional materno relativo a esse micronutriente é o aumento na concentração de retinol no leite decorrente de suplementação em áreas onde a DVA é endêmica.

Efeito da suplementação de vitamina $A$ na concentração de retinol sérico materno e infantil

Em relação à concentração de retinol sérico entre as mulheres e os bebês, os resultados da análise agregada indicam efeito protetor da suplementação até o $3^{\circ}$ mês pós-parto.

Os resultados que apontam o efeito protetor da suplementação com dose de 200.000Ul nas concentrações séricas de retinol no grupo infantil 
basearam-se nos dados de dois estudos, sendo que em um deles foi utilizada solução aquosa (emulsão) de vitamina A (VINUTHA et al., 2000). Este tipo de apresentação do suplemento resulta em maiores concentrações séricas, no fígado e menores perdas fecais da vitamina, quando comparadas às soluções à base de óleo. Estas considerações podem justificar a observação de maior diferença de médias de retinol sérico, entre os grupos intervenção e controle no estudo de VINUTHA et al. (2000), o que influenciou o resultado da metanálise.

Nos estudos de BHASKARAM et al. (2000) e VINUTHA et al. (2000), que foram incluídos na metanálise da concentração de retinol sérico infantil aos três meses, utilizou-se a espectrofluorimetria e espectrofotometria como métodos de determinação do retinol, respectivamente. Estas metodologias, segundo de PEE e DARY (2002), podem apresentar baixa especificidade, baixa acurácia e dificuldades de validação.

Para determinação do retinol sérico, o HPLC é considerado como a melhor metodologia, apesar de necessitar de treinamento técnico e comparações interlaboratoriais para assegurar a qualidade das mensurações. A utilização dessa metodologia na maior parte dos estudos incluídos na metanálise, com exceção dos estudos de BHASKARAM et al. (2000) e VINUTHA et al. (2000), indica que provavelmente houve boa quantificação dos níveis deste micronutriente (de PEE e DARY, 2002).

Segundo a WHO (1996), a concentração sérica de retinol está sob controle homeostático, refletindo, contudo, os estoques corpóreos dessa vitamina quando estes estão muito altos ou muito baixos. Assim, a 
concentração sérica de retinol é um bom indicador de DVA subclínica em populações, mas não em indivíduos. Deve-se considerar, porém, que a concentração de retinol sérico pode estar diminuída em situação de infecções subclínicas ou inflamação, pois o complexo retinol e RBP (proteína carreadora de retinol) é um reactante negativo de fase aguda (FILTEAU et al., 1993; WHO, 1996).

THURNHAM et al. (2003), propuseram que indivíduos com elevada concentração de proteínas de fase aguda, como a proteína $C$ reativa, sejam excluídos das análises em estudos que utilizam o retinol sérico como indicador de DVA subclínica. Por outro lado, há evidência de que indivíduos com DVA subclínica são mais suscetíveis a infecções, assim a exclusão daqueles indivíduos que apresentam alta concentração de proteínas de fase aguda poderia subestimar a prevalência de DVA.

Outro ponto importante é a interação entre a vitamina A e outros micronutrientes. Há evidências de que o estado nutricional de zinco influencia vários aspectos do metabolismo da vitamina $A$, incluindo absorção, transporte e utilização (CHRISTIAN e WEST, 1998). Alguns estudos de intervenção em crianças e gestantes indicam efeito benéfico da suplementação combinada de vitamina A ou beta-caroteno e zinco no estado nutricional de vitamina A do grupo materno-infantil (RAHMAN et al., 2002; DIJKHUIZEN et al., 2004).

Estudos conduzidos com animais apontam que o metabolismo da vitamina A esteja alterado também em situação de deficiência de ferro, caracterizando-se por baixa concentração sérica de retinol e aumento dos 
estoques hepáticos de éster de retinila, provavelmente decorrentes da redução da atividade de hidrolases de éster de retinila e conseqüente queda na mobilização da vitamina A hepática (STRUBE et al., 2002; JANG et al., 2000; ROSALES et al., 1999). Estudos de intervenção em crianças e gestantes relatam efeito benéfico da suplementação de ferro na diminuição das prevalências de DVA subclínica (MUÑOZ et al., 2000; SHATRUGNA et al., 1997).

Efeito da suplementação de vitamina $A$ nos demais parâmetros de estado nutricional de vitamina A materno

Na presente revisão, observou-se efeito protetor da suplementação com dose semanal (23.000UI) na incidência de cegueira noturna após o parto; o benefício, porém, não se estendeu ao limiar de adaptação ao escuro.

Apesar da importante redução de cerca de $50 \%$ no risco de cegueira noturna no período entre três e seis meses pós-parto, deve-se considerar que a suplementação combinada com outros micronutriente, como o zinco, pode ser ainda mais efetiva na redução da incidência desse sintoma. A deficiência de zinco pode prejudicar a conversão do retinol ao retinal, que é necessário para a produção da rodopsina, pois essa conversão é realizada por desidrogenase dependente de zinco (HUBER e GERSHOFF, 1975). O zinco é também necessário na produção da RBP, assim a deficiência desse mineral pode prejudicar o adequado transporte de vitamina, contribuindo também para ocorrência de cegueira noturna (CHRISTIAN e WEST, 1998). 
CONGDON et al. (2000) testaram o limiar de adaptação ao escuro entre gestantes e observaram que este indicador estava altamente associado ao retinol sérico e houve melhora significativa em resposta à suplementação de vitamina A. Segundo os autores, a ausência de associação entre o limiar de adaptação ao escuro e a concentração de retinol sérico no pós-parto pode ser explicada pela alta perda de seguimento $(>50 \%)$.

Observou-se, também, efeito protetor da suplementação com dose única de $300.000 U$ I na prevalência de CIC anormal, porém sem benefício para a constituição de reservas hepáticas no sexto mês pós-parto.

Segundo STOLZTFUS et al. (1993a), o RDR mostrou-se pouco responsivo a mudanças no estado nutricional de vitamina $A$ materno, possivelmente porque a dosagem do suplemento utilizada para realização do teste $(1,57 \mu \mathrm{mol}$ ou $1.500 \mathrm{UI})$ tenha sido apropriada para os bebês, mas não para as lactantes. Em relação à utilidade da CIC como indicador de DVA, STOLTZFUS et al. (1993c) apontam que esse indicador não é responsivo para medir o efeito da suplementação, mas pode ser útil em situações em que há pouco acesso a laboratórios.

Em outro estudo, que utilizou mega dose de 200.000Ul, também não foi observado benefício em relação constituição de reservas hepáticas de vitamina $A$ aos seis meses (RICE et al., 1999). Estudo metodológico indica que teste o MRDR, utilizado para estimar as reservas hepáticas de vitamina A, é um indicador mais sensível, quanto comparado ao retinol sérico, em 
detectar mudanças no estado nutricional de vitamina A de mulheres e crianças (RICE et al., 2000a).

Efeito da suplementação de vitamina $A$ na estimativa de reservas hepáticas infantis

Em relação à estimativa das reservas hepáticas infantis de vitamina $A$, os resultados indicam que suplementação com mega dose de $300.000 \mathrm{UI}$ (STOLZFUS et al., 1993a) ou suplementação combinada para mãe (200.000UI) e bebê (75.000UI) estão relacionadas com melhores reservas de vitamina A em crianças aos seis meses de idade (BAHL et al., 2002). O estudo que utilizou mega dose de 200.000Ul para mãe (RICE et al., 1999), não relata diferença na prevalência de baixas reservas entre os grupos suplementação e placebo.

Os achados desses estudos indicam que a suplementação de vitamina A somente para as lactantes com dose de 200.000 U não seja efetiva na constituição de adequadas reservas hepáticas infantis. Estudo que utiliza abordagem cinética aponta que a suplementação materna com uma ou duas mega doses (200.000Ul cada) e a administração conjunta de três doses de 50.000 U para os bebês até o $6^{\circ}$ mês de vida são vitais para prevenir a queda da concentração hepática de vitamina A para níveis de deficiência $(<20 \mathrm{mcg} / \mathrm{g})$ no grupo infantil.

ROSS (2002), com base neste estudo e na investigação de STOLTZFUS et al. (1993a) - que relatam aumento no teor de vitamina A no leite humano até o $8^{\circ}$ mês decorrente de suplementação com 300.000 Ul de vitamina A - apontou que a suplementação com duas mega doses de 
vitamina A (200.000Ul/cada) para lactantes, administradas separadamente com intervalo de 24 horas, poderia ser mais efetiva na manutenção das concentrações adequadas de retinol no leite materno, o que favoreceria a constituição de reservas hepáticas infantis. 


\section{Conclusões}

- Não há evidência de que a suplementação conjunta de vitamina A para a mãe e para o bebê esteja relacionada com a diminuição da ocorrência e duração de morbidades e mortalidade infantis,

- Há evidência de que a suplementação semanal (antes, durante e após o parto) de vitamina A está relacionada à diminuição dos episódios de febre (42mg de beta-caroteno), fraqueza e evacuações aquosas (23.000UI) no grupo materno no pós-parto,

- Não há evidência de efeito protetor da suplementação semanal (antes, durante e após o parto) de vitamina A (23.000Ul ou 42mg de beta-caroteno) na ocorrência de mortalidade materna entre a $7^{a}$ e $12^{a}$ semana pós-parto,

- Não há evidência de que a suplementação com mega dose de vitamina A (200.000 a 400.000UI) esteja relacionada com ocorrência de efeitos adversos no grupo materno-infantil,

- Há evidência de que a suplementação com 200.000 Ul de vitamina A esteja relacionada com manutenção de teor adequado de retinol no leite humano até o $6^{\circ}$ mês pós-parto,

- Há indicação de que a suplementação com mega dose de vitamina A (200.000 ou 300.000UI) ou com doses fracionadas de beta-caroteno (7,8mg/dia ou $42 \mathrm{mg} /$ semana) esteja relacionada à maior concentração sérica média de retinol materna aos três meses pós-parto quando comparada ao grupo placebo, 
- Há indicação de que a suplementação com dose semanal (antes, durante e após o parto) de vitamina A (23.000UI) tenha efeito protetor em relação à incidência de cegueira noturna materna no $6^{\circ}$ mês pós-parto, - Há indicação de que a suplementação de vitamina A (200.000Ul) esteja relacionada à maior concentração sérica média de retinol infantil aos três meses pós-parto quando comparada ao grupo placebo,

- Não há indicação de que a suplementação com mega dose $(200.000$ ou 300.000UI) esteja relacionada com constituição de adequadas reservas hepáticas de vitamina A no grupo materno aos seis meses pósparto,

- Há indicação que a suplementação com mega dose de $300.000 U$ l ou suplementação combinada para a lactante (200.000UI) e para o bebê (75.000UI) esteja relacionada com constituição de adequadas reservas hepáticas de vitamina A no grupo infantil até seis meses de idade. 


\section{Conflito de interesses}

Não houve conflitos de interesses envolvidos no desenvolvimento da presente revisão.

\section{Financiamento}

Projeto financiado pela FAPESP, processo $n^{\circ}$ 04/06907-09.

Auxílio Complementar - Pró-Reitoria de Pesquisa da USP, processo $\mathrm{n}^{\circ}$ 2005.1.4697.1.0. 


\section{Referências}

Alderson P, Green S. Cochrane reviewer's handbook. [Update March 2004]. Chichester, UK: Jhon Willy \& Sons; 2004.

Allen LH, Haskell M. Estimating the potential for vitamin A toxicity in women and young children. J Nutr. 2002;132:2907-19S.

Amine EK, Corey J, Hegsted DM, Hayes KC. Comparative hematology during deficiencies of iron and vitamin A in the rat. J Nutr. 1970;100:1033-40.

Atallah AN. Revisão sistemática da literatura e metanálise: a melhor forma de evidência para tomada de decisão em saúde e a maneira mais rápida de atualização terapêutica. Diagn Tratamento. 1997;2(2):12-15.

Atallah AN. Systematic review of medical literature and metanalysis. Sao Paulo Medical Journal . 1996;114(5):1285-1287.

Azais-Abraesco V, Pascal G. Vitamin A in pregnancy: requirements and safety limits. Am J Clin Nutr. 2000;71:1325-33S.

Bauernfeind JC. The safety use of vitamin A: a report of the international vitamin supplementation study group. Washington, DC: IVACG/The Nutrition Foundation; 1980.

Bireme. Biblioteca virtual em saúde. Disponível em URL:<www.bireme.br>. [2004 jun 06]

Blaner WS, Olson JA. Retinol and retinoic acid metabolism. In SPORN MB, ROBERTS AB, GOODMAN DS. Segunda edição. New York: Raven Press; 1994.

Blomhoff R, Green MH, Green JB, Berg T, Norum K. Vitamin A metabolism: new perspectives on absorption, transport, and storage. Physiological Reviews. 1991;71(4):951-90.

Butte NF, Lopez-Alarcon MG, Garza C. Nutrient adequacy of exclusive breastfeeding for the term infant during the first six months of life. Expert Consultation on the Optimal Duration of Exclusive Breastfeeding. Geneva: WHO; 2002.

Butte NF, Calloway DH, van Duzen JL. Nutritional assessment of pregnant and lactating Navajo women. Am J Clin Nutr. 1981;34(10):2216-28.

Canfield LM, Clandinin MT, Davies DP, Fernandez MC, Jackson J, Hawkes J, et al. Multinational study of major breast milk carotenoids of healthy mothers. Eur $\mathrm{J}$ Nutr. 2003;42:133- 41.

Circle Systems. Stat/Transfer [programa de computador]. Seattle: Circle Systems, 2003.

Clagett-Dame, DeLuca. The role of vitamin A in mammalian reproduction and embryonic development. Annu Rev Nutr. 2002;22:347-81. 
Christian P, West KP Jr, Khatry SK, Katz J, LeClerq S, Pradhan EK, Shrestha SR. Vitamin A or beta-carotene supplementation reduces but does not eliminate maternal night blindness in Nepal. J Nutr. 1998;128(9):1458-63.

Christian P, West KP Jr. Interactions between zinc and vitamin A: an update. Am J Clin Nutr. 1998;68(2S):435S-441S.

Dancheck B, Nussenblatt V, Ricks MO, Kumwenda N, Neville MC, Moncrief DT, Taha TE, Semba RD. Breast milk retinol concentrations are not associated with systemic inflammation among breast-feeding women in Malawi. J Nutr. 2005;135(2):223-226.

Dean AG, Dean JA, Burton AH, Dicker RC. Epi Info, versão 6.04 [programa de computador]. A word, processing, database and statistics system for epidemiology with microcomputers. Atlanta: CDC; 1994.

Debier C, Larondelle $\mathrm{Y}$. Vitamin $\mathrm{A}$ and $\mathrm{E}$ : metabolism, roles and transfer to offsprings. Br J Nutr. 2005;93(2):153-74.

Diniz AS, Santos LMP. Hipovitaminose A e xeroftalmia. J Pediatr. 2000;76(3S):311S-322S.

de Pee S, Dary O. Biochemical indicators of vitamin A deficiency: serum retinol and serum retinol binding protein. J Nutr. 2002;132(9S):2895S-2901S.

Dew SE, Ong DE. Specificity of the retinol transport of the rat small intestine brush border. Biochemistry. 1994;33:12340-5.

Dickiman ED, Smith SM. Selective regulation of cardiomyocyte gene expression and cardiac morphogenesis by retinoic acid. Dev Dyn. 1996;206:39-46.

Dijkhuizen MA, Wieringa FT, West CE, Muhilal. Zinc plus beta-carotene supplementation of pregnant women is superior to beta-carotene supplementation alone in improving vitamin A status in both mothers and infants. Am $\mathrm{J}$ Clin Nutr. 2004;80(5):1299-307.

D'Souza RM, D'Souza R. Vitamin supplementation for treating measles in children. (Cochrane Review). In: The Cochrane Library. Issue 2. Oxford: Update Software; 2005.

Egger M, Smith GD, Altman DG. Systematic reviews in health care. Meta-analysis in context. London: BMJ Books; 2001a.

Egger M, Smith GD, Sterne JAC. Uses and abuses of meta-analysis. Clin Med. $2001 ; 6: 478-484 b$.

Egger M, Smith GD, Altman DG, eds. Systematic reviews in health care: metaanalysis in context. Terceira edição. London: BMJ Books; 2003.

ERL-WebSPIRS. Electronic Reference Library. Acesso regulamentado pela USP.Disponível em URL:<www.usp.br/sibi>. [2004 jun 06] 
FAO/WHO - Food and Agriculture Organization of United Nations/World Health Organization. Human vitamin and mineral requirements. Thailand: Report of a joint FAO/WHO expert consultation; 2001.

Fawzi WW, Chalmers TC, Herrera MG, Mosteller F. Vitamin A supplementation and child mortality. JAMA. 1993;269(7):898-903.

Filteau SM, Morris SS, Abbott RA, Tomkins AM, Kirkwood BR, Arthur P, Ross DA, Gyapong JO, Raynes JG. Influence of morbidity on serum retinol of children in a community-based study in northern Ghana. Am J Clin Nutr. 1993;58:192-197.

Glasziou PP, Mackerras DEM. Vitamin A supplementation in infection diseases: a meta-analysis. BMJ. 1993;306:366-70.

GHANA VAST. Vitamin A supplementation in northern Ghana: effects on clinic attendances, hospital admissions, and child mortality. Lancet .1993;342:7-12.

Green HN, Pindar D, Davis G, Mellamby E. Diet as a prophylact agent against puerperal sepsis. Br Med J. 1931;2:595-8.

Gross R, Hansel H, Schultink W, Shrimpton R, Matulessi P, Gross G, Tagliaferri E, Sastroamdijojo $S$. Moderate zinc and vitamin A deficiency in breast milk of mothers from East-Jakarta. Eur J Clin Nutr. 1998;52(12):884-90.

Grotto I, Mimouni M, Gdalevich M, Mimouni D. Vitamin A supplementation and childhood morbidity from diarrhea and respiratory infections: a meta-analysis. J Pediatr. 2003;142(3):297-304.

Hakimi M, Dibley MJ, Suryono A, Nurdiati DTH, Ninuk SH, Dawiesah, Ismadi S. Impact of vitamin A and zinc supplements on maternal postpartum infections in rural central Java, Indonesia. International Vitamin A Consultative Group Meeting, March 8-11, Durban, South África; 1999.

Harrison EH. Enzymes catalyzing the hydrolysis of retinil ester. Biochim Biophys Acta. 1993;1170:99-108.

Hofmann C, Eichele G. Retionoids in development. In: SPORN MB, ROBERTS AB, GOODMAN DS. Segunda edição. New York: Raven Press; 1994.

Huber AM, Gershoff SN. Effects of zinc deficiency on the oxidation of retinol and ethanol in rats. J Nutr. 1975;105:1486-90.

IOM - Institute of Medicine. Dietary reference intakes for vitamin A, Vitamin K, Arsenic, Boron, Chromium, Copper, lodine, Iron, Manganese, Molybdenum, Nickel, Silicon, Vanadium and Zinc. Washington, DC: National Academy Press; 2001.

IOM - Institute of Medicine. Dietary Reference Intakes for Vitamin C, Vitamin E, Selenium, and Carotenoids. Washington, DC: National Academy Press; 2000.

Jang JT, Green JB, Beard JL, Green MH. Kinetic analysis shows that iron deficiency decreases liver vitamin A mobilization in rats. J Nutr. 2000;130:1291-6. 
Jayarajan $\mathrm{P}$, Reddy, Mohanram $\mathrm{M}$. Effect of dietary fat on absorption of betacarotene from green leafy vegetables in children. Indian J Med Res. 1980;71:53-6.

Jüni $P$, Altman DG, Egger M. Assessing the quality of randomised controlled trials. In: EGGER M, DAVEY SMITH G, ALTMAN DG, eds. Systematic reviews in health care: meta-analysis in context. Terceira edição. London: BMJ Books; 2003.

Katz DR, Drzymala M, Turton JA, Hicks RM, Hunt R, Palmer L, Malkovsky M. Regulation of accessory cell function by retinoids in murine immune responses. $\mathrm{Br} \mathrm{J}$ Exp Pathol. 1987;38:1-14.

Lammer E. Vitamin A and human developmental toxicity. In: WHO - World Health Organization. Safe vitamin A dosage during pregnancy and lactation: recommendations and report of a consultation. Geneva: WHO, Micronutrient Initiative; 1998.

Lynch SR. Intrection of iron with other nutrients. Nutr Rev. 1997;55(4):102-10.

McLaren DS, Frigg M. Sight and life manual on vitamin A deficiency disorders (VADD). Segunda edição. Geneva: IVACG; 2001.

McManaman JL, Neville MC. Mammary physiology and milk secretion. Advanced Drug Delivery Reviews 2003;55:629-41.

Mello Neto J. Influência de fatores nutricionais, obstétricos, sócio-econômicos e demográficos nas concentrações de vitamina $A$, ferro, zinco e cobre no sangue e no leite maduro de doadores do banco de leite humano de Marília, SP [tese doutorado]. São Paulo: Faculdade de Saúde Pública, Universidade de São Paulo; 2005.

Microsoft. Microsoft Office Excel [spreadsheet software]. Versão 5.1.2600. Microsoft Corporation/IBM; 2003.

Morris-Kay GM, Sokolova N. Embryonic development and pattern formation. FASEB J. 1996;10:961-8.

MS - Ministério da Saúde. Conversor.xls. Programa de computador. Brasília: MS; 2004 Disponível em URL: dtr2004.saude.gov.br/nutricao/documentos/conversor.xls. [17 06 2006]

Muñoz EC, Rosado JL, Lopez P, Furr HC, Allen LH. Iron and zinc supplementation improves indicators of vitamin A status of Mexican preschoolers. Am J Clin Nutr. 2000;71:789-94.

Ong DE. Absorption of vitamin A. In: BLOMHOFF R, ed. Vitamin A in health and disease. New York: Marcel Dekker; 1994.

Pai M, Flores LL, Pai N, Hubbard A, Riley LW, Colford Jr JM. Diagnostic accuracy of nucleic acid amplification test for tuberculous meningitis: a systematic review and meta-analysis. The Lancet. 2003;3:633-643. 
Pai M, McCulloch M, Gorman JD, Pai N, Enanoria W, Kennedy G, Tharyan P, Colford Jr JM. Systematic reviews and meta-analyses: an illustrated, step-by-step guide. Nat Med J India. 2004;17:86-95.

Panpanich R, Vitsupakorn K, Harper G, Brabin B. Serum and breast-milk vitamin A in women during lactation in rural Chiang Mai, Thailand. Ann Trop Paediatr. 2002;22(4):321-324.

Parker RS. Absorption, metabolism, and transport of carotenoids. FASEB J. 1996;10:542-51.

Patton S, Canfield LM, Huston GE, Ferris AM, Jensen RG. Carotenoids of human colostrum. Lipids. 1990;25:159-65.

Picciano MF. Pregnancy and lactation: physiological adjustments, nutritional requirements and the role of dietary supplements. J Nutr. 2003;133:1997-2002S.

Presta FMP. Composição do leite materno em vitamina A, carotenóides e vitamina $\mathrm{E}$ : relação com o estado nutricional e características maternas [dissertação mestrado]. Rio de Janeiro: Universidade Federal do Rio de Janeiro; 2001.

PUBMED. National Library of Medicine. Disponível em URL: <www.pubmed. org>. [2004 jun 06]

Rahman MM, Vermund SH, Wahed MA, Fuchs GJ, Baqui AH, Alvarez JO. Simultaneous zinc and vitamin A supplementation in Bangladeshi children: randomised double blind controlled trial. BMJ. 2001;323:314-8.

Rasmussen K. Vitamin A needs during pregnancy and lactation for the health of the mother and her fetus or infant. In: WHO - World Health Organization. Safe vitamin A dosage during pregnancy and lactation: recommendations and report of a consultation. Geneva: WHO, Micronutrient Initiative; 1998.

Rosales FJ, Jang JT, Pinero DJ, Erikson KM, Beard JL, Ross AC. Iron deficiency in young rats alters the distribution of vitamin $A$ between plasma and liver and between hepatic retinol and retinyl esters. J Nutr. 1999;129:1223-8.

Ross JS, Harvey PWJ. Contribution of breastfeeding to vitamin A nutrition of infants: a simulation model. Bulletin of the World Health Organization. 2003;81:80-6.

Ross DA. Recommendations for vitamin A supplementation. J Nutr. 2002;131:2902$6 \mathrm{~S}$.

Russel RM. The vitamin A spectrum: from the deficiency to toxicity. Am J Clin Nutr. 2000;71:878-84.

Saari JC. Retinoids in photosensitive system. In: SPORN MB, ROBERTS AB, GOODMAN DS. Segunda edição. New York: Raven Press; 1994.

Statacorp. Stata statistical software [programa de computador]. Release 8.0. College Station, TX: Stata Corporation; 2005. 
Semba RD, Kumwenda N, Taha TE, Mtimavalye L, Broadhead R, Garret E et al. Impact of vitamin A supplementation on anaemia and plasma erythropoietin concentrations in pregnant women: a controlled clinical trial. European Journal of Haematology. 2001;66(6):389-95.

Semba RD, Munasir Z, Akib A, Melikian G, Permaesih D, Muherdiyantiningsih, Marituti S, Muhilal. Integration of vitamin A supplementation with the expanded programme on immunization: lack of impact on morbidity or infant growth. Acta Paediatr. 2001;90(10):1107-11.

Shatrugna V, Raman L, Uma K, Sujatha T. Interaction between vitamin A and iron: effects of supplements in pregnancy. International Journal for Vitamin and Nutrition Research. 1997;67:145-8.

Sommer A. Vitamin A deficiencyand its consequences: a field guide to detection and control. Terceira edição. Geneva: WHO; 1995.

Sommer A, West KP, Olson JA, Ross AC. Vitamin A deficiency: health, survival, and vision. New York: Oxford University Press; 1996.

Stoltzfus RJ, Underwood BA. Breast milk vitamin A as an indicator of the vitamin A status of women and infants. Bulletin of the World Health Organization. 1995;73(5):703-711.

Strube YN, Beard JL, Ross AC. Iron deficiency and marginal vitamin A deficiency affect growth, hematological indices and the regulation of iron metabolism genes in rats. J of Nutr. 2002;132: 3607-15.

Suharmo D, West CE, Muhilal, Logman MH, de Waart FG, Karyadi D, Hautvast JG. Supplementation with vitamin A and iron for nutritional anemia in pregnant woman in West Java, Indonesia. Lancet. 1993;342:1235-8.

Tanumihardjo SA. Assessing vitamin A status: past, present and future. J Nutr. 2004;134:290-3S.

Thein M. Study on milk vitamin A, serum vitamin A and serum protein levels of lactating mothers of Bochessa village, rural Ethiopia. East Afr Med J. 1979;56(11):542-7.

Thomson. EndNote [programa de computador]. Versão 7.0. ISI - Thompson Scientific; 2003.

Thurnham DI, Mccabe GP, Northrop-Clewes CA, Nestel P. Effects of subclinical infection on plasma retinol concentrations and assessment of the prevalence of vitamin A deficiency: meta-analysis. Lancet. 2003;362:2052-8.

Trechsel $\mathrm{U}$, Evequoz V, Fleisch $\mathrm{H}$. Simulation of interleukin 1 and 3 prodiction by retinoic acid in vitro. Biochen J. 1985;230:339-44.

Underwood BA, Olson JA, ed. A brief guide to current methods of assessing vitamin A status. Washington, DC: IVACG; 1993. 
Underwood BA. Maternal vitamin A status and its importance in pregnancy and early childhood. Am J Clin Nutr. 1994;59:517S-524S.

van den Broek NR, White SA, Cook JD, Letsky EA, Molyneux M, Neilson JP. Double-blind randomised trial of antenatal vitamin A supplementation in pregnant anaemic women in rural Malawi. Malawi; 2001. [Resultados de pesquisa não publicados].

van den Broek N, Kulier R, Gülmezoglu AM, Villar J. Vitamin supplementation during pregnancy. (Cochrane Review). In: The Cochrane Library. Issue 2. Oxford: Update Software; 2004.

Web OF SciencE. ISI Web of Science. Acesso regulamentado pela USP. Disponível em URL:<www.usp.br/sibi>. [2004 jun 06]

WHO - World Health Organization. Global prevalence of vitamin A deficiency. MDIS working papper 2. Geneva: WHO; 1995.

WHO - World Health Organization. Indicators for assessing vitamin A deficiency and their application in monitoring and evaluating intervention programmes. Geneva: WHO; 1996.

WHO - World Health Organization. Safe vitamin A dosage during pregnancy and lactation: recommendations and report of a consultation. Geneva: WHO, Micronutrient Initiative; 1998.

Villamor E, Fawzi WW. Effects of vitamin A supplementation on immune responses and correlation with clinical outcomes. Clinical Microbiology Reviews. 2005;18(3):446-464 .

Zhao Z, Ross C. Retinoic acid repletion restores the number of leukocytes and their subsets and stimulates natural cytotoxicity in vitamin A deficiency rats. J Nutr. 1995;125:2064-73.

\section{Estudos excluídos}

Alvarez MC. Efecto de la suplementación combinada con hierro y vitamina A sobre el status del hierro en mujeres lactantes. Quito; 1995. [Tese de Mestrado Faculdade de Ciências Médicas].

Bahl R, Bhandari N, Kant S, Molbak K, Ostergaard E, Bhan MK. Effect of vitamin A administered at Expanded Program on Immunization contacts on antibody response to oral polio vaccine. Eur J Clin Nutr. 2002;56(4):321-5.

Basu S, Sengupta B, Paladhi PK. Single megadose vitamin A supplementation of Indian mothers and morbidity in breastfed young infants. Postgrad Med J. 2003;79(933):397-402.

Berhe G. Tulimbe Nutrition Project: a community-based dietary intervention to combat micronutrient malnutrition in rural southern Malawi. SCN News. 1997;15:256. 
Buller H, Peters M, Berger B Nagelkerke N, Tencate JW, Breederveld C, Heymans $\mathrm{H}$. Vitamin $\mathrm{k}$ status beyond the neonatal period: a prospective study in normal breast-fed formula fed infants. Eur J Pediatr. 1986;145(6):469-99.

Canfield LM, Giuliano AR, Neilson EM, Blashil BM, Graver EJ, Yap HH. Kinetics of the response of milk and serum beta-carotene to daily beta-carotene supplementation in healthy, lactating women. Am J Clin Nutr. 1998;67(2):276-83.

Canfield LM, Giuliano AR, Neilson EM, Yap HH, Graver EJ, Cui HA, et al. betaCarotene in breast milk and serum is increased after a single beta-carotene dose. Am J Clin Nutr. 1997;66(1):52-61.

Canfield LM, Kaminsky RG, Taren DL, Shaw E, Sander JK. Red palm oil in the maternal diet increases provitamin A carotenoids in breastmilk and serum of the mother-infant dyad. Eur J Nutr. 2001;40(1):30-8.

Christian P, Shrestha J, Leclerq SC, Khatry SK, Jiang T, Wagner T, et al. Supplementation with micronutrients in addition to iron and folic acid does not further improve the hematologic status of pregnant women in rural Nepal. J Nutr. 2003;133(11):3492-8.

Christian P, West KP, JR., Khatry SK, Leclerq SC, Kimbrough-Pradhan E, Katz J, et al. Maternal night blindness increases risk of mortality in the first 6 months of life among infants in Nepal. J Nutr. 2001;131(5):1510-2.

Christian P, West KP, Khatry SK, Leclerq SC, Pradhan EK, Katz J, et al. Effects of maternal micronutrient supplementation on fetal loss and infant mortality: a clusterrandomized trial in Nepal. Am J Clin Nutr. 2003;78(6):1194-202.

Dary O. Intervenciones para la prevención y control de la deficiencia de vitamina A en América Latina y el Caribe. Arch Latinoam Nutr. 1992;3S:123-6

de Pee S, West CE, Muhilal, Karyadi D, Hautvast JG. Lack of improvement in vitamin $A$ status with increased consumption of dark-green leafy vegetables. Lancet. 1995;346(8967):75-81.

Filteau SM, Rice AL, Ball JJ, Chakraborty J, Stoltzfus R, F De Francisco A, et al. Breast milk immune factors in Bangladeshi women supplemented postpartum with retinol or beta-carotene. Am J Clin Nutr. 1999;69(5):953-8.

Ganguly C, Mukherjee KL. Relationship between maternal serum vitamin A and vitamin A status of the corresponding fetuses. J Trop Pediatr. 1988;34(6):313-5.

Gossage C, Deyhim M, Moser-Veillon PB, Douglas LW, Kramer TR. Effect of betacarotene supplementation and lactation on carotenoid metabolism and mitogenic $T$ lymphocyte proliferation. Am J Clin Nutr. 2000;71(4):950-5.

Gossage CP, Deyhim M, Yamini S, Douglas LW, Moser-Veillon PB. 2002. Carotenoid composition of human milk during the first month postpartum and the response to beta-carotene supplementation. Am J Clin Nutr. 2002;76(1):193-7. 
Greer FR, Searcy JE, Levin RS, Steinhen JJ, Steinchenasche PS, Tsang RC. Bone mineral content and serum 25-hydroxyvitamin D concentrations in breastfed infants with and without supplemental vitamin D: one year follow up. J Pediatr. 1982;100(6):919-22.

Johnson EJ, Qin J, Krinsky NI, Russell RM. Beta-carotene isomers in human serum, breast milk and buccal mucosa cells after continuous oral doses of all-trans and 9cis beta-carotene. J Nutr. 1997;127(10):1993-9.

Latham MC, Ash DM, Makola D, Tatala SR, Ndossi GD, Mehansho H. Efficacy trials of a micronutrient dietary supplement in schoolchildren and pregnant women in Tanzania. Food and Nutrition Bulletin. 2003;24(4S):120S-8S.

Lietz G, Henry CJ, Mulokozl G, Mugyabuso JK, Ballart A, Ndossi GD, et al. Comparison of the effects of supplemental red palm oil and sunflower oil on maternal vitamin A status. Am J Clin Nutr. 2001;74(4):501-9.

Lukoianova OL, Vrzhesinskaia OA, Kodentsova VM, Beketova NA, Kharitonchik LA. Dependence of vitamin composition of breast milk on multivitamin intake during pregnancy and lactation. Vopr Pitan. 1999;68(4):24-6.

Muhilal, Murdiana A, Azis I, Saidin S, Jaharl AB, Karyadi D. Vitamin A-fortified monosodium glutamate and vitamin A status: a controlled field trial. Am J Clin Nutr. 1988;48(5):1265-70.

Muhilal, Permeisih D, Idjradinata YR, Muherdiyantiningsih, Karyadi D. Vitamin Afortified monosodium glutamate and health, growth, and survival of children: a controlled field trial. Am J Clin Nutr. 1988;48(5):1271-6.

Ncube TN, Greiner T, Malaba LC, Gebre-Medhin M. Supplementing lactating women with pureed papaya and grated carrots improved vitamin A status in a placebo-controlled trial. J Nutr. 2001;131(5):1497-502.

Rice AL, Stoltzfus RJ, de Francisco A, Kjolhede CL. Evaluation of serum retinol, the modified-relative-dose-response ratio, and breast-milk vitamin $A$ as indicators of response to postpartum maternal vitamin A supplementation. Am J Clin Nutr. 2000a;71(3):799-806.

Rice AL, Stoltzfus RJ, de Francisco A, Kjolhede CL. Low breast milk vitamin A concentration reflects an increased risk of low liver vitamin A stores in women. Adv Exp Med Biol. 2000b;478:375-6.

Ross JS, HArvey PW. Contribution of breastfeeding to vitamin A nutrition of infants: a simulation model. Bull World Health Organ. 2003;81(2):80-6.

Roy SK, Islam A, Molla A, Akramuzzaman SM, Jahan F, Fuchs G. Impact of a single megadose of vitamin $A$ at delivery on breastmilk of mothers and morbidity of their infants. Eur J Clin Nutr. 1997;51(5):302-7.

Saowakontha S, Pongpaew P, Migasena P, Khumpal P. Distribution and content of vitamin A in the liver of Thais. J Med Assoc Thai. 1975;58(5):249-52 
Stoltzfus RJ, Habicht JP, Rasmussen KM, Hakimi M. Evaluation of indicators for use in vitamin $A$ intervention trials targeted at women. Int $\mathrm{J}$ Epidemiol. 1993b;22(6):1111-8.

Stoltzfus RJ, Miller KW, Hakimi M, Rasmussen KM. Conjunctival impression cytology as an indicator of vitamin A status in lactating Indonesian women. Am J Clin Nutr. 1993c;58(2):167-73.

Villard L, Bates CJ. Effect of vitamin A supplementation on plasma and breast milk vitamin A levels in poorly nourished Gambian women. Hum Nutr Clin Nutr. 1987;41(1):47-58.

Wedner SH, Ross DA, Congdon N, Balira R, Spitzer V, Foster A. Validation of night blindness reports among children and women in a vitamin A deficient population in rural Tanzania. Eur J Clin Nutr. 2004;58(3):409-19.

\section{Estudos incluídos}

Bahl R, Bhandarl N, Wahed MA, Kumar GT, Bhan MK. Vitamin A supplementation of women postpartum and of their infants at immunization alters breast milk retinol and infant vitamin A status. J Nutr. 2002;132(11):3243-8.

Bhaskaram P, Balakrishna N, Nair KM, Sivakumar B. Vitamin A deficiency in infants: Effects of postnatal maternal vitamin A supplementation on the growth and vitamin A status. Nutr Res. 2000;20(6):769-778.

Bhaskaram P, Balakrishna N. Effect of administration of 200,000 IU of vitamin A to women within $24 \mathrm{hrs}$ after delivery on response to PPV administered to the newborn. Indian Pediatr. 1998;35(3):217-22.

Christian P, West KP, JR., Khatry SK, Katz J, Leclerq S, Pradhan EK, et al. Vitamin A or beta-carotene supplementation reduces but does not eliminate maternal night blindness in Nepal. J Nutr. 1998;128(9):1458-63.

Christian P, West KP Jr, Khatry SK, Katz J, Leclerq SC, Kimbrough-Pradhan E, et al. Vitamin $A$ or beta-carotene supplementation reduces symptoms of illness in pregnant and lactating Nepali women. J Nutr. 2000;130(11):2675-82.

Congdon NG, Dreyfuss ML, Christian P, Navitsky RC, Sanchez AM, Wu LS, et al. Responsiveness of dark-adaptation threshold to vitamin $A$ and beta-carotene supplementation in pregnant and lactating women in Nepal. Am J Clin Nutr. 2000;72(4):1004-9.

lliff PJ, Humphrey JH, Mahomva Al, Zvandasara P, Bonduelle M, Malaba L, et al. Tolerance of large doses of vitamin A given to mothers and their babies shortly after delivery. Nutr Res. 1999;19(10):1437-1446.

Katz J, West KP Jr, Khatry SK, Pradhan EK, Leclerq SC, Christian P, et al. Maternal low-dose vitamin A or beta-carotene supplementation has no effect on fetal loss and early infant mortality: a randomized cluster trial in Nepal. Am J Clin Nutr. 2000;71(6):1570-6. 
Malaba LC, Iliff PJ, Nathoo KJ, Marinda E, Moulton LH, Zijenah LS, et al. Effect of postpartum maternal or neonatal vitamin A supplementation on infant mortality among infants born to HIV-negative mothers in Zimbabwe. Am $\mathrm{J}$ Clin Nutr. 2005;81(2):454-60.

Rice AL, Stoltzfus RJ, de Francisco A, Chakraborty J, Kjolhede CL, Wahed MA. Maternal vitamin A or beta-carotene supplementation in lactating bangladeshi women benefits mothers and infants but does not prevent subclinical deficiency. $J$ Nutr. 1999;129(2):356-65.

Stoltzfus RJ, Hakimi M, Miller KW, Rasmussen KM, Dawiesah S, Habicht JP, et al. High dose vitamin A supplementation of breast-feeding Indonesian mothers: effects on the vitamin A status of mother and infant. J Nutr. 1993a;123(4):666-75.

Venkatarao T, Ramakrishnan R, Nair NG, Radhakrishnan S, Sundaramoorthy L, Koya PK, et al. Effect of vitamin A supplementation to mother and infant on morbidity in infancy. Indian Pediatr. 1996;33(4):279-86.

Vinutha B, Mehta MN, Shanbag P. Vitamin a status of pregnant women and effect of post partum vitamin a supplementation. Indian Pediatr. 2000;37(11):1188-93.

West KP Jr, Katz J, Khatry SK, Leclerq SC, Pradhan EK, Shrestha SR, et al. Double blind, cluster randomised trial of low dose supplementation with vitamin A or beta carotene on mortality related to pregnancy in Nepal. The NNIPS-2 Study Group. BMJ. 1999;318(7183):570-5.

WHO/CHD ILVASS Group. Randomised trial to assess benefits and safety of vitamin A supplementation linked to immunisation in early infancy. Lancet. 1998;352(9136):1257-63.

Yamini S, West KP Jr, WU L, Dreyfuss ML, Yang DX, Khatry SK. Circulating levels of retinol, tocopherol and carotenoid in Nepali pregnant and postpartum women following long-term beta-carotene and vitamin A supplementation. Eur J Clin Nutr. 2001;55(4):252-9. 
ANEXOS 
ANEXO 1 - Questionário para avaliação dos critérios de inclusão 
ID:

AVALIADOR:

\begin{tabular}{|c|c|c|c|c|}
\hline \multirow[b]{2}{*}{ O estudo foi realizado com mulheres "saudáveis" no período pós-parto? } & SIM & NÃO & $\begin{array}{c}\text { NÃ̃ } \\
\text { CLARO }\end{array}$ & $\begin{array}{c}\text { NÃO } \\
\text { MENCIONA }\end{array}$ \\
\hline & & & & \\
\hline de um estudo que avalia os efeitos da suplementação de vitamina $A$ ? & & & & \\
\hline Trata-se de um ensaio clínico? & & & & \\
\hline
\end{tabular}

\begin{tabular}{|r|c|c|c|}
\cline { 2 - 4 } Resultado: & SIM & NÃO & $\begin{array}{c}\text { NÃO } \\
\text { CLARO }\end{array}$ \\
\cline { 3 - 4 } Incluído: & & & \\
\hline
\end{tabular}


ANEXO 2 - características das buscas nas bases de dados bibliográficos 
Base de dados bibliográficos: Pubmed

Nome do servidor: National Library of Medicine (www.pubmed.org)

Data da pesquisa: 01/03/2005

Período coberto pela busca: 1966-2005

Não houve restrição de idiomas

Estratégia de busca:

\begin{tabular}{|c|c|c|}
\hline Busca & Estratégia & Resultado \\
\hline$\# 4$ & $\# 1$ and $\# 2$ and $\# 3$ & 1291 \\
\hline \#3 & $\begin{array}{l}\text { "postpartum period"[mesh] or "maternal-child nursing"[mesh] or "maternal } \\
\text { nutrition"[mesh] or "lactation"[mesh] or "breast feeding"[mesh] or "milk, } \\
\text { human"[mesh] or "postnatal care"[mesh] or "infant, newborn"[mesh] or "infant"[mesh] } \\
\text { or puerp* or matern* or lacta* or breastfe* or "breast fe }{ }^{\star \prime} \text { or breast-fe* or "human } \\
\text { milk" or milk-human or postnatal or postpart* or infant-newborn* or newborn* or } \\
\text { infant }\end{array}$ & 1029335 \\
\hline$\# 2$ & $\begin{array}{l}\text { (randomized controlled trial[pt] or controlled clinical trial[pt] or randomized controlled } \\
\text { trials[mh] or random allocation[mh] or double-blind method[mh] or single-blind } \\
\text { method[mh] or clinical trial[pt] or clinical trials[mh] or ("clinical trial"[tw]) or ((singl*[tw] } \\
\text { or doubl*[tw] or trebl*[tw] or trip/*[tw]) and (mask*tw] or blind*[tw])) or ("latin } \\
\text { square"[tw]) or placebos[mh] or placebo*[tw] or random*[tw] or research } \\
\text { design[mh:noexp] or comparative study[mh] or evaluation studies[mh] or follow-up } \\
\text { studies[mh] or prospective studies[mh] or cross-over studies[mh] or control*[tw] or } \\
\text { prospectiv*[tw] or volunteer*[tw]) not (animal[mh] not human[mh]) }\end{array}$ & 2583561 \\
\hline$\# 1$ & $\begin{array}{l}\text { "vitamin a"[mesh] or "vitamin a deficiency"[mesh] or "carotenoids"[mesh] or caroten* } \\
\text { or retinol* or "vitamin a" }\end{array}$ & $\underline{53154}$ \\
\hline
\end{tabular}

Base de dados bibliográficos: CCTR- Cochrane Controlled Trials Register (Central) Nome do servidor: Bireme e Update Software (www.bireme.br/cochrane)

Data da pesquisa: $24 / 02 / 2005$

Período coberto pela busca: Sem Informação

Não houve restrição de idiomas

Estratégia de busca:

\begin{tabular}{|c|l|c|}
\hline Busca & \multicolumn{1}{|c|}{ Estratégia } & Resultado \\
\hline \#1 & $\begin{array}{l}\text { ((lact\$ or breastfe\$ or breast-fe\$ or "breast fe\$":de or "breast fe\$":ab or milk- } \\
\text { human\$:de or milk-human\$:ab or matern\$ or puerp\$ or perinatal or postnatal or } \\
\text { postpart\$ or infant-newborn\$) and (retinol\$ or "vitamin a \$":ab or "vitamin a } \$ \text { ":de or } \\
\text { caroten\$)) }\end{array}$ & $\underline{143}$ \\
\hline
\end{tabular}


Base de dados bibliográficos: ERL (Eletronic Reference Library)

Nome do servidor: SilverPlatte - WebSpirs (www.portaldapesquisa.com.br)

Data da pesquisa: 04/03/2005

Período coberto pela busca:

\begin{tabular}{|c|c|}
\hline Base de Dados & Período \\
\hline Agris & $1979-2004 / 09$ \\
\hline Biological astracts & $1998-2004 / 06$ \\
\hline Human Nutrition & $1982-2004 / 09$ \\
\hline Food Science and Tech. Abs. & $1969-2004 / 12$ \\
\hline Food and Human Nutrition & $1975-2004 / 06$ \\
\hline
\end{tabular}

Não houve restrição de idiomas

Estratégia de busca:

\begin{tabular}{|c|c|c|}
\hline Busca & Estratégia & Resultado \\
\hline$\# 4$ & $\# 1$ and $\# 2$ and $\# 3$ & 649 \\
\hline \#3 & $\begin{array}{l}\text { ('vitamin a' in de) or ('vitamin a deficiency' in de) or ('carotenoids' in de) or caroten* or } \\
\text { retinol* or 'vitamin a' }\end{array}$ & 52036 \\
\hline$\# 2$ & 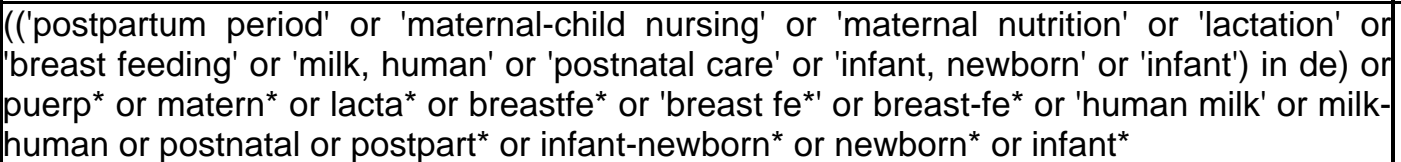 & 308377 \\
\hline \#1 & 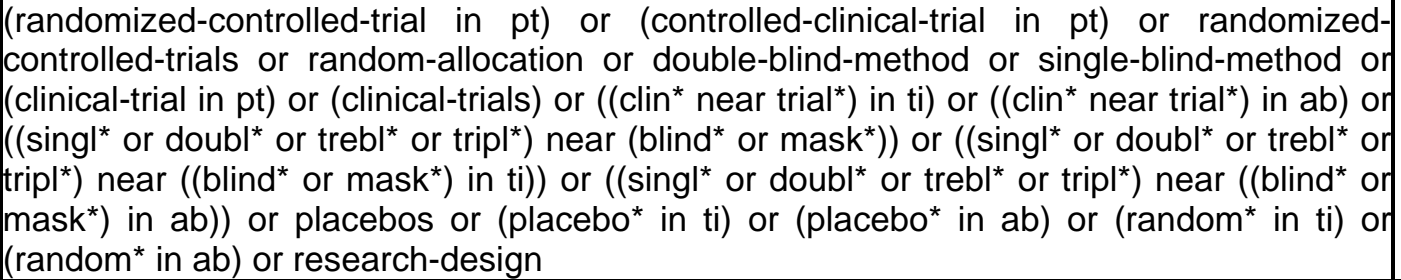 & 236741 \\
\hline
\end{tabular}

Base de dados bibliográficos: WOS - Web of Science

Nome do servidor: ISI Web of Knowledge (www.webofscience.com)

Data da pesquisa: 04/03/2005

Período coberto pela busca: 1945-2005

Não houve restrição de idiomas

Estratégia de busca:

\begin{tabular}{|c|c|c|}
\hline Busca & Estratégia & $\begin{array}{l}\text { Resultad } \\
0\end{array}$ \\
\hline$\# 4$ & \#3 AND \#2 AND \#1 & 1141 \\
\hline \#3 & TS $=$ retinol* or TS $=($ vitamin A) or TS $=$ caroten $*$ or TS $=($ Vitamin A Deficiency $)$ & $\geq 100,000$ \\
\hline \#2 & 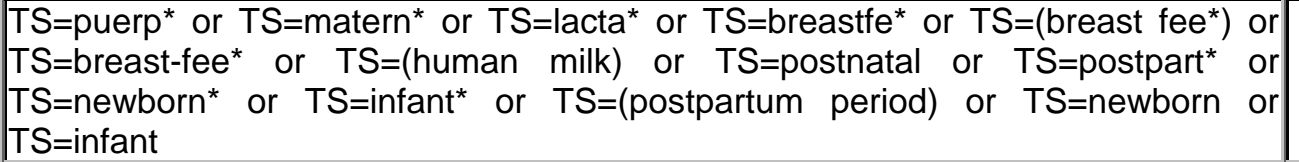 & $\geq 100,000$ \\
\hline \#1 & 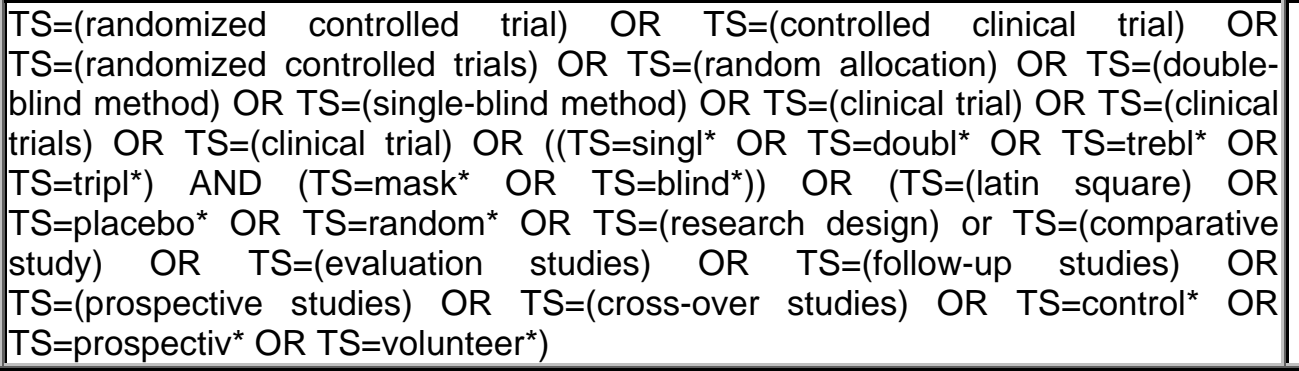 & $\geq 100,000$ \\
\hline
\end{tabular}


Base de dados bibliográficos: LILACS - Literatura Latino-Americana e do Caribe em Ciências da Saúde Nome do servidor: Bireme (www.bireme.br)

Data da pesquisa: 02/03/2005

Período coberto pela busca: 1982-2005

Não houve restrição de idiomas

Estratégia de busca:

\begin{tabular}{|c|c|c|}
\hline Busca & Estratégia & Resultado \\
\hline \#3 & $\# 1$ and \#2 & 201 \\
\hline$\# 2$ & retinol or "vitamin A" or caroten $\$$ [Palavras] & 622 \\
\hline \#1 & 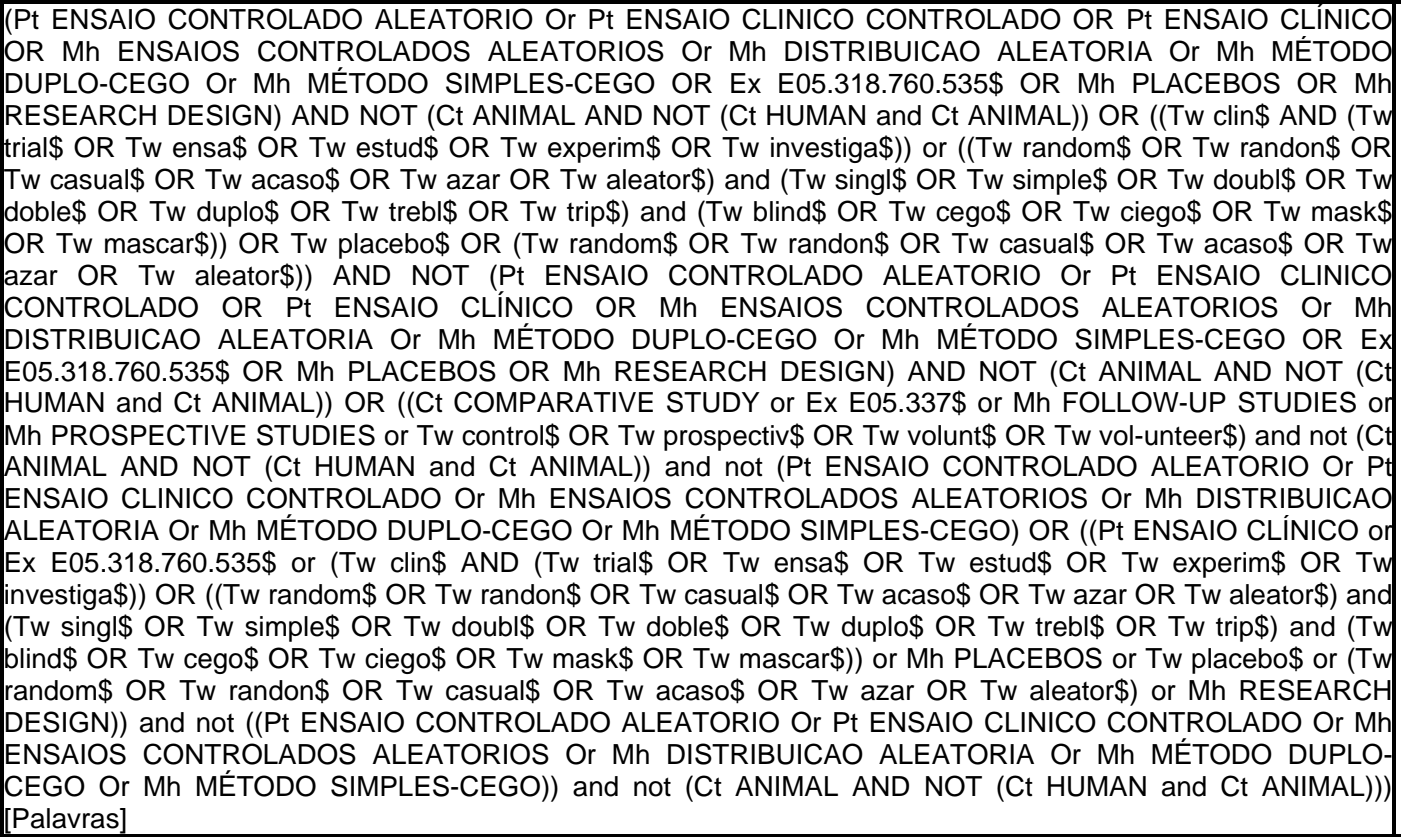 & 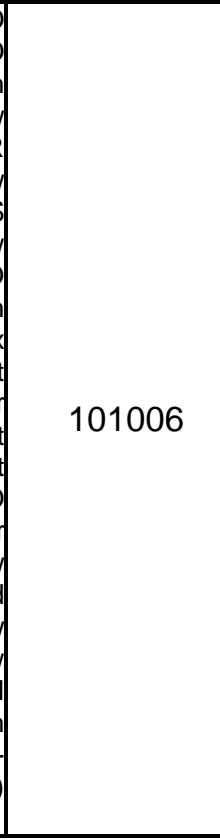 \\
\hline
\end{tabular}


ANEXO 3 - Formulários para avaliação da qualidade dos estudos 


\section{INSTRUMENTO 1 - AVALIAÇÃO DA QUALIDADE DOS ESTUDOS - COCHRANE}

ID:

AVALIADOR:

DATA:

Viés de Seleção (aleatorização)

O processo de alocação dos participantes foi aleatório?

\begin{tabular}{|c|c|}
\hline & \\
\hline & \\
\hline Não claro & 3 \\
\hline Não menciona & 4 \\
\hline
\end{tabular}

Viés de Desempenho (sigilo de alocação)

Os participantes desconheciam a qual grupo pertenciam?

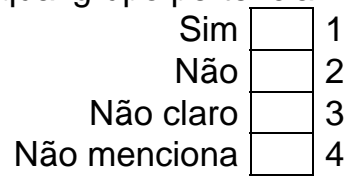

Os responsáveis pelos cuidados de saúde desconheciam a quais grupos cada participante

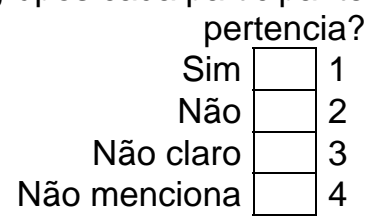

Viés de Seguimento

As perdas de seguimento foram semelhantes nos dois grupos?

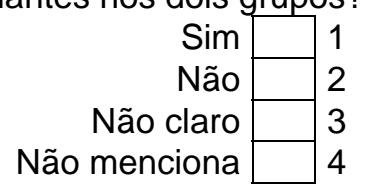

Viés de Detecção

Os responsáveis pelas análises dos dados desconheciam quais eram os grupos intervenção e

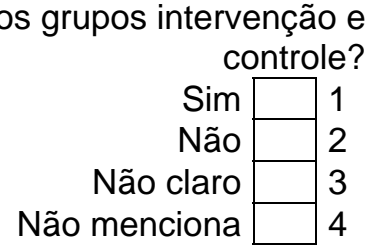

Foi realizada análise por intenção de tratamento ("ITT")?

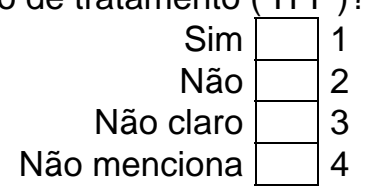

Classificação do estudo:

A - Baixo risco de vieses $B$ - Moderado risco de vieses C - Alto risco de vieses 1
2
3 


\section{INSTRUMENTO 2 - AVALIAÇÃO DA ADEQUAÇÃO DO SIGILO DE ALOCAÇÃO - COCHRANE}

\section{Categorias de Classificação do Sigilo de Alocação}

Aleatorização centralizada; administração seqüencial de pacotes/envelopes pré-codificados ou numerados; dados gerados por um programa de computador; pessoa responsável pelo sorteio não envolvida diretamente da alocação dos pacientes.

A - Adequado

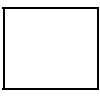

Sem mencionar qual abordagem de alocação foi utilizada ou se houver suspeita de falha.

Alternância; utilização de números de prontuários; datas de nascimento; dias da semana; ou qualquer outro processo não sigiloso (lista aberta de números aleatórios).

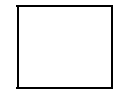

C - Inadequado

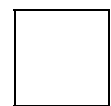

3

D - Não utilizado 
ANEXO 4 - Formulário para coleta de dados dos estudos 
Id:

Data:

FORMULÁRIO DE EXTRAÇÃO DE DADOS

Revisor:

2. Autores:

3. Período de desenvolvimento do estudo, início:

4. País e Cidade de realização do estudo:

5. ID de outros estudos:

6. Desenho do estudo:

7. População:

Ano de Publicação:

término:

\section{Tamanho de amostra em cada grupo no baseline:}

\section{Características da intervenção}

9.Características da administração:

Dose única (mega

\begin{tabular}{r|r|} 
dose $)$ & \\
& \\
Semanal & \\
Não menciona & \\
Não claro &
\end{tabular}

10.Duração da suplementação:

$$
\text { Dias }
$$

\begin{tabular}{|c|c|}
\hline Semanas & \\
\hline Meses & \\
\hline Não menciona & (7) \\
\hline Não claro & (8) \\
\hline Não se aplica & (9) \\
\hline
\end{tabular}

11.Momento do tratamento:

\begin{tabular}{|c|}
\hline Antes da gravidez \\
\hline Durante a gravidez \\
\hline No pós-parto \\
\hline Não menciona \\
\hline Não clar \\
\hline
\end{tabular}

12.Composição do suplemento: Grupo 1:

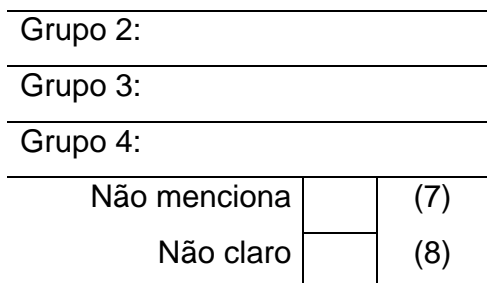

13.Quantidade do suplemento: Grupo 1:

\begin{tabular}{l}
\hline Grupo 2: \\
\hline Grupo 3: \\
\hline Grupo 4: \\
\hline
\end{tabular}

14.Controle do consumo do suplemento:

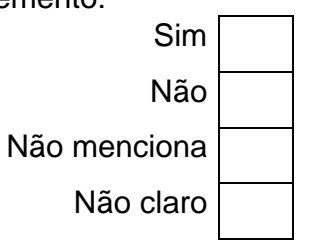

15.Método de determinação de retinol e/ou beta-caroteno:

16.Suplementação do bebê:

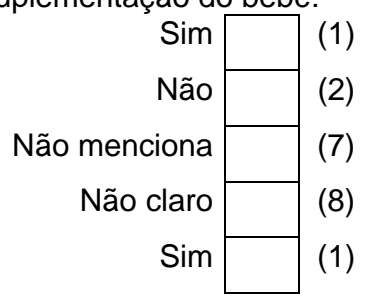

17.Quantidade do suplemento: Grupo 1:

\begin{tabular}{l}
\hline Grupo 2: \\
\hline Grupo 3: \\
\hline Grupo 4: \\
\hline
\end{tabular}

Características dos participantes no baseline: 
; unidade:

\section{Grupo 1:}

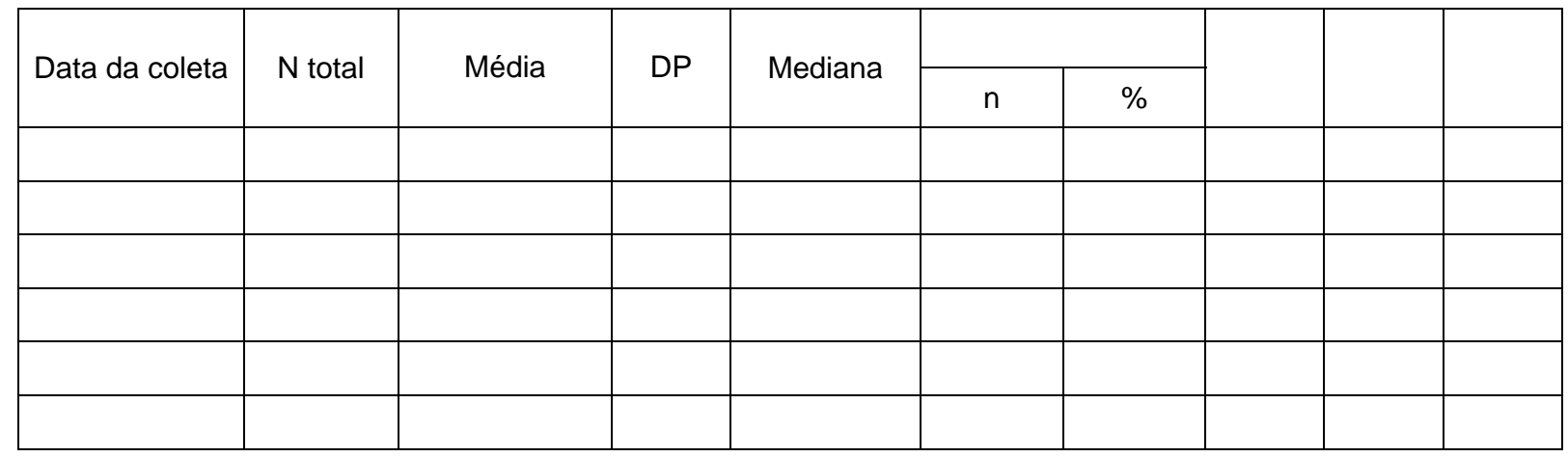

Grupo 2:

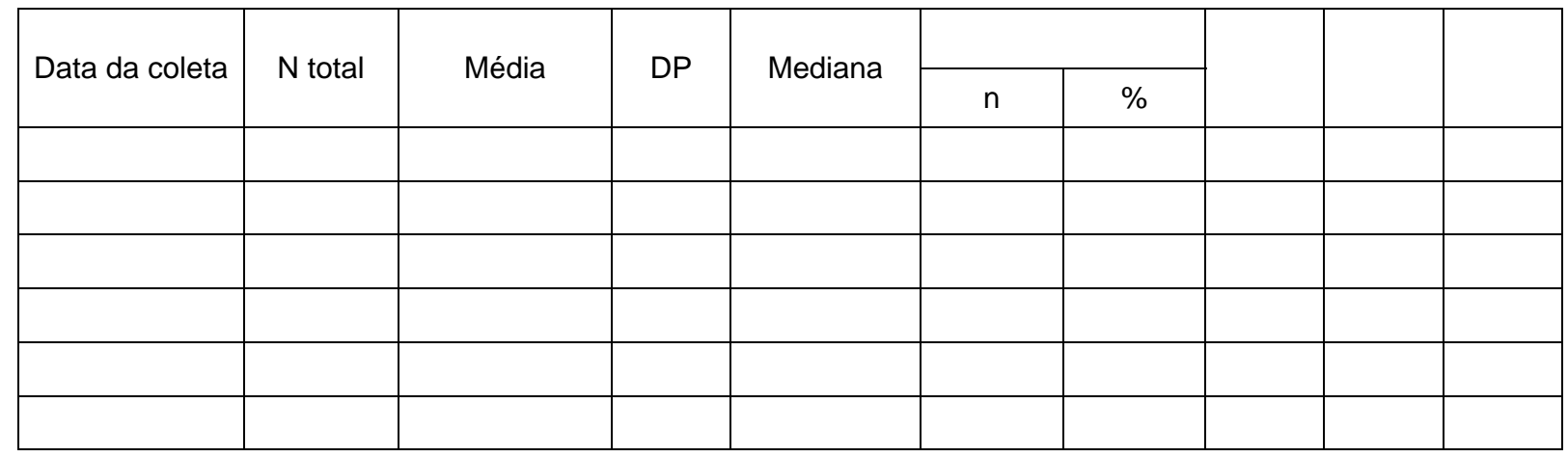

\section{Grupo 3:}

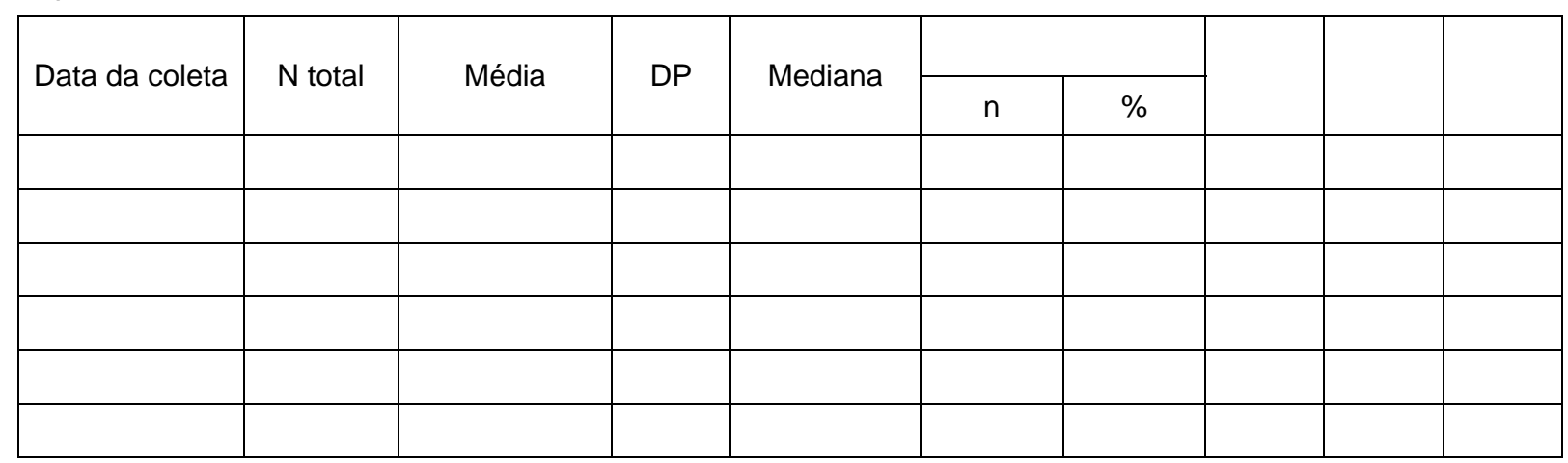

\section{Grupo 4:}

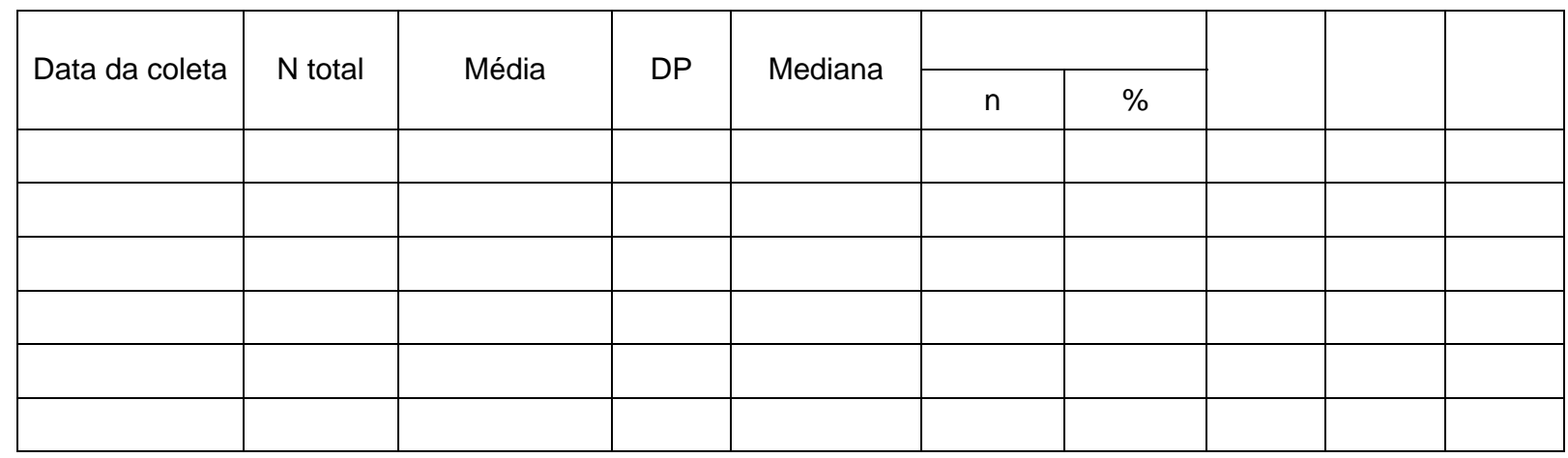


Observações: 
ANEXO 5 - Saídas da metanálise realizada no Stata 


\section{RETINOL NO LEITE HUMANO $(\leq 0,28 \mu \mathrm{mol} / \mathrm{g}$ de lipídio) - odds ratio}

* OR de retinol no leite aos seis meses

metan comdvan61 semdvan61 comdvan62 semdvan62, or xlab $(.1,1,10) 1$ label (namevar=referencia, yearvar=pais)

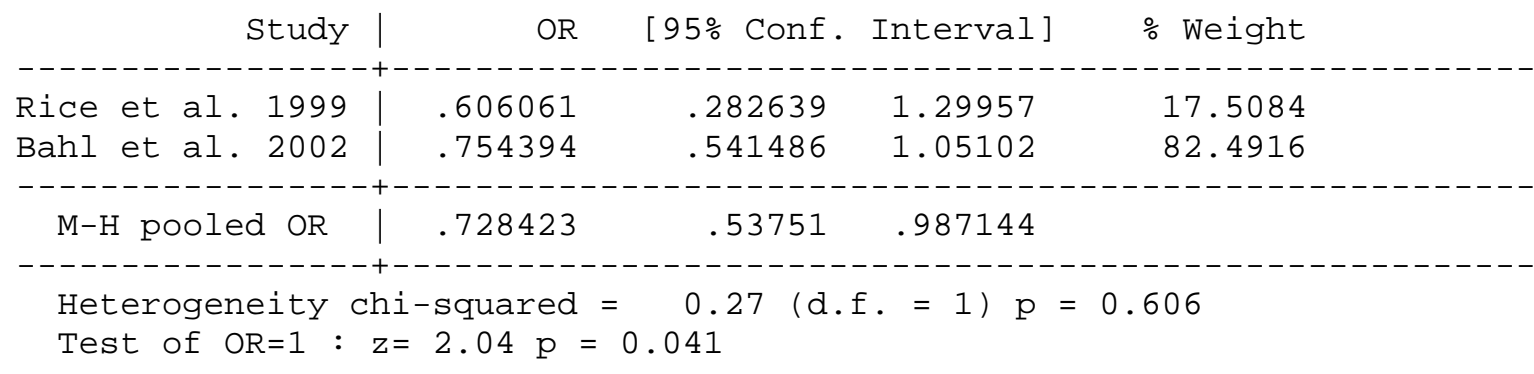

*OR de retinol no leite aos nove meses

metan comdvan91 semdvan91 comdvan92 semdvan92, or xlab $(.1,1,10)$ label (namevar=referencia, yearvar=pais)

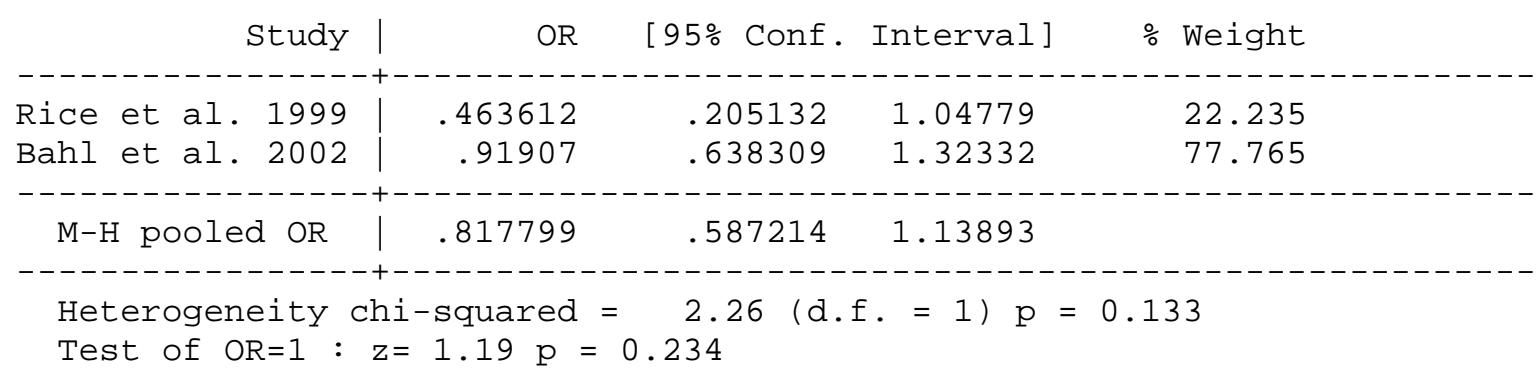

\section{RETINOL NO LEITE HUMANO $(\leq 1,05 \mu \mathrm{mol} / \mathrm{L})$ - odds ratio}

*OR de retinol aos três meses

metan comdvan31 semdvan31 comdvan32 semdvan32, or $x$ lab $(.1,1,10)$ label (namevar=referencia, yearvar=pais)

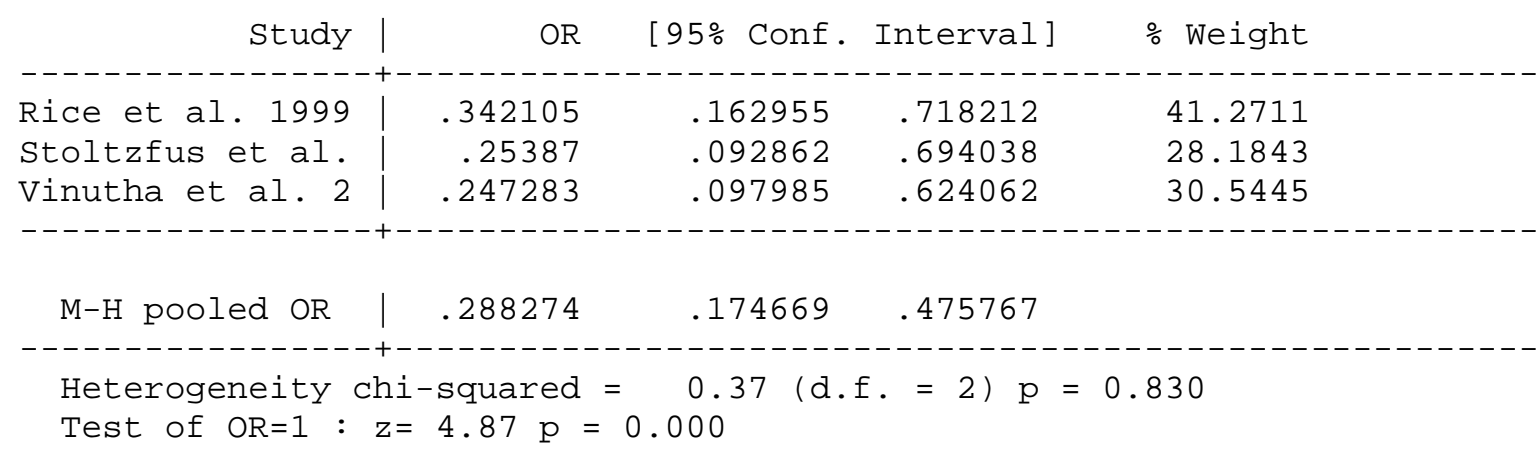

*OR de retinol aos seis meses metan comdvan61 semdvan61 comdvan62 semdvan62, or xlab $(.1,1,10)$ label (namevar=referencia, yearvar=pais)

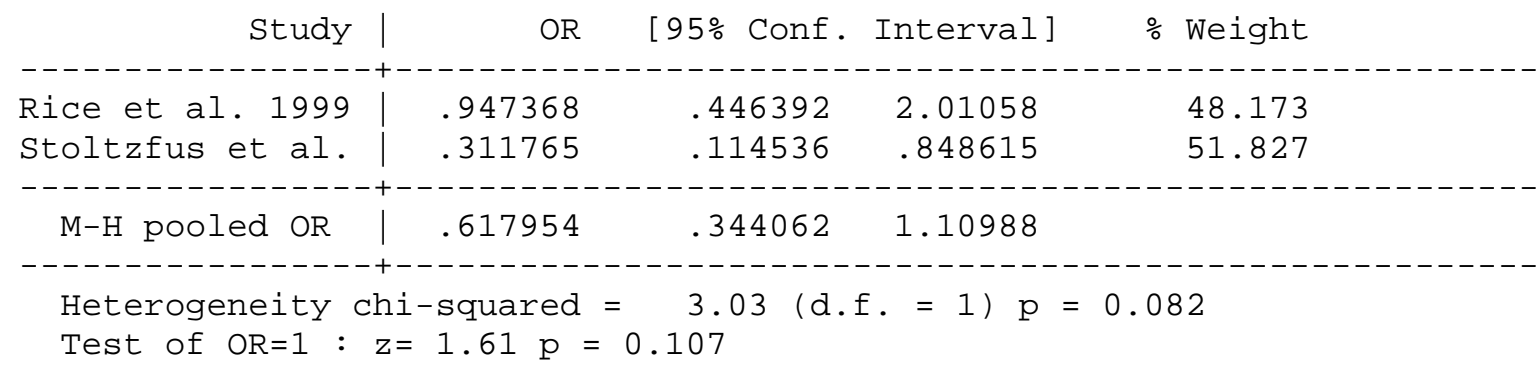


*OR de retinol aos três meses retirando-se stolztfus et al. 1993a metan comdvan31 semdvan31 comdvan32 semdvan32, or xlab $(.1,1,10) 1$ label (namevar=referencia, yearvar=pais)

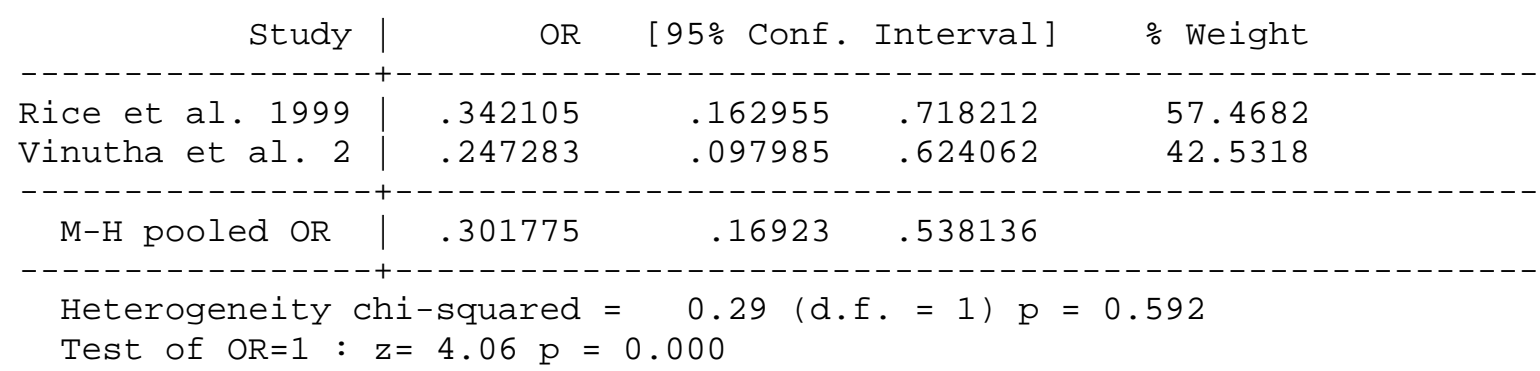

RETINOL NO LEITE HUMANO - diferença de médias sumária

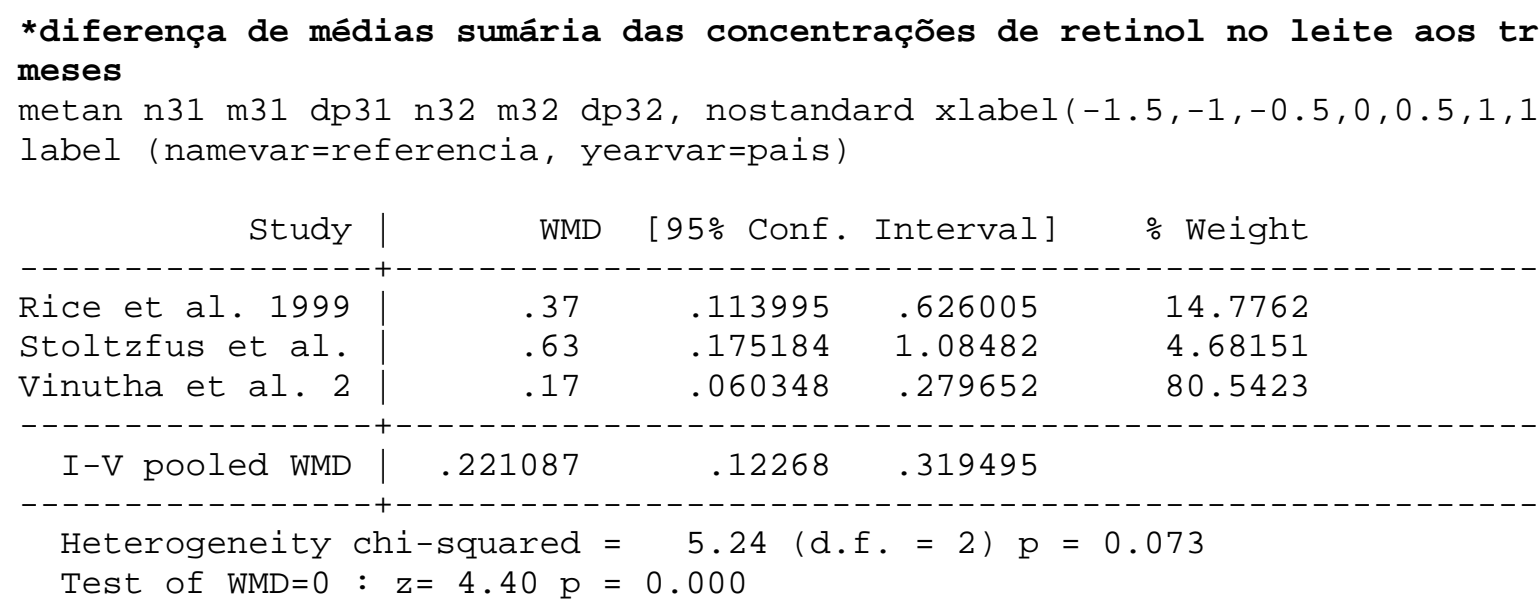

*diferença de médias sumária das concentrações de retinol no leite aos seis meses

metan n61 m61 dp61 n62 m62 dp62, nostandard xlabel(-1.5,-1, - $0.5,0,0.5,1,1.5)$ label (namevar=referencia, yearvar=pais)

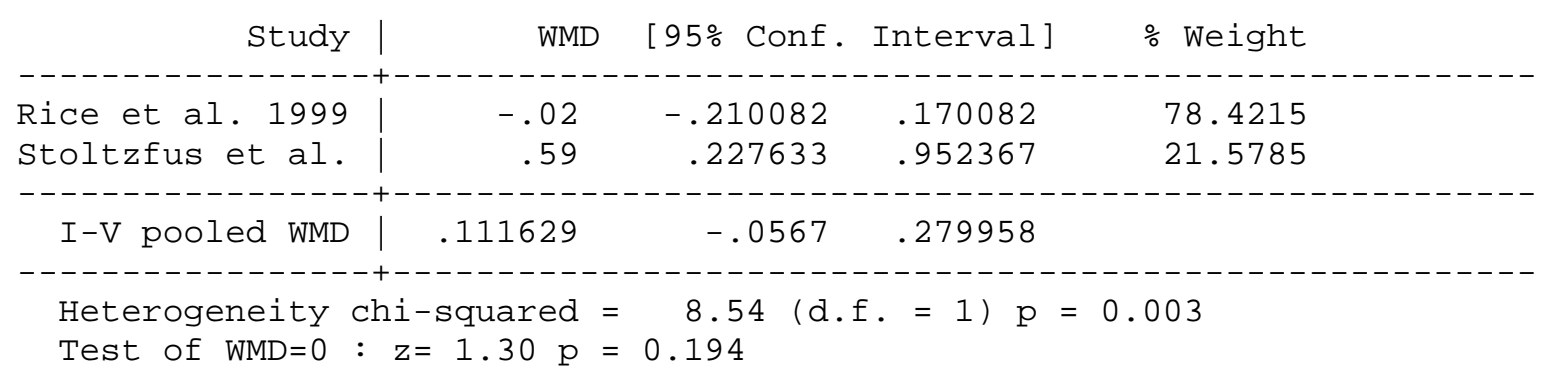


*diferença de médias sumária das concentrações de retinol no leite aos três meses retirando-se Stoltzfus et al. 1993a

metan n31 m31 dp31 n32 m32 dp32, nostandard xlabel $(-1.5,-1,-0.5,0,0.5,1,1.5)$ label (namevar=referencia, yearvar=pais)

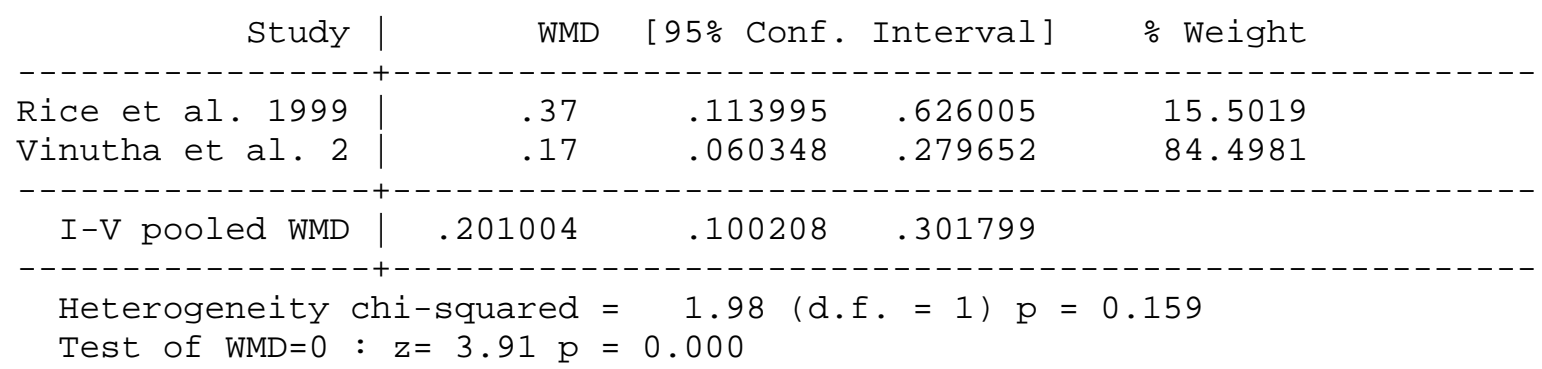

RETINOL SÉRICO MATERNO - diferença de médias sumária

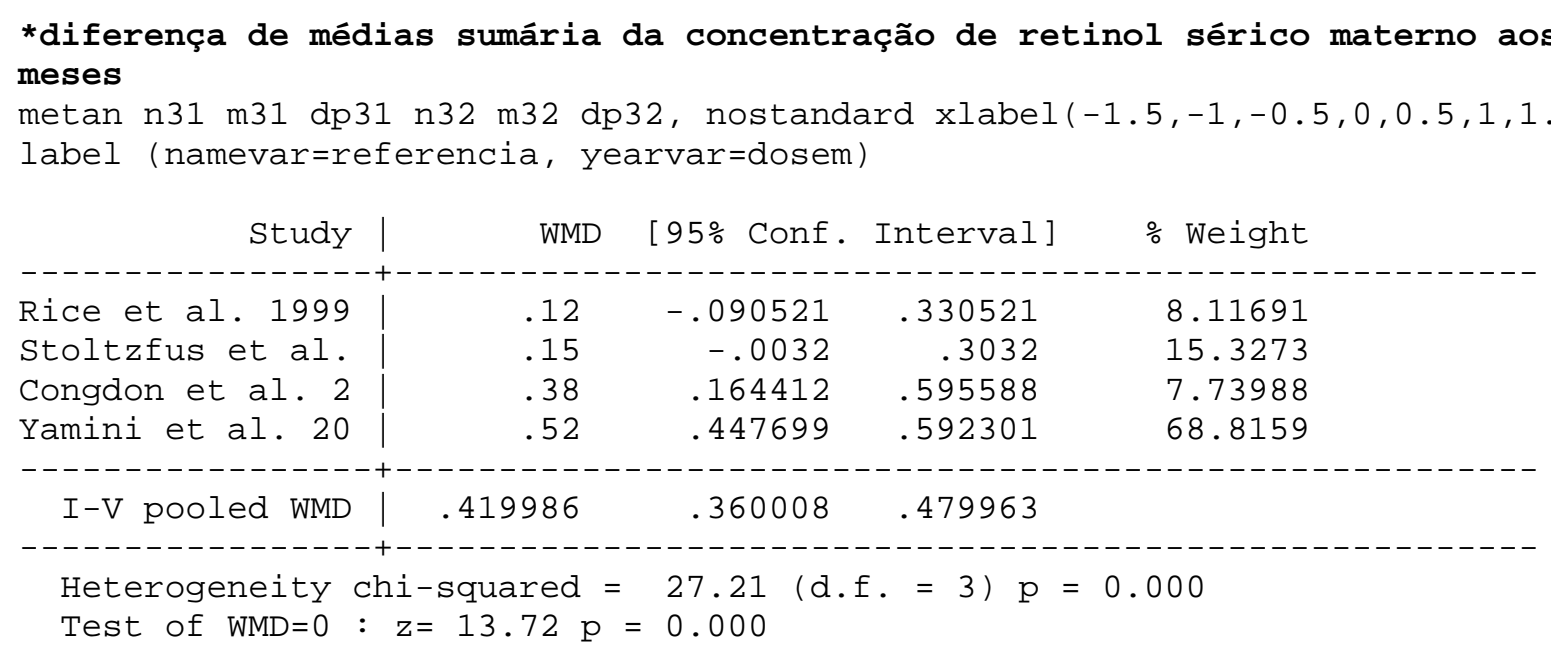

*diferença de médias sumária da concentração de retinol sérico materno aos seis meses

metan n61 m61 dp61 n62 m62 dp62, nostandard xlabel(-1.5,-1, - 0.5, 0,0.5,1,1.5) label (namevar=referencia, yearvar=dosem)

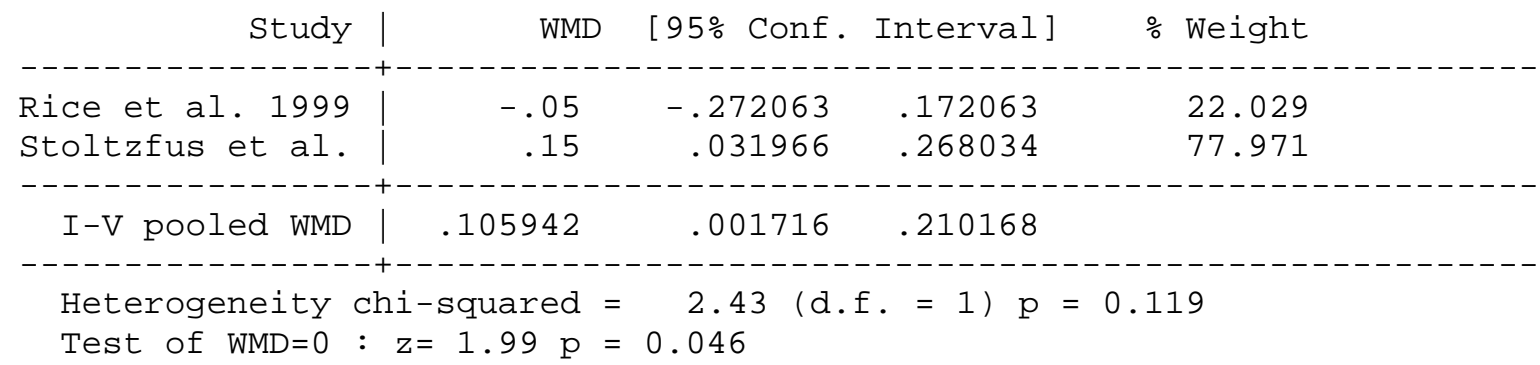


*diferença de médias sumária da concentração de retinol sérico materno aos três meses retirando-se os estudos com doses fracionadas (Congddon et al. 2000 e Yamini et al. 2001)

metan n31 m31 dp31 n32 m32 dp32, nostandard xlabel $(-1.5,-1,-0.5,0,0.5,1,1.5)$

label (namevar=referencia, yearvar=dosem)

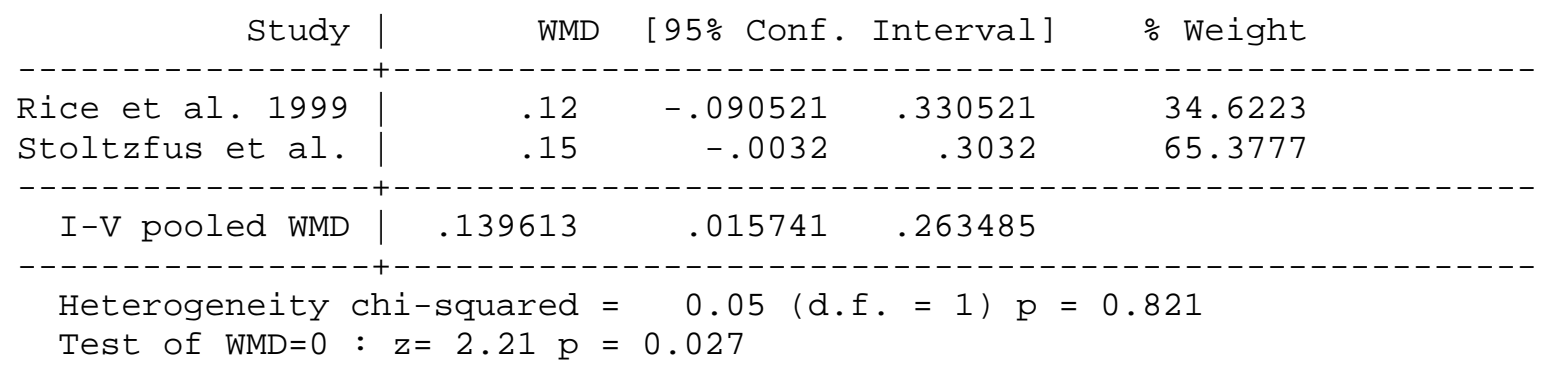

*diferença de médias sumária da concentração de retinol sérico materno aos três decorrente da suplementação fracionada de beta-caroteno

metan n31 m31 dp31 n32 m32 dp32, nostandard xlabel $(-1.5,-1,-0.5,0,0.5,1,1.5)$

label (namevar=referencia, yearvar=dosem)

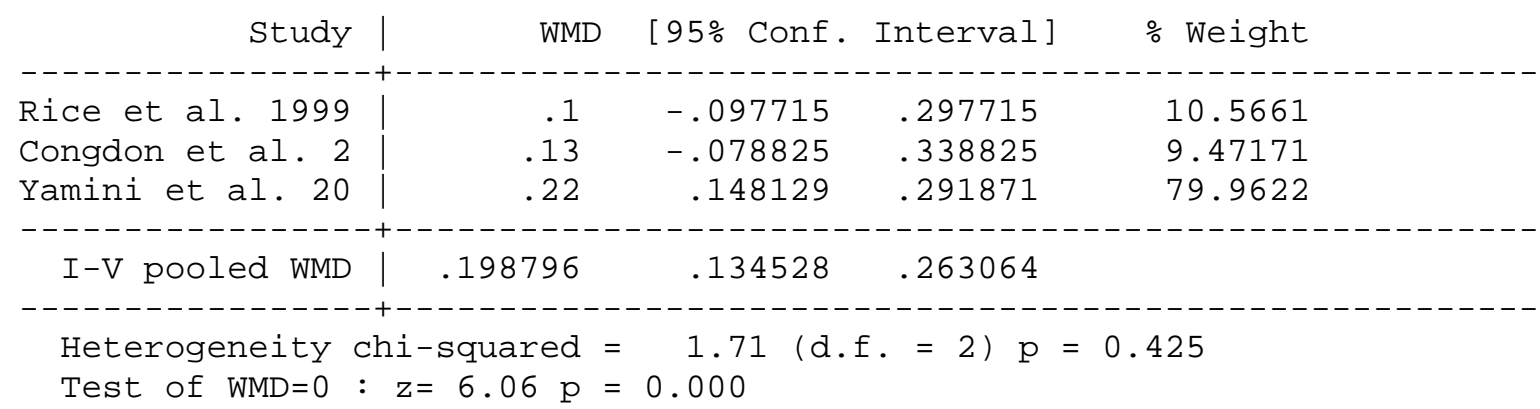

\section{RETINOL SÉRICO INFANTIL - diferença de médias sumária}

*diferença de médias sumária da concentração de retinol infantil aos três meses metan n31 m31 dp31 n32 m32 dp32, nostandard xlabel(-1.5,-1, - 0.5, 0, 0.5,1,1.5) label (namevar=referencia, yearvar=dosem)

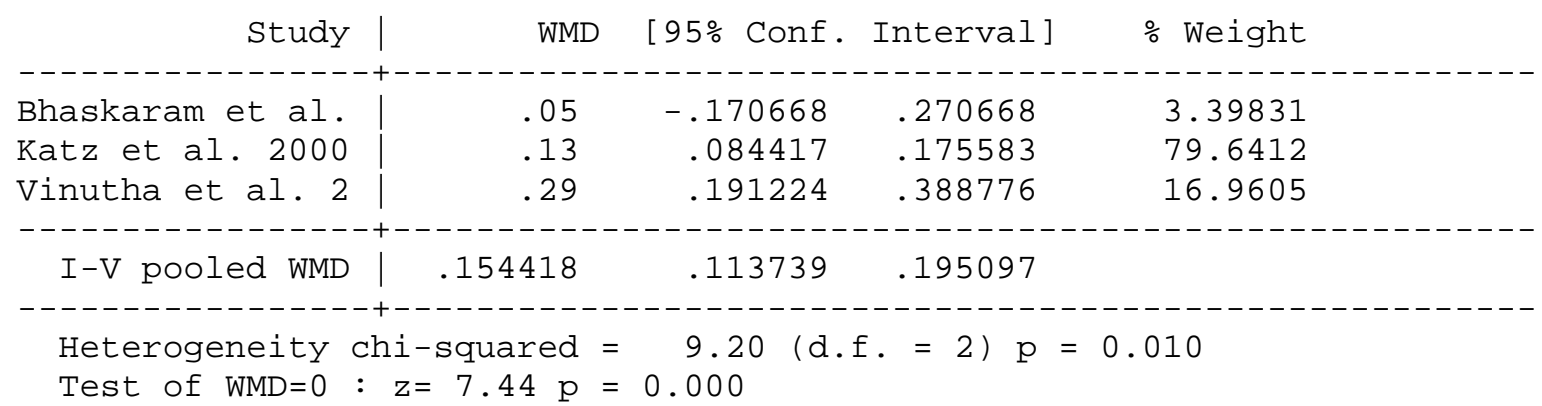


*diferença de médias sumária da concentração de retinol infantil aos seis meses metan n61 m61 dp61 n62 m62 dp62, nostandard xlabel(-1.5, -1, - $0.5,0,0.5,1,1.5)$ label (namevar=referencia, yearvar=dosem)

\begin{tabular}{|c|c|c|c|c|}
\hline Study | & WMD & {$[95 \%$ Conf. } & Interval] & $\%$ Weight \\
\hline - - - - - - - - - - - - & $-\ldots$ & $-\ldots$ & ------ & -- \\
\hline Bhaskaram et al. | & -.07 & -.260149 & .120149 & 7.12855 \\
\hline Rice et al. 1999 & .07 & -.003248 & .143248 & 48.0396 \\
\hline Stoltzfus et al. & .02 & -.055823 & .095823 & 44.8319 \\
\hline------------+ & ------ & -------- & -------- & -- \\
\hline I-V pooled WMD | & .037604 & -.013164 & .088373 & \\
\hline
\end{tabular}

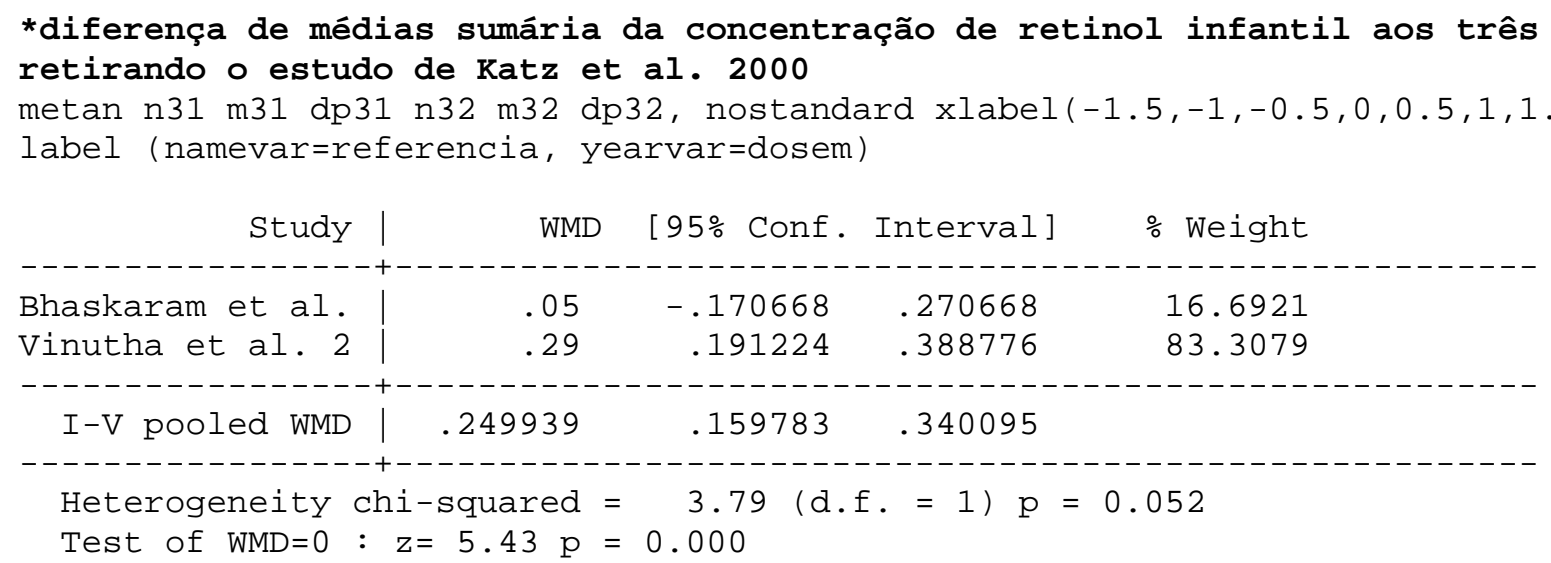

*diferença de médias sumária da concentração de retinol infantil aos seis meses retirando o estudo de Stoltzfus et al. 1993

metan n61 m61 dp61 n62 m62 dp62, nostandard xlabel(-1.5,-1, - $0.5,0,0.5,1,1.5)$

label (namevar=referencia, yearvar=dosem)

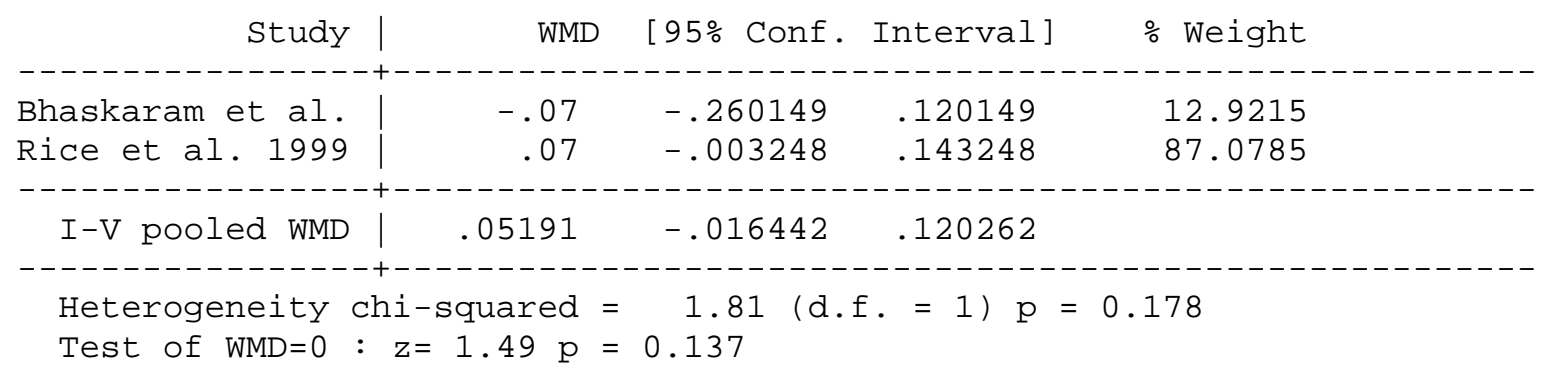

